UNIVERSIDADE DE SÃO PAULO

ESCOLA DE ENGENHARIA DE SÃO CARLOS

DEPARTAMENTO DE ENGENHARIA DE ESTRUTURAS

ANÁLISE LEVEL SET DA OTIMIZAÇÃO TOPOLÓGICA DE ESTRUTURAS PLANAS UTILIZANDO O MÉTODO DOS ELEMENTOS DE CONTORNO

PAULO CEZAR VITORIO JUNIOR 



\author{
UNIVERSIDADE DE SÃO PAULO \\ ESCOLA DE ENGENHARIA DE SÃO CARLOS \\ DEPARTAMENTO DE ENGENHARIA DE ESTRUTURAS
}

\title{
ANÁLISE LEVEL SET DA OTIMIZAÇÃO TOPOLÓGICA DE ESTRUTURAS PLANAS UTILIZANDO O MÉTODO DOS ELEMENTOS DE CONTORNO
}

\author{
PAULO CEZAR VITORIO JUNIOR
}

\section{VERSÃO CORRIGIDA}

A VERSÃO ORIGINAL ENCONTRA-SE NA ESCOLA DE ENGENHARIA DE SÃO

CARLOS

\begin{abstract}
Dissertação apresentada à Escola de Engenharia de São Carlos, da Universidade de São Paulo, como parte dos requisitos necessários à obtenção do título de Mestre em Engenharia de Estruturas
\end{abstract}

Orientador: Prof. Dr. Edson Denner Leonel

São Carlos 
AUTORIZO A REPRODUÇÃO TOTAL OU PARCIAL DESTE TRABALHO POR QUALQUER MEIO COONVENCIONAL OU ELETRÔNICO, PARA FINS DE ESTUDO E PESQUISA, DESDE QUE CITADA A FONTE.

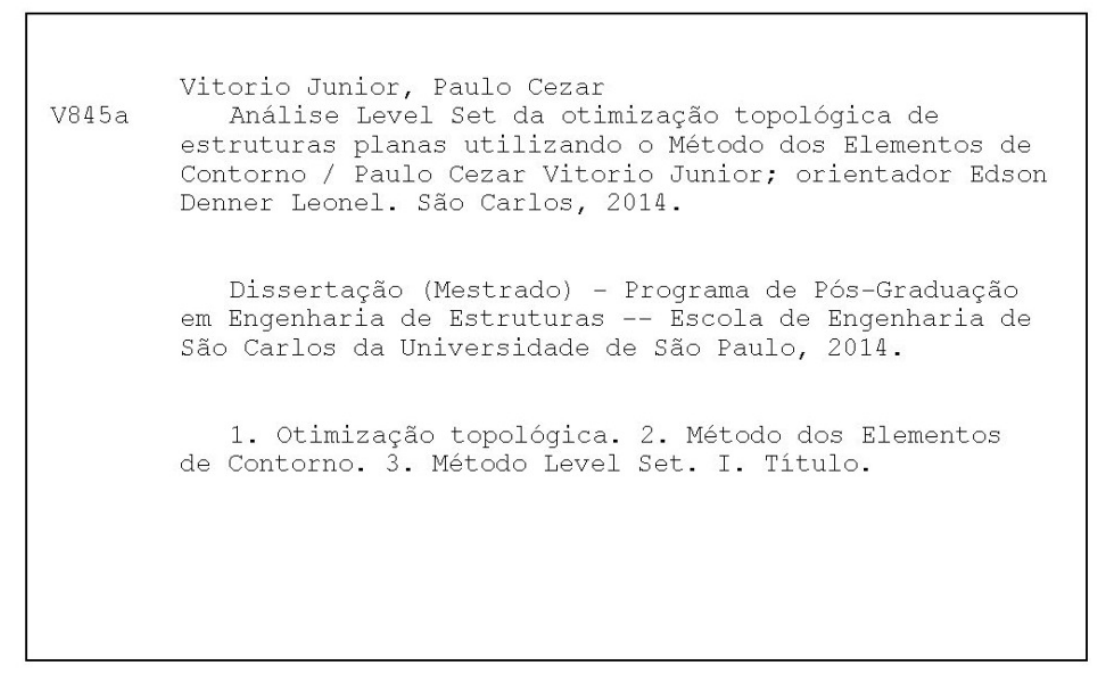


FOLHA DE JULGAMENTO

Candidato: EngenheirO PAULO CEZAR VITORIO JUNIOR.

Título da dissertação: "Análise level SET da otimização topológica de estruturas planas utilizando o método dos elementos de contorno".

Data da defesa: 01/08/2014

\section{Comissão Julgadora:}

Prof. Dr. Edson Denner Leonel (Orientador)

(Escola de Engenharia de São Carlos/EESC)

Prof. Associado João Batista de Paiva

(Escola de Engenharia de São Carlos/EESC)

Prof. Dr. Luttgardes de Oliveira Neto

(Universidade Estadual Paulista 'Júlio de Mesquita Filho"/UNESP- Bauru)

\section{Resultado:}
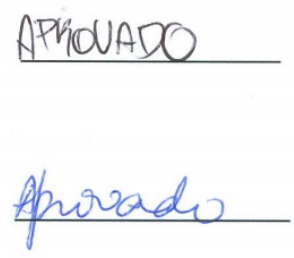

APRONADO

Coordenadora do Programa de Pós-Graduação em Engenharia Civil (Engenharia de Estruturas):

Profa. Associada Ana Lucia Homce de Cresce El Debs

Presidente da Comissão de Pós-Graduação:

Prof. Associado Paulo César Lima Segantine 

À minha FAMÍLIA e EQUIPE, Sueli, Paulão, Lucas, Fátima e Natalina (in memoriam) 



\section{AGRADECIMENTOS}

Agradeço a Deus por todas as oportunidades colocadas em minha vida, pela saúde, força e coragem concedidas para lutar e buscar caminhos melhores.

Minha família pelo apoio incondicional em todos os momentos, por serem meu chão nos momentos de fraqueza e me incentivarem a ser uma pessoa melhor, vocês são fundamentais, são o meu exemplo e é pelo sucesso da nossa equipe que eu batalho todos os dias, obrigado Su, Paulão, Lucas e Fá. Agradeço também minha avó Natalina que não está mais presente fisicamente, mas tenho plena certeza de que está muito feliz acompanhando nossa caminhada e crescimento, a Sra. também faz parte de tudo isso.

Ao meu orientador de mestrado, Edson Denner Leonel, por todo o conhecimento transmitido sempre com muito profissionalismo, tranquilidade e humildade. Obrigado pelas conversas, por confiar em meu trabalho e pela oportunidade de ter vivido 5 meses na Áustria, o período foi muito enriquecedor, de desenvolvimento profissional, cultural e pessoal.

Ao meu orientador do período de graduação, Carlos Humberto Martins, por todos os conhecimentos e conselhos transmitidos desde a minha primeira iniciação científica. Obrigado pelo apoio, incentivo e direcionamento dados para minha formação e ingresso na pósgraduação.

Ao amigo e afilhado de crisma, Hugo Luiz Oliveira (Hugo Monstro), por toda a ajuda e apoio. Essa dissertação tem muitas horas de trabalho, minhas e suas. Obrigado pelas dicas, conversas, ajuda nas formulações e implementação. Pela ajuda via e-mail e Skype enquanto estive na Áustria. É admirável sua humildade e capacidade de transmitir conhecimento. Obrigado, Hugão!

Ao amigo Gabriel Rocha, pelas horas de conversas casuais e matemáticas na tentativa de entender e solucionar o método level set.

Aos professores João Batista de Paiva (SET - EESC/USP) e Julio Flóres López (Universidad de Los Andes) pelas contribuições dadas em meu exame de qualificação.

Aos funcionários do Departamento de Engenharia de Estruturas da Escola de Engenharia de São Carlos (EESC/USP), por toda a atenção e seriedade no trabalho, todas as burocracias ficam mais simples com o trabalho de vocês.

Aos professores Christian Duenser e Thomas Fries, aos colegas e funcionários do Institut für Baustatik da Technische Universität Graz pela recepção e conhecimento transmitidos em Graz. 
Ao Conselho Nacional de Desenvolvimento Científico e Tecnológico (CNPq) pelo apoio financeiro concedido.

Ao programa IRSES - Marie Curie Actions pelo apoio financeiro concedido no período em que estive na Áustria.

Às velhas amizades feitas em Cornélio Procópio e Maringá. Às amizades feitas em São Carlos. E às novas amizades feitas por toda a Europa.

E a todos que de alguma forma contribuíram para minha formação como pessoa até agora. 
“Apliquei-me a conhecer a sabedoria (...) observei o conjuto da obra de Deus e percebi que o homem não consegue descobrir tudo o que acontece embaixo do sol. Por mais que o homem se fatigue em pesquisar, não chega a compreendê-la. E mesmo que o sábio diga que a conhece, nem por isso é capaz de entendê-la.”

$($ Ecl 8, 17) 



\section{RESUMO}

\section{VITORIO JUNIOR, P. C. Análise Level Set da otimização topológica de estruturas planas}

utilizando o Método dos Elementos de Contorno. 2014. 146 p. Dissertação (Mestrado em Engenharia de Estruturas) - Escola de Engenharia de São Carlos, Universidade de São Paulo, São Carlos, 2014.

A otimização topológica de estruturas está relacionada à concepção de projetos que executem suas funções com nível de segurança adequado empregando a quantidade mínima de material. Neste trabalho, determina-se a geometria ótima de estruturas planas por meio do acoplamento do Método dos Elementos de Contorno (MEC) ao Método Level Set (MLS). O algoritmo é composto por 3 etapas: problema mecânico, otimização topológica e reconstrução da estrutura. O problema mecânico é resolvido pelas equações algébricas do MEC. A otimização topológica é determinada pelo MLS, este representa a geometria do corpo e suas evoluções por meio da função Level Set (LS) avaliada em seu nível zero. Na reconstrução realiza-se o remalhamento, pois a cada iteração a estrutura é modificada. O acoplamento proposto resulta na geometria ótima da estrutura sem a necessidade da aplicação de filtros. Os exemplos analisados mostram que algoritmo desenvolvido capta adequadamente a geometria ótima das estruturas. Com esse trabalho, avança-se no campo das aplicações do acoplamento MEC MLS e no desenvolvimento de soluções inovadoras para problemas complexos de engenharia.

Palavras Chave: Otimização Topológica. Método dos Elementos de Contorno. Método Level Set. 

VITORIO JUNIOR, P. C. A level set analysis of topological optimization in $2 \mathrm{D}$ structures using the boundary element method. 2014. 146 p. Dissertation (M. Sc. in Structural Engineering) - School of Engineering of São Carlos, University of São Paulo, São Carlos, 2014.

In general, the topological optimization of structures is related to design projects that perform their functions with appropriate security levels using the minimum amount of material. This research determines the optimal geometry of 2D structures by coupling the Boundary Blement Method (BEM) to Level Set Method (LSM). The algorithm consists of 3 steps: mechanical model, topology optimization and structure reconstruction. The mechanical model is solved by BEM algebraic equations. The topology optimization is determined using the MLS, the geometry of the body is determined by the Level Set (LS) function evaluated at the zero level. The reconstruction achieves the remeshing, because for each iteration of the structure is modified. The proposed coupling results in the optimal geometry of the structure without the filters application. The examples show that the algorithm developed captures adequately the optimal geometry of the structures. With this dissertation, it is possible advance in the field of applications of the BEM - LSM and develop innovative solutions to complex engineering problems.

Key words: Topology Optimization. Boundary Element Method. Level Set Method. 

1 INTRODUÇÃO ........................................................................ 19

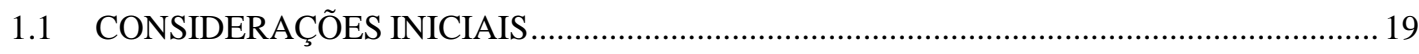

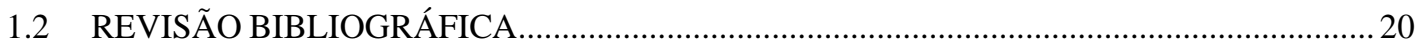

1.2.1 MÉTODO DOS ELEMENTOS DE CONTORNO..........................................................22

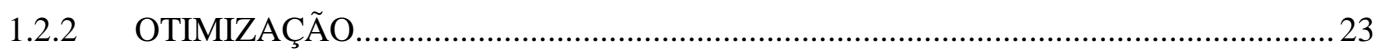

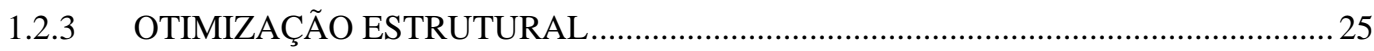

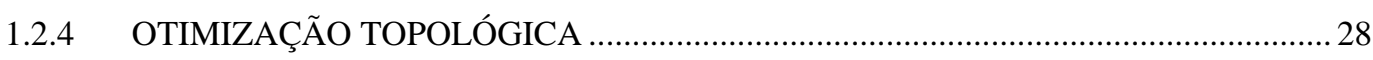

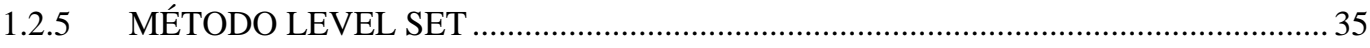

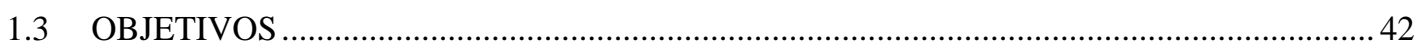

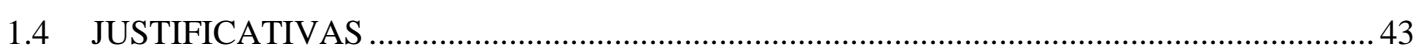

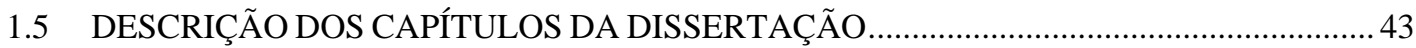

2 MÉTODO DOS ELEMENTOS DE CONTORNO ........................ 45

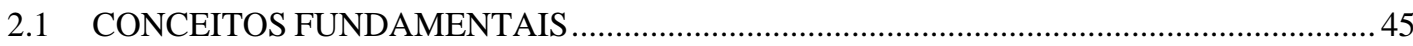

2.1.1 SOLUÇÃO FUNDAMENTAL PARA PROBLEMAS PLANOS ……………………...... 45

2.1.2 EQUACIONAMENTO PARA O PROBLEMA ELÁSTICO PLANO................................. 48

2.1.3 APROXIMAÇÕES SOBRE O CONTORNO............................................................... 54

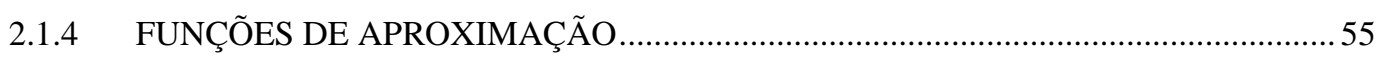

2.1.5 POLINÔMIOS DE LAGRANGE …………………………………………………….... 56

2.1.6 CONSTRUÇÃO DO SISTEMA DE EQUAÇÕES.......................................................... 59

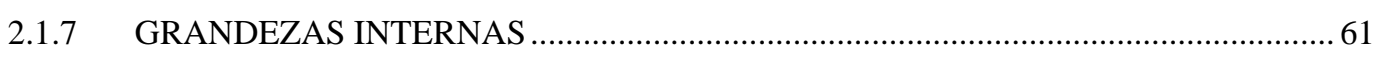

2.1.8 SINGULARIDADES DO MÉTODO DOS ELEMENTOS DE CONTORNO.................63

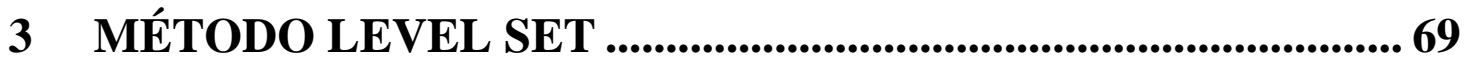

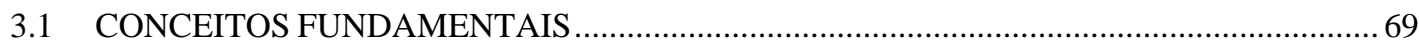

3.1.1 MOVIMENTOS DE UM CAMPO DE VELOCIDADE GERADO EXTERNAMENTE 69

3.1.2 MOVIMENTO ENVOLVENDO CURVATURA PRINCIPAL ……………………....... 77

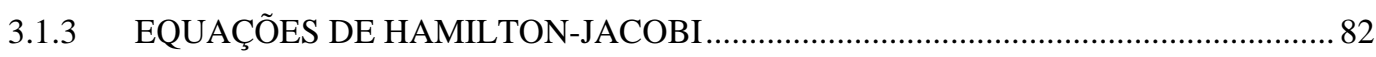

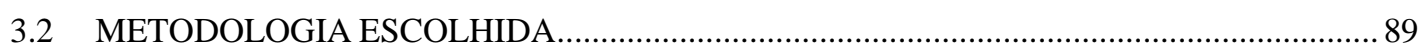

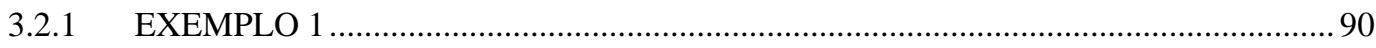

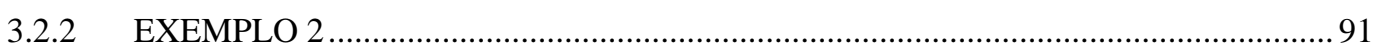

4 OTIMIZAÇÃO ESTRUTURAL ................................................93

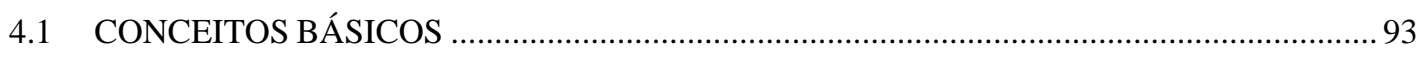

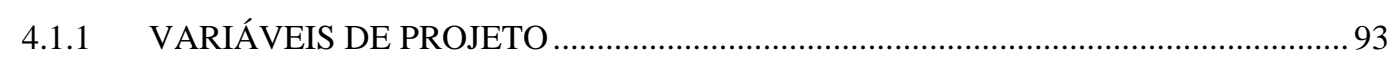




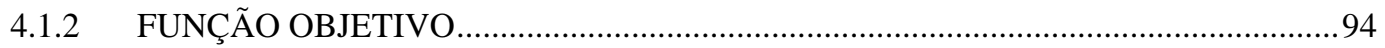

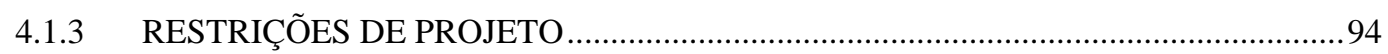

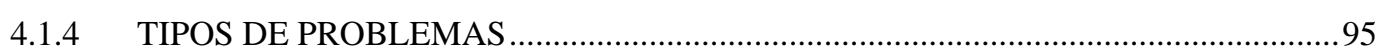

\section{OTIMIZAÇÃO TOPOLÓGICA ATRAVÉS DO}

\section{ACOPLAMENTO MEC-MLS..............................................................99}

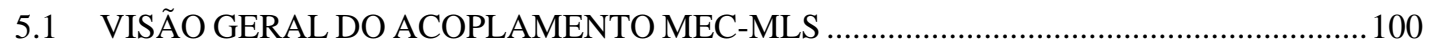

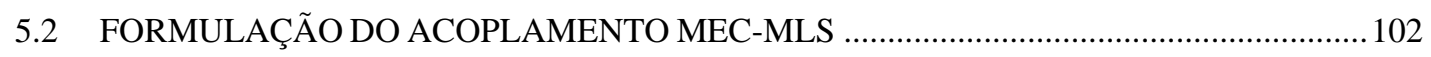

5.2.1 GEOMETRIA INICIAL DA ESTRUTURA, CARREGAMENTOS E CONDIÇÕES DE CONTORNO 103

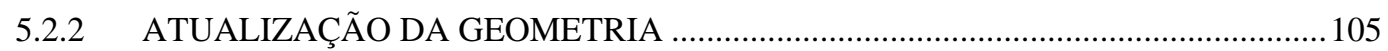

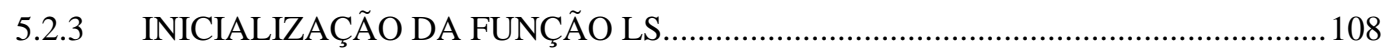

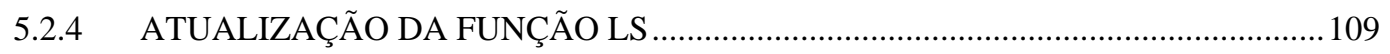

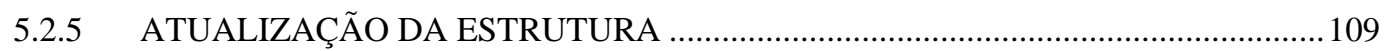

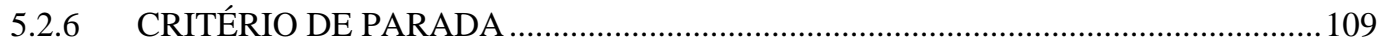

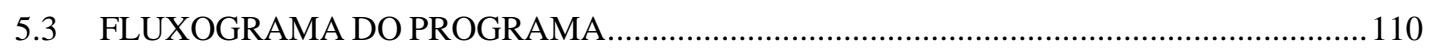

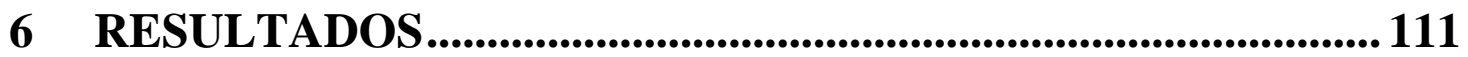

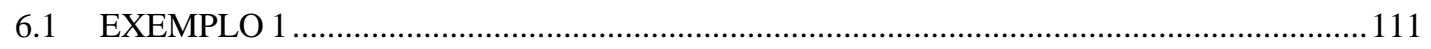

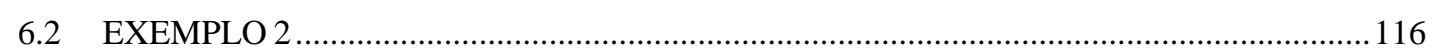

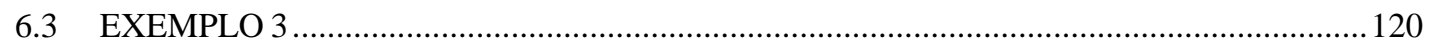

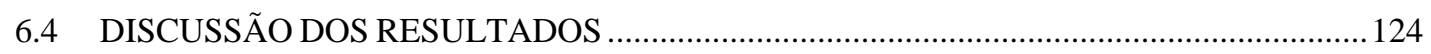

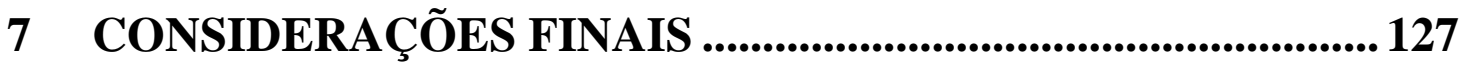

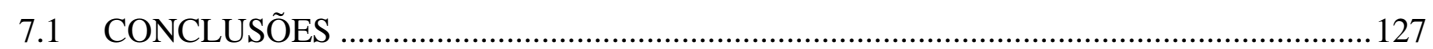

7.2 PROPOSTAS PARA TRABALHOS FUTUROS …….........................................................130

REFERÊNCIAS BIBLIOGRÁFICAS .................................................... 131

ANEXO A - TÓPICOS DA TEORIA DA ELASTICIDADE ............ 139

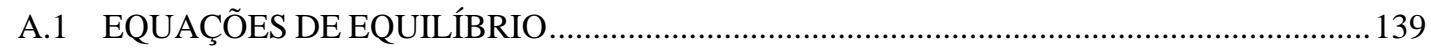

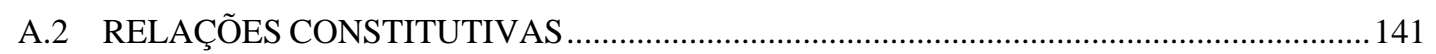

A.3 RELAÇÕES DEFORMAÇÃO-DESLOCAMENTO............................................................... 142

A.4 CONDIÇÕES DE COMPATIBILIDADE DE DEFORMAÇÕES ............................................143

A.5 EQUACIONAMENTO DOS PROBLEMAS ELÁSTICOS ……..............................................143

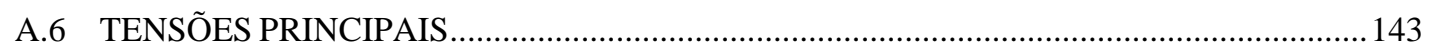

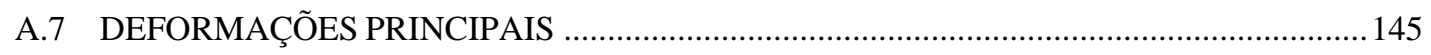




\section{INTRODUÇÃO}

\subsection{CONSIDERAÇÕES INICIAIS}

Um projeto estrutural deve garantir condições adequadas de serviço, segurança ao colapso e, sobretudo, ser economicamente viável. A fim de assegurar essas condições, é necessário que o engenheiro escolha as características que melhor se adaptem às especificações do projeto, partindo dos sistemas estruturais, materiais e recursos disponíveis. Em grande parte dos projetos, a solução desejada não é encontrada facilmente, pois a mesma varia de acordo com as dimensões, resistências e sistema estrutural adotados.

Através das técnicas de otimização é possível alcançar a perfeita combinação de fatores, que atenda aos requisitos pertinentes a cada projeto.

Espath (2009) cita "Eneida” do século I a.C., onde Virgílio exalta as origens e o espírito do povo romano. Nessa obra, a fenícia Dido persuadiu um chefe africano a dar-lhe tanta terra quanto fosse possível cercar com a tripa de um touro. Ela dividiu a tripa em centenas de tiras bem finas e uniu-as traçando um semicírculo no chão, à beira do Mar Mediterrâneo. Era a máxima área costeira que ela poderia envolver, Dido teria resolvido o primeiro problema de otimização da história. Mesmo sendo literário, o relato demonstra que os povos da antiguidade detinham o conhecimento a respeito de áreas e comprimentos, e sabiam que dentre as figuras de igual perímetro, o círculo é aquela com maior área.

Com o passar dos anos o conceito de otimização é cada vez mais utilizado por empresas e pesquisadores nos campos da física, química, engenharia, economia, entre outros.

Apesar do embasamento teórico e matemático dos métodos clássicos de otimização, há conceitos fundamentados em eventos da natureza como os algoritmos genéticos e evolutivos. Estes empregam condições de energia presentes em fenômenos físicos e químicos, forma das moléculas, inteligência de enxames (formigas, abelhas, vespas), evolução de genes para a determinação de pontos ótimos de funções.

Para projetos de engenharia de estruturas, em geometrias e condições de contorno simples, obtêm-se às soluções através de métodos clássicos, hipóteses e soluções analíticas baseadas na teoria da elasticidade. Em estruturas e sistemas estruturais onde geometrias e condições de contorno são complexas é necessário o emprego de métodos numéricos. 
Dentre todas as variáveis passíveis de otimização, aplica-se às estruturas o conceito de otimização topológica. Busca-se a melhor distribuição de material, onde todos os pontos operem no máximo de sua capacidade sem qualquer prejuízo à mesma.

Nesse trabalho, a configuração inicial de uma estrutura contínua é interpretada como problema original. No cálculo das tensões e deformações atuantes na estrutura emprega-se o método dos elementos de contorno (MEC). Após o cálculo mecânico realiza-se a adequada inserção de furos de acordo com o critério de tensão de Von Mises e utiliza-se o método level set (MLS) para o tratamento às mudanças de topologia da peça. O MLS é discretizado pelo método diferença upwind e modifica o domínio da estrutura a cada instante de tempo fictício imposto. O acoplamento MEC-MLS garante a obtenção da topologia ótima da estrutura sem o uso de filtros ou similares. É importante destacar que a palavra topologia descreve a morfologia viável para estrutura ou componente estrutural, não se referindo à terminologia utilizada no contexto matemático de análise funcional.

O produto final dessa dissertação é um programa computacional em linguagem FORTRAN, capaz de identificar a geometria ideal para estruturas planas submetidas a carregamentos estáticos. Além disso, os grupos de pesquisa em métodos numéricos e mecânica dos materiais de Departamento de Engenharia (SET) da Escola de Engenharia de São Carlos (EESC-USP) têm desenvolvido trabalhos significativos nos campos da mecânica dos sólidos, dos materiais e das estruturas. Baseado nisso, essa dissertação visa contribuir nas aplicações práticas do MEC e ser precursor da linha de pesquisa de otimização topológica.

\subsection{REVISÃO BIBLIOGRÁFICA}

\subsubsection{MÉTODO DOS ELEMENTOS DE CONTORNO}

Problemas mecânicos são analisados por meio das condições de contorno impostas, ou seja, locais onde há restrições do quanto o corpo pode deslocar-se de acordo com as forças de superfície aplicadas. O resultado é dado pela relação entre as tensões e deformações dependentes do tipo de material empregado. Para problemas simples é possível determinar a solução final analiticamente. Em problemas complexos é essencial o emprego de métodos numéricos.

Os métodos numéricos representam o comportamento mecânico de corpos contínuos por meio de elementos e nós que são entidades discretas. O método dos elementos finitos 
(MEF) e o método das diferenças finitas (MDF) são técnicas numéricas que possuem aproximações no domínio do corpo, enquanto no método dos elementos de contorno (MEC) aplicado a problemas elásticos lineares, as aproximações são realizadas diretamente no contorno do corpo.

Nesse trabalho utiliza-se o MEC. A Figura 1.1 mostra o esquema da localização do MEC dentro dos métodos numéricos.

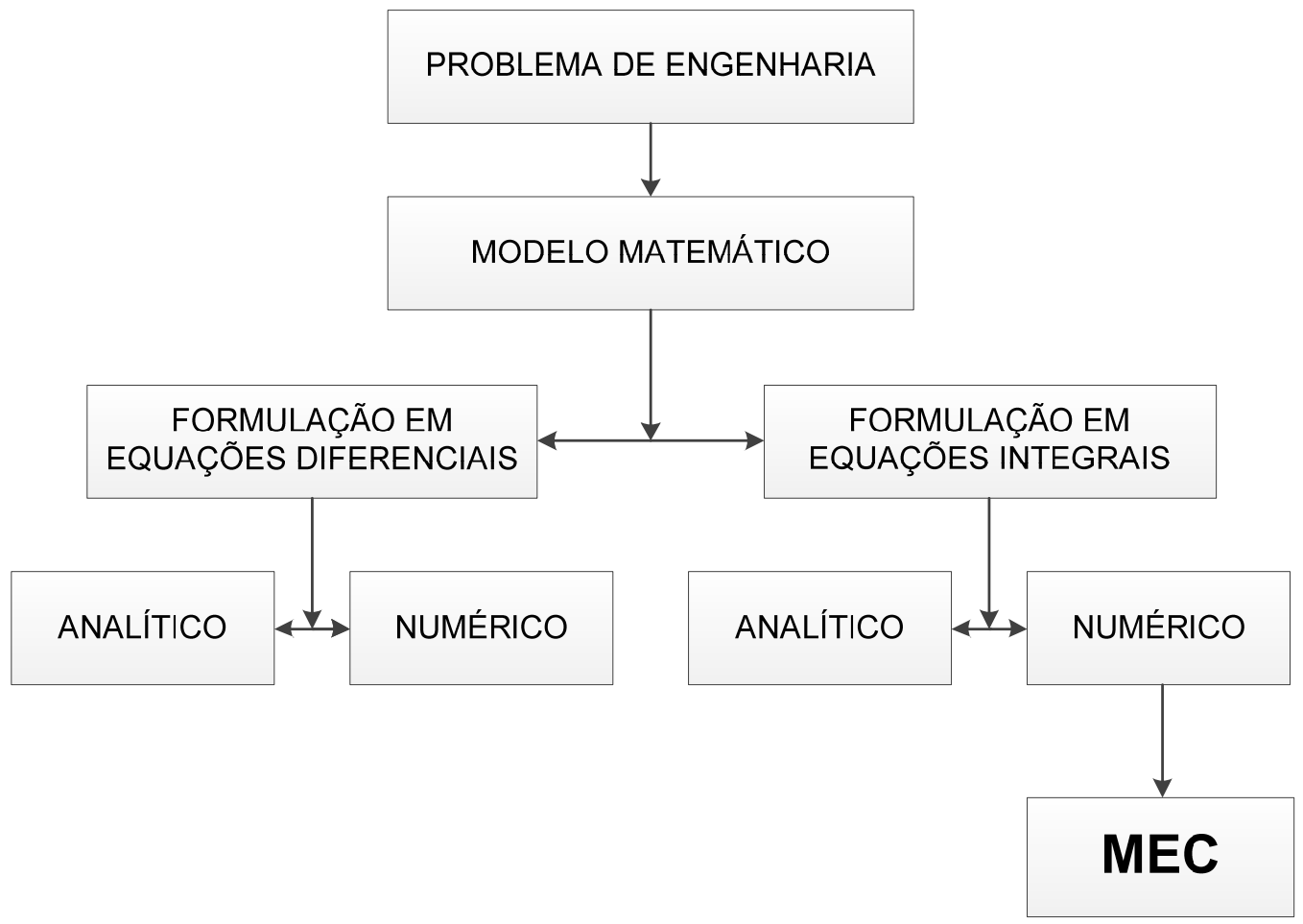

Figura 1.1 - Posicionamento do MEC na classificação dos métodos.

Nos métodos com formulação em equações diferenciais como o MEF, a aproximação é feita sobre as próprias equações de campo que regem o problema. As soluções encontradas representam aproximações das grandezas e respeitam aproximadamente as equações de campo. Chega-se à solução através de um sistema de equações cujas incógnitas estão tanto no domínio como no contorno do problema. O sistema algébrico final gerado é de grande dimensão, mas é esparso.

Nos métodos de formulação em equações integrais, o sistema resolvido apresenta menores dimensões se comparado aos métodos com formulação em equações diferenciais, o que pode ser explicado pelo emprego de funções especiais, como soluções fundamentais, funções de Green, funções de Trefftz (T-functions); com esse tipo de artifício o sistema resolvido utiliza apenas as variáveis presentes no contorno. Apesar do tamanho reduzido, as matrizes trabalhadas são não esparsas. 
O método dos elementos de contorno (MEC) é um método numérico empregado na solução de problemas de valor de contorno. É uma ferramenta robusta e precisa para a solução de problemas de engenharia de estruturas. Suas formulações são baseadas em equações integrais, motivo pela qual também é conhecido como método das equações integrais.

As soluções numéricas para as integrais de contorno foram introduzidas na ciência na década de 60. Primeiramente, Jaswon apresentou em 1963 o procedimento para a solução da identidade Somigliana para problemas potenciais e, posteriormente, Rizzo fez o mesmo para problemas elasto-estáticos em duas dimensões. Brebbia apresentou o MEC usando a formulação de resíduos ponderados. O desenvolvimento de soluções para problemas de valor de contorno usando funções definidas em domínios locais foi fortemente influenciado pelo desenvolvimento dos princípios variacionais estendidos e resíduos ponderados de meados dos anos 60. Diante disso, Brebbia (1978) e Brebbia e Dominguez (1989), apresentam soluções diversas para o MEC.

A teoria e a fundamentação matemática do MEC justificam a pouca utilização do método por parte de pesquisadores e engenheiros. Além disso, para problemas ainda não estudados a obtenção de soluções fundamentais pode ser complexa. Pela inexistência de softwares comerciais que incluam a formulação do MEC, é necessário o conhecimento de linguagens de programação para o desenvolvimento de algoritmos de integração numérica.

Para a engenharia de estruturas, as principais aplicações do MEC encontram-se em problemas elásticos de interação solo-estrutura, problemas de geometrias de grandes dimensões e problemas onde existem concentrações de tensões. O método possui grande aplicabilidade para as indústrias mecânica, automobilística, aeronáutica, entre outras.

A grande vantagem do MEC é a redução na dimensionalidade da malha, isso reduz os tempos na preparação e processamento dos modelos. As soluções fundamentais oferecem ótima qualidade e precisão. Outra vantagem é o tratamento de singularidades ou problemas externos (descontinuidades, concentrações de tensões, etc.), o que é altamente desejado e importante para a otimização topológica. Além disso, é possível associar o MEC a outros métodos, aumentando as possibilidades na simulação de problemas.

O método dos resíduos ponderados utilizado por Brebbia e Dominguez (1992) e o princípio da reciprocidade de Betti são os caminhos usuais para a obtenção das formulações direta ou indireta do MEC. Na formulação direta, as grandezas envolvidas são empregadas e obtidas diretamente, sem a necessidade de funções auxiliares. A formulação indireta é caracterizada pelo desprendimento do problema físico e empregam-se funções fictícias para a representação das grandezas do problema. 
O MEC mostra-se um método preciso para análise de problemas em engenharia. Para a engenharia de estruturas destaca-se a determinação de grandezas como tensões e deformações.

Aplicados à otimização topológica, o MEF é bastante utilizado pela facilidade no uso do método e pela quantidade de softwares comerciais disponíveis. O MEC ainda possui poucas aplicações nesse campo, alguns trabalhos de pesquisadores como Neches e Cisilino (2007), Abe et al. (2007), Marczak (2007), Anflor e Marczak (2008), Bertsch et al. (2010), Yamada et al (2010), Otomori et al (2011), Jing et al. (2013), Yamasaki et al. (2013), Yamada et al. (2013), Ullah et al. (2014) e outros, estudam o acoplamento do MEC com outros métodos; este permite encontrar a geometria ótima de estruturas de acordo com o equacionamento proposto e restrições impostas. No decorrer dessa dissertação, os trabalhos desses pesquisadores são discutidos em mais detalhes.

\subsubsection{OTIMIZAÇÃO}

Com o passar dos anos, o conceito de otimização é constantemente empregado, sendo alvo de estudos de vários pesquisadores nos campos da física, química, engenharia e economia.

O problema de otimização é fundamentado em conceitos matemáticos. Luenberger (2008) faz considerações importantes a respeito dos conceitos de otimização. A resolução de problemas desse tipo contém uma elegância invejada por outros métodos, sendo sua simplicidade um fator indispensável. O problema de otimização começa com a determinação de variáveis, parâmetros e restrições que definem um problema físico. Em função destas variáveis define-se a função objetivo que, matematicamente, é maximizada ou minimizada. $\mathrm{O}$ valor final atribuído e a velocidade para a chegada ao resultado determinam a qualidade da metodologia empregada.

Silva (2001) apresenta a otimização como a maneira hábil de se identificar a melhor solução dentre as inúmeras disponíveis. Souza (2001) interpreta como a busca de melhores resultados de uma função ou processo para atingir um ou mais pontos de ótimo. Vianna (2003) explica a otimização ou programação matemática como a técnica de determinação da melhor solução para problemas matematicamente definidos, que são frequentemente a modelagem de um problema físico. 
A otimização apresenta-se na engenharia em diversos segmentos. O escopo de um problema de otimização pode ser uma planta, processo, equipamento, peça ou quaisquer sistemas intermediários entre estes. No interior de uma empresa, a otimização é efetuada em diferentes níveis, envolvendo desde unidades menores até a combinação complexa de setores (SECCHI, 2001).

Usualmente, as soluções ótimas para engenharia são encontradas por meio de avaliações de experiências anteriores, comparação entre várias simulações, ensaios de tipo e utilização de ferramentas matemáticas (PINTO, 2006).

A construção de um problema de otimização é resumida em três etapas. A primeira é a formulação do problema, nessa fase são identificadas as variáveis de projeto de acordo com o conjunto de parâmetros que definem a estrutura ou o componente. A segunda etapa trata-se da identificação da função objetivo. E a terceira identifica e desenvolve as expressões matemáticas responsáveis pela imposição das restrições ao projeto.

De forma simplista, otimizar significa melhorar até onde for possível sob determinadas restrições, escolher a alternativa ótima entre muitas. É uma ferramenta de conceituação e análise de uma solução filosoficamente correta. A busca de valores extremos de funções estabelecem a relação entre a matemática e os conceitos de otimização.

Grande parte dos problemas de otimização não possui solução ótima em um tempo viável, alcançando apenas uma solução aproximada. Por isso, é errôneo definir a otimização com um processo de busca do melhor absoluto, e sim como a procura pelo melhor prático, executando a tarefa de maneira mais eficiente possível.

Os algoritmos são os recursos matemáticos fundamentais para resolver um problema de otimização. São um conjunto regras e processos pré-definidos destinados à solução de problemas em um número finito de etapas (processos iterativos). São procedimentos computacionais que recebem um ou mais valores de entrada e produzem um ou mais valores de saída para o problema analisado.

O problema de programação matemática consiste em encontrar numericamente um ponto admissível para a função especificada, este ponto é chamado solução ótima, mínimo ou máximo do problema. Dentre os tipos de problemas de programação matemática destacam-se a programação linear e a programação não linear.

A programação linear é o mecanismo mais natural para a formulação de problemas com pequeno esforço matemático. É caracterizada por funções lineares nas incógnitas. As formulações da programação linear são populares tanto pela riqueza da teoria, quanto pela simplicidade da matemática e da computação envolvidos. 
Na programação não linear o grau de complexidade é aumentado, pois são utilizadas funções não lineares. Nessa classe, os problemas são subdivididos em irrestritos e restritos.

Nos problemas irrestritos, o escopo é ampliado para a consideração de todas as variáveis de decisões relevantes. Não existe limitação imposta por outras funções para se chegar ao ponto de ótimo. Matematicamente, o mínimo ou máximo da função já é a resposta esperada. Os problemas restritos são convertidos em problemas irrestritos, de modo que suas variáveis fiquem em função umas das outras.

Nos problemas restritos, além da função objetivo existem outras funções que limitam a determinação do ponto de ótimo. A solução pode não ser o mínimo absoluto da função objetivo, e sim o valor que melhor se adeque às limitações impostas. Essas limitações são funções secundárias do problema e são, geralmente, inequações. A maioria dos problemas práticos é formulada dessa maneira.

Para todos os tipos de problema, a complexidade é medida através de sua dimensão, que é dada pelo número de incógnitas e restrições impostas. Atualmente, devido ao avanço da computação e das teorias, a quantidade de problemas resolvidos eficientemente é crescente. A dimensão dos problemas tem sido de menor relevância. Entretanto, ainda é importante a separação dos problemas através da sua dimensão.

Os problemas de pequena escala (5 ou menos incógnitas e restrições) são resolvidos manualmente ou por pequenos computadores. Os problemas de escala intermediária (entre 5 e 10.000 incógnitas e restrições) são resolvidos por computadores comuns com o uso de códigos matemáticos convenientes. E os problemas de larga escala (mais de 10.000 incógnitas e restrições) requerem códigos sofisticados que exploram estruturas especiais e grandes clusteres.

Esta classificação não é totalmente rígida, mas reflete as diferenças básicas nas aproximações que acompanham os diferentes tamanhos dos problemas como uma regra grosseira (LUENBERGER, 2008).

\subsubsection{OTIMIZAÇÃO ESTRUTURAL}

Existem relatos que apontam Galileu Galilei como o primeiro a utilizar os conceitos de otimização estrutural, ele determinou a melhor forma de uma estrutura baseada em sua resistência por volta do ano de 1638. James Clerk Maxwell também empregou o conceito por volta do ano de 1872. Naquela época as principais estruturas estudadas eram as pontes, os 
engenheiros preocupavam-se em desenvolver modelos para o cálculo preciso das tensões mecânicas na configuração da ponte proposta.

Maxwell decidiu obter o projeto de ponte que utilizasse a menor quantidade de material e verificar o risco de falha da mesma. Ele estudou alguns problemas bem simples utilizando conceitos de teoria de elasticidade. Calculou o campo de tensões mecânicas presentes para um dado carregamento atuando num domínio infinito, os pontos onde esse domínio estaria apoiado e as direções das tensões principais atuantes. Maxwell sugeriu, conceitualmente, que a estrutura com a menor utilização de material, seria constituída de elementos de treliça alinhados com das direções principais. Essa solução mostrou-se mais tarde ser também a solução ótima para o projeto de uma estrutura com a máxima rigidez e menor peso, considerando-se um único carregamento.

Em 1904, Anthony Michell retomou a ideia de Maxwell. Ele aplicou o método em vários tipos de estruturas e encontrou o menor volume de material para cada uma delas. No entanto, seus resultados foram considerados acadêmicos e sem aplicação prática, pois eram difíceis de serem construídos na época.

De 1904 a 1950 não houve evolução nos estudos de otimização estrutural, sendo estudados apenas problemas acadêmicos.

No início na década de 50, iniciou-se o uso da programação linear para otimizar estruturas no regime plástico.

Na década de 60, empregaram-se técnicas de programação não linear em otimização de projetos estruturais. As maiores aplicações concentraram-se em engenharia aeronáutica e envolviam estruturas reticuladas enrijecidas por cascas e placas. Devido às complexidades matemáticas e falta de recursos computacionais suficientes, as pesquisas permaneceram estritamente no âmbito acadêmico durante vários anos. O desenvolvimento acelerado de recursos computacionais e a criação de algoritmos eficientes capazes de suportar formulações complexas impulsionaram o interesse na área de otimização de estruturas. Assim, cientistas, engenheiros e fabricantes passaram a investir na busca por projetos mais eficientes e econômicos, dando origem a uma forte atividade na área.

Durante a década de 70, desenvolveram-se trabalhos que atualmente fazem parte da literatura clássica da otimização estrutural. Vários temas foram tratados: projeto com tensões limites, algoritmos com critérios de otimalidade, programação matemática e algoritmos de programação linear. Iniciaram-se estudos na área de implementação de algoritmos numéricos e métodos discretos como elementos finitos, elementos de contorno e diferenças finitas passaram a ganhar destaque. Os interesses também estavam em problemas de análise de 
sensibilidade, programação linear sequencial, funções de penalização para problemas com restrições e programação dinâmica.

No início da década de 80, os trabalhos de Michell foram relembrados, estudados e implementados detalhadamente. No final dessa década desenvolveu-se o método de otimização topológica (MOT) que representa o conceito de síntese estrutural na sua essência, sendo o método mais genérico e poderoso disponível atualmente.

Nas décadas seguintes pacotes computacionais foram e continuam sendo desenvolvidos, principalmente, devido ao grande interesse das indústrias aeronáutica, automotiva e mecânica. Dando ênfase à capacidade de modelagem geométrica (geração automática de malhas), segurança e rapidez na análise (algoritmos eficientes), e facilidades de visualização (estações gráficas) (SILVA, 2003).

Os projetos de engenharia são embasados em normas e códigos resultantes do estudo de diversos pesquisadores. Grande parte das teorias aplicadas leva em conta a prática de ensaios experimentais.

Em um projeto estrutural isto também é executado, pois experimentos diversificados são efetuados até se atingirem os padrões de projeto vigentes. De modo convencional, primeiramente, obtém-se a disposição ideal das peças estruturais que capacite o suporte adequado dos carregamentos impostos. Posteriormente, busca-se a melhor distribuição de material que forneça o menor custo. Concentrando-se na determinação de proporções de materiais e formas, sujeitos a atuação de carregamentos distintos, é possível estabelecer uma estrutura com maior desempenho global.

A determinação de uma configuração eficiente não garante que o resultado final seja efetivamente o ótimo absoluto, visto que é inerente um processo de tentativas e erros. Cada projetista adota a melhor solução fundamentando-se em suas experiências vivenciadas anteriormente. A otimização estrutural surge como artifício para eliminar a solução ótima assim encontrada.

A otimização estrutural é tratada como uma fusão de áreas da engenharia e matemática capaz de adicionar variáveis ao projeto que vão além da experiência do projetista. Para um problema de otimização estrutural o interesse está em definir uma ou mais funções objetivo, sujeitas ou não a restrições, que sejam capazes de gerar um projeto que atenda às condições de resistências e rigidez com menor custo possível.

No processo de otimização estrutural, o projetista é quem define as variáveis contidas na função objetivo, as restrições, os níveis ou limites aos quais as restrições devem ser 
satisfeitas. Em um número tão elevado de variáveis, são realizadas algumas simplificações, pois relações entre esses parâmetros são difíceis de serem obtidas.

É comum que a tarefa principal da função objetivo seja a minimização do peso da estrutura, justificando a atratividade econômica presente nessa redução. Exemplos são verificados em projetos de estruturas metálicas e confecção de peças da indústria automotiva, onde o custo é um fator influente. Na indústria aeronáutica, a redução do peso é importante, entretanto, o custo não é fator preponderante. Em projetos de torres de transmissão ou peças mecânicas, onde o produto final é executado múltiplas vezes, a mínima economia em cada unidade corresponde a um montante considerável. Outros exemplos são otimização da forma da asa de uma aeronave, da seção transversal de uma ponte, da espessura de uma placa. Para cada um desses projetos é preciso encontrar uma geometria que satisfaça o estado de tensões dentro dos limites especificados.

Há casos onde se necessita aumentar a quantidade de restrições, logo o processo de otimização deve conter facilidades de flexibilização referentes às decisões tomadas durante o processo, isso auxilia na formação de soluções alternativas para os problemas. Restrições comuns em problemas estruturais são tensões, deslocamentos, frequências de vibração, cargas críticas de flambagem, etc.

O projetista deve ater-se a alguns aspectos importantes da otimização estrutural como:

- Tamanho, forma e topologia sendo otimizadas no mesmo problema em diferentes partes da estrutura;

- Critérios diferentes de otimização em partes diferentes da estrutura;

- Estrutura submetida a vários carregamentos;

- Estrutura com possíveis variações no sistema de apoios;

- Estrutura composta por vários tipos de materiais;

- Consideração de análises bi e tridimensionais;

- Otimização considerando-se análise estática, dinâmica e estabilidade simultaneamente;

- Otimização com não-linearidades físicas e geométricas (LEMONGE, 1999).

\subsubsection{OTIMIZAÇÃO TOPOLÓGICA}

A otimização topológica (OT) foi proposta na área acadêmica por Martin P. Bendsøe e Noboru Kikuchi no ano de 1988. Foi difundida nos EUA e Europa a partir da publicação do 
artigo "Generating Optimal Topologies in Structural Design Using a Homogenization Method".

Na década de 90, a OT passou a ser largamente utilizada pelas indústrias automotiva e aeronáutica dos EUA, Japão e Europa para o projeto de peças mecânicas otimizadas. Recentemente, em algumas áreas da engenharia, expandiram-se estudos acadêmicos em projetos de mecanismos flexíveis, atuadores piezoelétricos, antenas, motores eletromagnéticos, etc.

Estudos de pesquisadores como Vanderplaals (1984); Suzuki e Kikuchi (1991); Haftka e Gürdal (1995); Rozvany, Bendsøe e Kirsch (1995); Kikuchi et al. (1998) entre outros, tornaram-se grandes referências na área.

A OT torna o processo de projeto genérico, sistemático e independente da experiência específica do engenheiro. Obviamente, a presença do mesmo é indispensável para a obtenção do projeto final e verificação do desempenho através de métodos numéricos e experimentais.

A OT envolve a busca pela topologia ótima de uma estrutura, que permita a execução das funções estruturais com o menor uso possível de recursos. Consiste em um método computacional que permite projetar a topologia ótima de estruturas segundo determinado critério de custo (máxima rigidez, menor peso, etc). Para determinados projetos a escolha da topologia ótima influencia fortemente no custo e na segurança do sistema empregado. Verifica-se que este é um campo que sofre mudanças significativas, devido a crescente importância dada ao longo do tempo (FONSECA, 2008).

O método distribui o material no interior de um domínio fixo de forma a maximizar ou minimizar uma função custo especificada. Em cada ponto do domínio, o material pode variar desde ar (ausência de material) até sólido (total presença de material), assumindo densidades intermediárias entre ar e sólido de acordo com um modelo de material definido.

O algoritmo encontra de forma iterativa a distribuição ótima de material, o que torna o processo rápido, caso contrário inúmeras análises seriam necessárias para encontrar a distribuição ótima.

Na aceleração do processo de busca da distribuição ótima de material, os métodos de otimização utilizam-se da informação dos gradientes (ou derivadas) da função custo em relação à quantidade de material em cada elemento.

Em um projeto estrutural analisa-se, primeiramente, a definição conceitual da geometria e os materiais a serem empregados, de maneira que todos os requisitos de projeto sejam atendidos. Além disso, a engenharia busca melhorar o desempenho das estruturas e reduzir o seu custo de fabricação das mesmas. 
Stump (2006) faz uma ampla revisão sobre OT, que também é conhecida como Otimização de Leiaute ou Otimização de Forma Generalizada. Esse leiaute ou topologia da estrutura é definido não apenas por sua forma delimitada pelo contorno externo, mas também por sua forma interna, furos e conectividade existentes em seu domínio.

Eschenauer et al. (1994) propôs o Bubble Method na qual faz-se a inserção de novos furos na estrutura e o subsequente uso do método de otimização de forma, o processo de otimização é capaz de determinar qual a melhor forma das mesmas.

Maute e Ramm (1995) utilizam o método adaptativo para a obtenção da estrutura ótima. Esse método é baseado na suavidade no domínio de projeto que é calculada por meio da aproximação de curvas Bézier; estas por sua vez são relacionadas à distribuição da densidade do corpo. Essa abordagem reduz a quantidade de variáveis de projeto e melhora a geometria em estudo.

Papalambros e Chirehdast (1990) utilizam um método de homogeneização. A aproximação integra a otimização estrutural ao CAD (Computer aided design).

Xie e Steven (1993) propõem o método ESO (Evolutionary structural optimization). Inspirados em elementos naturais como ossos, árvores, conchas, entre outros, que mesmo submetidos a condições adversas atingem suas formas ótimas ao longo do tempo. O método remove material, progressivamente, de acordo com os critérios de tensão local impostos.

Garcia e Steven (1999) empregam o conceito de grid fixo juntamente ao MEF a fim de simplificar a malha empregada e aumentar a eficiência computacional em problemas de mudança de geometria em função do tempo. Entretanto, as tensões podem ser comprometidas em função da malha empregada.

Dunning et al. (2011) também empregam a técnica de grid fixo com o MEF. Para determinação da forma ótima eles acoplam um esquema baseado na sensibilidade e garantem o funcionamento do esquema para análise de carregamento com incertezas.

Os esquemas de grid fixo e ESO têm se tornado populares por sua simplicidade de equacionamento e implementação. Apesar de numerosas experiências empíricas mostrarem que as soluções ótimas obtidas assemelham-se a dos métodos mais rigorosos, existem controvérsias relacionadas à validade dos resultados, principalmente, quanto à remoção e adição de material através de um dado critério de tensão local.

Haftka e Grandhi (1986) destacaram a otimização de forma e dificuldade de garantir a precisão da análise para mudanças de geometria contínuas utilizando o MEF. A mudança na geometria pode causar distorção na malha dos elementos finitos, levando a deterioração da 
precisão das soluções para tensões e deformações. A combinação do MEF com o esquema de grid fixo pode reduzir a distorção. Contudo, alguns erros ainda permanecem.

As abordagens usuais da OT são realizadas com o auxílio do MEF. O primeiro passo consiste em definir o domínio no qual a estrutura pode existir. Esse domínio é limitado pelas condições de contorno da estrutura e pelos pontos de aplicação de carregamentos. Outras limitações são relacionadas com a restrição do espaço ocupado. A Figura 1.2 apresenta o procedimento.

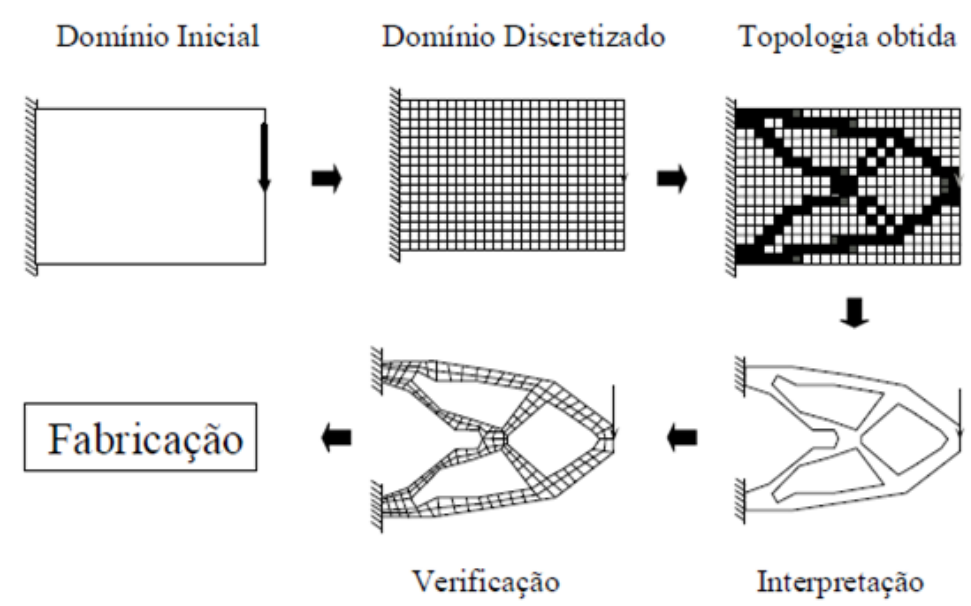

Figura 1.2 - Procedimento típico de projeto estrutural por OT. Fonte: Silva (2003).

É importante definir o domínio com o maior tamanho possível, de forma a não limitar o trabalho da OT. Como em qualquer método de otimização, quanto mais restrições são impostas, menor é a melhora de desempenho da solução obtida. Assim, restrições de espaço de ocupação da estrutura reduzem a otimalidade da solução no caso da otimização topológica.

No segundo passo o domínio é discretizado em elementos finitos e são aplicadas as condicões de contorno.

No terceiro passo, os dados do domínio são fornecidos ao software de OT que num processo iterativo distribui o material no domínio de forma a minimizar (ou maximizar) a função objetivo especificada, no caso, flexibilidade. O resultado obtido é do tipo mostrado na Figura 1.2 (“topologia obtida”), onde a cor escura indica a presença de material e a cor branca indica a ausência de material no ponto do domínio.

Nesse processo surgem pontos com cores intermediárias, denominados escalas de cinza (gray scale). Eles indicam a presença de materiais intermediários que não podem ser implementados na prática. A escala de cinza é inerente à obtenção da solução ótima pelo MEF. Dessa forma, a imagem da estrutura obtida por OT representa um excelente ponto de partida que necessita ser interpretado para se atingir o projeto final da estrutura. 
A interpretação é a quarta etapa, esta é realizada usando-se métodos de processamento de imagem, ou simplesmente desenhando-se uma estrutura baseada na imagem obtida por OT.

A quinta etapa consiste na verificação do resultado final da estrutura, que em geral, não são intuitivos e é interessante fazer uma verificação da estrutura final. A última etapa é a fabricação da estrutura.

Nesse trabalho utiliza-se a metodologia para OT, porém, aplicando-se o MEC.

A Figura 1.3 ilustra como o material é distribuído pela OT no interior do domínio fixo ao longo das iterações (somente metade do domínio é mostrado), utilizando o MEF. O problema consiste em obter a estrutura com máxima rigidez e menor peso em um domínio biapoiado sujeito a um carregamento no seu centro. 


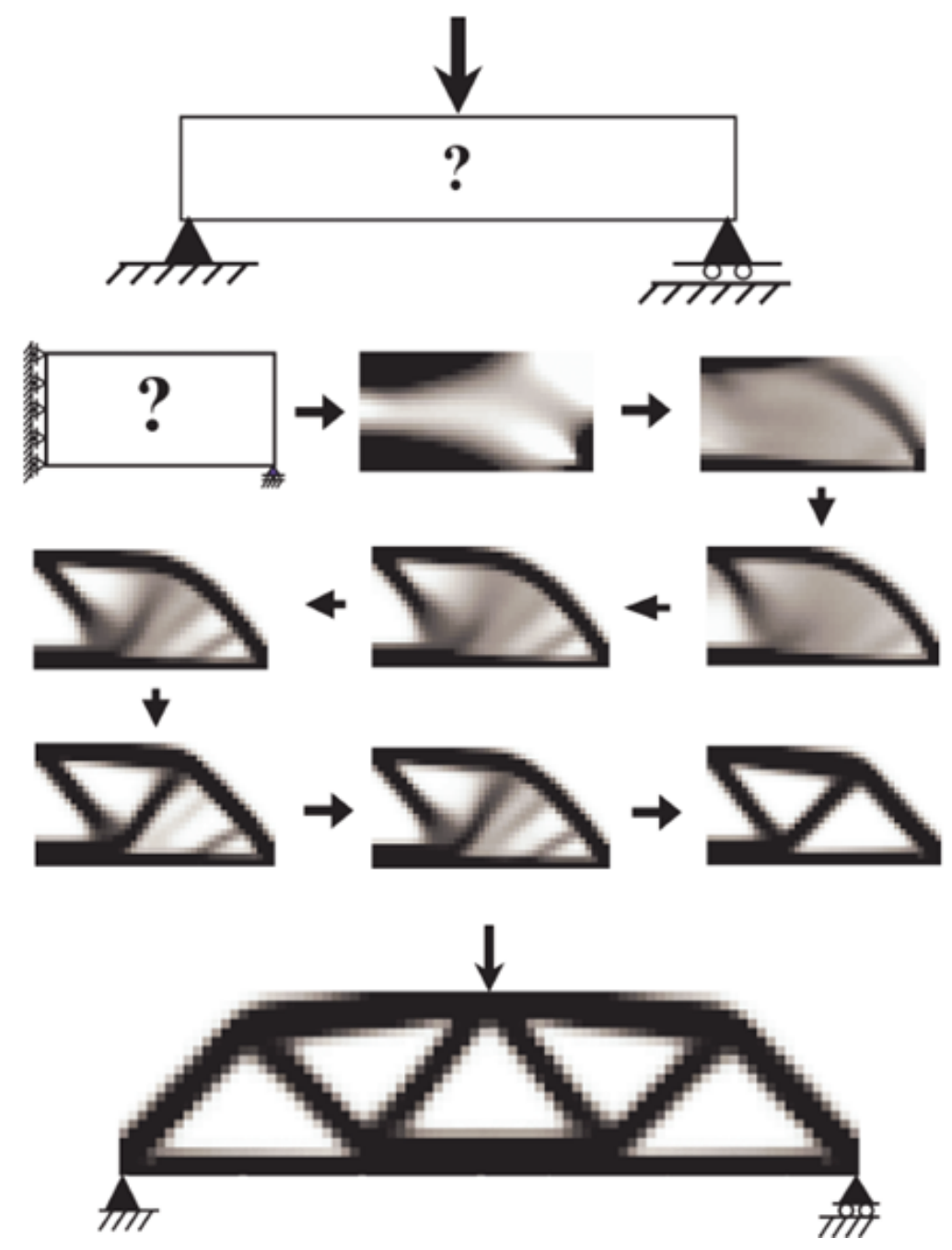

Figura 1.3 - Distribuição de material no interior de um domínio fixo ao longo das iterações. Fonte: Silva (2003).

Nota-se que o resultado se aproxima de uma estrutura de treliças como sugerido por Anthony Michell no início do século XX.

É conhecido o comportamento estrutural de uma treliça, onde os elementos estão sujeitos à tração ou compressão. Na viga inicial existem esforços de flexão. A distribuição de tensões numa barra sujeita à flexão, apresenta uma variação linear com as tensões máximas em módulo (tração ou compressão).

$\mathrm{Na}$ abordagem tradicional de otimização de forma alteram-se os contornos internos e externos do domínio da estrutura de forma a obter a solução ótima. Furos internos no domínio podem ser aumentados, diminuídos ou deslocados, porém novos furos não podem ser criados.

Na abordagem de OT encontra-se a distribuição de material no domínio fixo estendido que melhore a função objetivo. Portanto, novos furos podem ser criados.

Os conceitos de modelo do material estão relacionados à variação de material em cada parte, num intervalo entre zero (ar) e um (sólido). A utilização de valores discretos em OT 
mostra-se problemática, dando origem às instabilidades numéricas. Em uma formulação bem sucedida permite-se que o material assuma valores intermediários durante a otimização definidos pelo chamado modelo de material que determina a lei de mistura entre os materiais zero e um. A formulação do modelo de material é o ponto chave da formulação de OT utilizando o MEF.

Além do problema das escalas de cinza, pode ocorrer também um problema conhecido como "tabuleiro de xadrez" mostrado na Figura 1.4. Este também é conhecido como instabilidade de tabuleiro; nesse fenômeno aparecerem elementos de cor preta que representam material sólido e elementos de cor branca que representam ar, a disposição desses dois tipos de elementos assemelha-se a um tabuleiro de xadrez. Isso acontece devido a formulação do MEF e a malha quadriculada utilizada pelo método. É possível notar a dependência do processo de otimização à discretização da malha empregada, quando mais elementos possuir a malha, menor a quantidade de descontinuidades problemas.

A fim de minimizar o efeito das instabilidades presentes na formulação de OT utilizando o MEF utilizam-se filtros de vizinhança. A filtragem impõe uma uniformização nas propriedades de elementos próximos, impedindo uma variação brusca de propriedades entre elementos adjacentes.

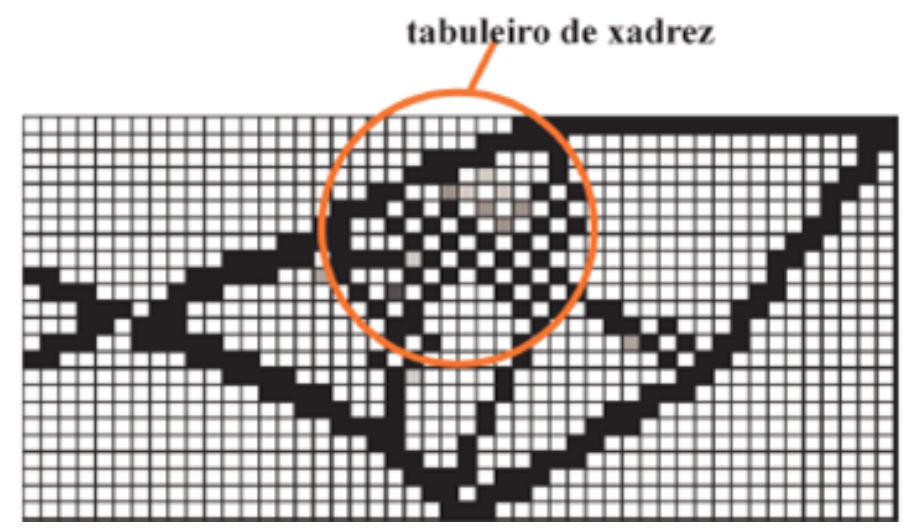

Figura 1.4 - Efeito 'tabuleiro de xadrez'. Fonte: Silva (2003).

A OT também pode ser aplicada para projeto de estruturas discretas, como treliças. Ao final da otimização, a topologia da estrutura discreta é dada pelos elementos de treliça com área maior que um valor mínimo. Além do problema clássico de otimização de maximização de rigidez para o menor volume de material, outras funções objetivo são possíveis ainda na área de mecânica estrutural clássica, como maximização da freqüência de ressonância, maximização da carga de flambagem, minimização da resposta em freqüência da estrutura e 
maximização da energia de impacto. Algumas dessas funções já estão implementadas em softwares comerciais.

Utilizando o MEC espera-se resolver o problema sem a necessidade de relaxação do algoritmo apresentado pelo MEF. Isso pode ser justificado pela malha do MEC ser discretizada apenas no contorno da estrutura, o domínio não é influenciado pela discretização empregada, eliminando as instabilidades e dispensando a utilização de filtros ou similares.

\subsubsection{MÉTODO LEVEL SET}

Tanto na ciência como na engenharia, diversos problemas envolvem contornos e interfaces. Formalmente, o contorno é uma linha que fecha ou limita exteriormente um corpo. Na matemática, o contorno é entendido como uma curva (função) que cerca uma determinada área.

Com o passar dos anos, é crescente o desenvolvimento de técnicas para reprodução de fenômenos físicos onde as funções matemáticas que os representam variam de acordo com o tempo. Em muitos casos, a movimentação e a evolução das funções com o tempo são fundamentais para a representação precisa dos problemas.

Para exemplificar a evolução de uma interface, utiliza-se a Figura 1.5.

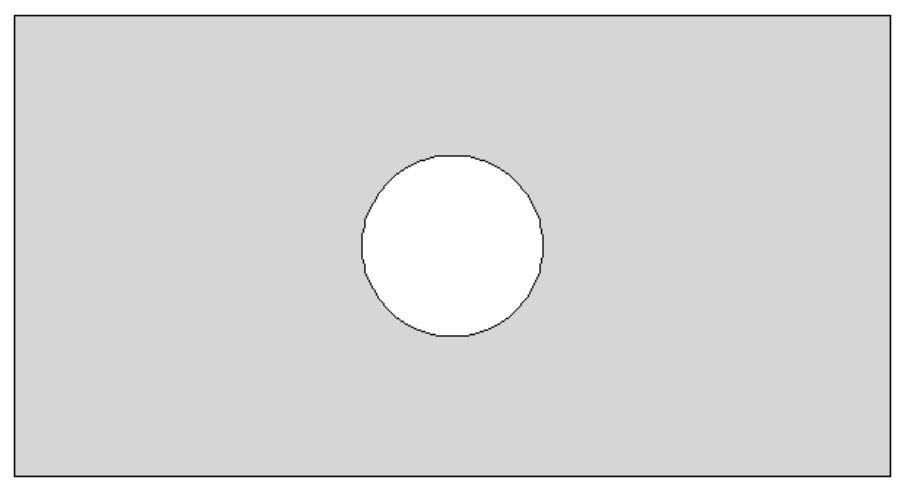

Figura 1.5 - Interface separando dois meios.

Considera-se um ácido corroendo um material, na Figura 1.5 - Interface separando dois meios. a área cinza, o círculo branco e a circunferência representam, respectivamente, o material, a ausência de material e o ácido. A velocidade da corrosão depende da resistência encontrada pelo ácido, nas partes mais resistentes, a velocidade da corrosão é menor do que em outros locais. 
Ainda para a Figura 1.5, seja o círculo um bloco de gelo dentro de um recipiente com água. A borda do gelo (interface de interação) pode diminuir se a temperatura da água aumentar e pode aumentar caso a temperatura diminua. A velocidade de propagação da interface depende da diferença de temperatura entre o gelo e água. Neste caso a interface pode avançar ou recuar, possibilitando que a velocidade de propagação seja positiva ou negativa.

Como a interface pode avançar ou recuar, é possível que ela passe pela mesma posição em instantes diferentes. Portanto, não é possível definir uma função temporal T que associe a interface a pontos do espaço (PEIXOTO; VELHO, 2000).

A movimentação das curvas pode ser realizada através das aproximações Lagrangeana (explícita) e Euleriana (implícita). Maistrou (2008) discute essas aproximações, aponta suas características e diferenças, além das vantagens e desvantagens de se adotar uma ou outra aproximação.

A maneira mais simples para a representação de movimentos do contorno é a aproximação Lagrangeana (explícita), nesse modelo são delimitados nós conectados através de segmentos de reta. Devido à similaridade da avaliação do contorno com o movimento de uma cobra, a interface resultante é chamada snake. O método trabalha o movimento dos nós de acordo com a velocidade $\vartheta$ por meio da resolução de sistemas de equações diferenciais ordinárias.

O contorno tem uma representação paramétrica e o método é baseado na ideia de minimização de energia. Para uma dada função, considera-se que a cada instante de tempo t a mesma esteja em um ponto diferente do espaço. A procura do mínimo para essas funções é realizada através de métodos numéricos clássicos como: steepest descent, gradientes conjugados, método simplex, entre outros.

A equação que representa o método é Lagrangeana e sua resolução é bem definida. Apesar da simplicidade, a mesma possui algumas limitações. Durante a evolução, os nós têm uma distribuição desigual, fazendo a representação numérica da curva tornar-se ineficiente. Com a inserção e a remoção de nós é possível melhorar a representação, entretanto, isso introduz erros. Em curvas que apresentam ‘quinas', o esquema não produz os efeitos esperados. Em mudanças topológicas como fusão e separação de curvas, requer-se um tratamento especial que pode dificultar a operação do método. Em funções de velocidade dependentes de curvaturas $\mathrm{F}(\kappa)$ é comum utilizar a velocidade na direção normal à curva. $\mathrm{A}$ curvatura é um vetor que aponta na direção normal à curva. O esquema é sensível, pequenas perturbações podem levar a instabilidades. 
Na aproximação Euleriana (implícita) das geometrias encontra-se o método level set (MLS), proposto em 1988, por James Sethian (atual membro do Departamento de Matemática na Universidade da Califórnia em Berkeley) e Stanley Osher (atual membro do Departamento de Matemática na Universidade da Califórnia em Los Angeles). Eles propuseram o modelo de propagação e movimentação de curvas por meio de equações diferenciais parciais adequadas e valores de funções escalares, resultando na associação de problemas de valor inicial.

O MLS simula e analisa movimentos de curvas em diferentes cenários físicos, representa uma determinada curva (ou superfície) $\Gamma$ como a curva de nível zero (zero level set) de uma função $\phi$ de maior dimensão, denominada função Level Set (LS). A Figura 1.6 ilustra um exemplo clássico da função LS.

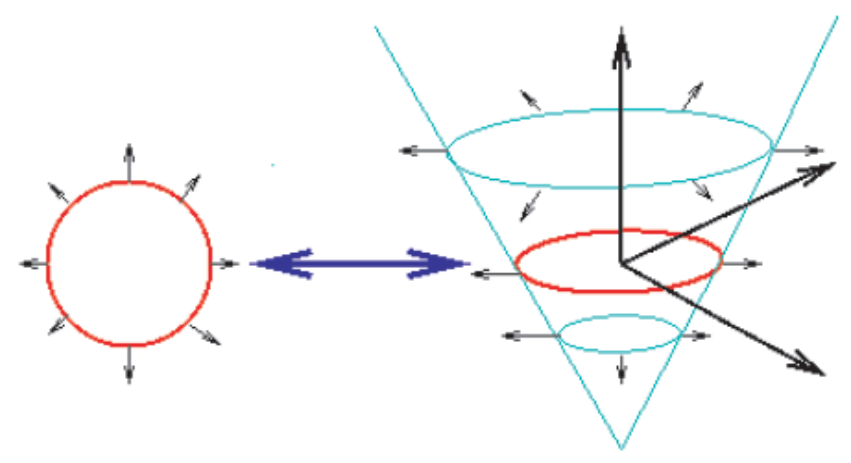

Figura 1.6 - Função Level Set. Fonte: Napolitano (2004).

Sethian (1999) introduz poderosas técnicas numéricas para analisar e implementar movimentos de curvas. A metodologia proposta permite deslocamentos fundamentais para contornos, repensando a geometria natural da perspectiva Lagrangeana e substituindo-a pela perspectiva das equações diferenciais parciais Eulerianas.

De um ponto de vista teórico-matemático o MLS elimina algumas complexidades do movimento de curvas, particularmente, singularidades, soluções fracas, formação de choques, condições de entropia, e mudanças topológicas que envolvem interfaces.

Da perspectiva numérica, o MLS utiliza-se de caminhos computacionais naturais e precisos. Inclui-se a habilidade de construir esquemas de alta ordem, para problemas em duas ou três dimensões. Representam-se facilmente quinas acentuadas e extremidades, além de ser possível a manipulação de mudanças topológicas na fusão e divisão de formas. 
No aspecto de implementação, as aproximações são baseadas em equações diferenciais parciais, onde esquemas robustos resultam de parâmetros numéricos. A adaptação computacional é a chave da técnica.

O MLS é empregado na mecânica dos fluidos, processamento de imagens e visão computacional, crescimento de cristais, geometria computacional, ciência dos materiais, entre outros.

Merriman et al. (1994) fornecem subsídios para o entendimento da teoria de movimento de junções de curvas. O MLS é utilizado para movimentar múltiplas junções de curvas. A equação de difusão é apresentada para gerar movimentos dependentes da curvatura e estas são usadas para desenvolver um algoritmo para mover as múltiplas junções com velocidades dependentes da curvatura.

Russo e Smereka (2000) apresentam uma formulação LS para movimento de interfaces facetadas de cristais. A evolução é representada como o zero level set de uma função fase. O cristal é identificado pela orientação e velocidade das faces.

Sethian e Smereka (2003) mostram uma visão geral do MLS para cálculo de problemas fluido-interface. As funções utilizadas na solução dependem da formulação implícita da interface, representadas através de uma equação diferencial parcial de valor inicial dependente do tempo. Realiza-se o acoplamento MLS-MEF para determinação dos fluxos compressíveis e incompressíveis.

Bianchi (2003) apresenta os principais modelos computacionais de simulação neural, funcionais e de crescimento neural. Na modelagem neural discute técnicas computacionais de evolução de contornos que podem ser utilizados na simulação do desenvolvimento, propagação de frentes e contornos ativos. Os crescimentos são baseados na velocidade normal ao contorno. Aborda-se a evolução da membrana neural baseada em contornos, utilizando a formulação de contornos ativos sob a ação do campo elétrico externo e a curvatura da forma.

Min e Gibou (2004) apresentam o MLS para grids cartesianos onde a relação entre células não é restringida. Eles discutem o esquema de reinicialização que transforma uma função arbitrária LS em uma função distância com sinal. Em seus exemplos em duas e três dimensões demonstram a eficiência do método.

Garzon et al. (2005) constroem um método numérico para problemas de movimento de contornos livres baseado no MLS e em integrais de contorno. A velocidade na interface é obtida da solução da integral de contorno usando a técnica de Galerkin. Introduz-se uma nova técnica LS propagando livremente o contorno no tempo. Eles atingem resultados similares aos obtidos por outras metodologias. 
Preto et al. (2009) apresentam uma solução que usa o MLS para modelar o movimento da interface para obtenção de transformações de imagens. A manipulação de um conjunto de parâmetros e funções velocidade fornece controle sobre a forma final do objeto a ser reconstruído. Os resultados experimentais obtidos demonstram a eficiência do método.

Li et al. (2012) propõem a otimização estrutural em 2D e 3D com método dos elementos finitos estendidos (XFEM). A combinação do XFEM com o MLS promove um elegante caminho para a resolução de problemas de otimização topológica em uma estrutura convencional.

Lim et al. (2003) apresentam um método que combina o MLS e o MEC para simulação da dinâmica de bolhas. Propõem-se uma formulação para atualização da função potencial no contexto e o MLS é capaz de manipular naturalmente mudanças de topologia.

No campo da otimização topológica é comum o acoplamento do MLS a outras metodologias.

Majava e Tai (2004) apresentam uma nova metodologia para simulação de bolhas dinâmicas, chamada Level Set Indirect Boundary Element Method (LSBEM). Esta combina as vantagens do MLS e do MEC.

Wang et al. (2003) mostram que os modelos LS são flexíveis na manipulação de mudanças topológicas complexas e são concisos na descrição da forma dos contornos das estruturas. O procedimento matemático é bem fundamentado e conduz a um algoritmo numérico que descreve a otimização estrutural como uma sequência de movimentos do contorno implícitos convergindo para uma solução ótima e satisfazendo restrições específicas. Os resultados demonstraram que o MLS pode facilmente representar contornos complexos, é capaz de formar buracos, realizar divisões de contornos em múltiplos pedaços ou fundir várias curvas para formar um único contorno.

Cervera e Trevelyan (2005) usaram o MEC para otimização topológica para problemas em 2D e 3D onde a estrutura foi representada explicitamente através da abordagem NURBS (Non Uniform Rational Basis Spline) que é um modelo matemático utilizado em programas gráficos para gerar curvas e superfícies. As splines são movidas de acordo com a resposta de valores de tensão local calculados.

Abe et al. (2007) propõem a utilização de um grid de pontos para auxiliar a mudança de topologia da estrutura. Eles utilizam o MLS como função distância com sinal entre o contorno da estrutura e os pontos do grid. O MEC é utilizado para o cálculo das tensões e deformações do problema, os elementos de contorno são discretizados ao longo dos pontos onde a distância é nula. A análise de sensibilidade é realizada para reconstrução da estrutura, 
isso fornece a velocidade de propagação do contorno. Os exemplos numéricos validam e mostram eficiência do acoplamento MEC-MLS.

Marczak (2007) apresenta a implementação de conceitos da derivada topológica acoplados a formulação do MEC. A derivada topológica é avaliada em pontos internos impostos em todo o domínio da estrutura, estes são eliminados onde seus valores forem inferiores a valores especificados, assim é possível a formação de furos. Os resultados comprovam que a formulação fornece a topologia ótima da estrutura.

Neches e Cisilino (2007) utilizam a derivada topológica e o MEC para calcular tensões e deformações. Os modelos são discretizados através de elementos lineares e com distribuição de pontos no interior de todo o domínio. O funcional principal calculado é a energia potencial total. O material é reduzido através da eliminação dos pontos internos ao domínio e nós do contorno onde os valores de derivada topológica são inferiores a uma faixa estipulada. A nova geometria é reconstruída com um algoritmo de triangulação capaz de detectar furos onde o material é eliminado. O procedimento é repetido até que critério de parada é satisfeito.

Dijk et al. (2008) abordam os conceitos do MLS aplicados a otimização topológica usando parametrização da conectividade do elemento. Para as estruturas entende-se que o MLS é uma aproximação que usa uma descrição implícita flexível do domínio do material. Este domínio estrutural é descrito por uma função LS onde o zero level set representa o seu contorno. Durante a otimização o contorno da função LS é deslocado em uma direção favorável baseada na análise da sensibilidade da forma, enquanto a descrição da interface permite as mudanças topológicas do contorno zero level set.

Bertsch et al. (2010) apresentam o acoplamento do MEC à derivada topológica para a determinação da topologia ótima de estruturas em 3D. A derivada topológica representa a sensibilidade do problema a mudanças de topologia. O funcional de energia total é a função objetivo a ser otimizada. O problema de otimização é resolvido incrementalmente. Porções pequenas de material são eliminadas a cada etapa e é necessária a reconstrução da estrutura. Alguns exemplos ratificam o adequado funcionamento do acoplamento.

Shichi et al. (2012) realizam a otimização topológica através do acoplamento MECMLS. Eles discutem otimização para problemas elásticos em 3D usando o MLS e o Método de Regularização de Tikhonov. Restrições de volume são empregadas no processo. Os resultados apresentados mostram a eficiência do acoplamento.

Yamazaki et al. (2012) propõem o acoplamento MEC-MLS onde as coordenadas dos elementos de contorno são substituídas por funções nodais do MLS e coordenadas da malha Euleriana que auxilia a evolução da função LS. Essa substituição das coordenadas gera uma 
imersão na malha Euleriana, então a formulação recebe o nome de 'MEC-imersos'. A imersão elimina os problemas de escalas de cinza, tabuleiro de xadrez e outras dificuldades numéricas comuns em problemas de otimização topológica. A formulação trabalha com a minimização da flexibilidade da estrutura. Os resultados são satisfatórios e validam a proposta do método.

Yamada et al. (2010) apresentam uma nova proposta para a otimização topológica por meio do acoplamento do MEF-MLS incorporando interfaces de energia fictícias ao problema. Primeiramente, o problema de otimização é formulado pelo MLS e um método de regularização é introduzido explicando a existência das interfaces de energia fictícias, estas substituem a topologia original e reconstroem a estrutura adequadamente. O funcional minimizado resolve a equação de reação-difusão do MLS. Os resultados para estruturas em 2D e 3D mostram a eficiência do método e representatividade da formulação.

Otomori et al. (2011) propõem a otimização topológica através no acoplamento do MLS-MMA (Método de Movimentos Assintóticos). A utilização do MLS elimina todas as descontinuidades numéricas como escalas de cinzas e similares, pois sua representação para as funções é implícita. O método proposto atualiza a função LS usando programação matemática para facilitar o tratamento das funções e restrições. O cálculo de tensões e deformações é realizado através do MEF. Os resultados são satisfatórios e mostram a eficiência do método proposto.

Yamada et al. (2013) realiza a OT de estruturas em 3D através do acoplamento MECMLS. A função LS é utilizada para controlar o contorno ótimo da estrutura. As condições de contorno são impostas explicitamente e variam ao longo do contorno. Eles propõem a existência de um problema adjunto que juntamente com o problema real é parte do funcional a ser otimizado. A parcela de regularização contendo a função LS e as restrições de volume também fazem parte do funcional. A análise de sensibilidade é realizada para atualização da função LS e dos multiplicadores de Lagrange presentes. O processo é repetido até que as restrições sejam atendidas e os valores para a função LS são praticamente constantes de uma iteração para a outra. Os exemplos mostrados apontam para a eficiência e bom funcionamento da formulação proposta.

Ullah et al. (2014) utilizam uma abordagem evolucionária de otimização topológica aplicada ao acoplamento MEC-MLS. Durante o processo de otimização, o método introduz furos automaticamente. O zero level set descreve as geometrias interna e externa da estrutura. O contorno é representado através da abordagem NURBS para curvas suaves na malha do MEC. O método proposto gera geometrias ótimas para estruturas em duas dimensões, os resultados são validados através de exemplos de referência presentes na literatura. 
A otimização topológica fornece ao MLS uma larga aplicabilidade. Ao contrário de outros tipos de otimização de geometria, a locação da interface é conhecida tão bem quanto a direção normal ao contorno. No contexto geral da otimização o MLS pode ser dividida nas etapas de parametrização, atualização e discretização.

A parametrização define um espaço na qual a configuração ótima é solicitada. Uma função level set pode ser parametrizada em termos de uma função base, dada em relação à coordenada espacial (x, y, z) e ao parâmetro de tempo t.

A atualização acontece de acordo com os campos de forma, contorno e velocidades definidos, utilizando-se análises de sensibilidade de forma. A velocidade do contorno é derivada das equações que governam a formulação da mecânica do contínuo.

Verifica-se na bibliografia que a formulação do MLS contém grandes vantagens teóricas e práticas sobre os modelos convencionais, especialmente no contexto da otimização topológica. Primeiramente, os modelos LS são topologicamente flexíveis. A função escalar $\phi$ é definida para fornecer sempre uma topologia simples; entretanto, representar superfícies complexas, permitir a formação de descontinuidades, divisão em múltiplos contornos ou fusão de vários contornos em um único, o modelo sofre significantes mudanças de forma para qualquer contorno convencional.

\subsection{OBJETIVOS}

Como objetivos gerais encontram-se estudar e compreender o método dos elementos de contorno (MEC), o método level set (MLS) e o software FORTRAN e utilizá-los, adequadamente, para formular problemas relacionados à otimização topológica de estruturas planas.

Especificamente, objetiva-se acoplar o MLS a um modelo baseado nas equações algébricas do MEC. Espera-se que o acoplamento proposto resulte a geometria otimizada da estrutura sem a necessidade da aplicação de filtros.

Portanto, esta dissertação resulta em um programa computacional, implementado na linguagem computacional FORTRAN 90, capaz de determinar a topologia ótima de uma estrutura plana. O programa é aplicado a diversos problemas, e seus resultados são analisados minuciosamente, para avaliar a eficiência do acoplamento MLS - MEC como um gerador de soluções estruturais ótimas. 


\subsection{JUSTIFICATIVAS}

Os projetos de engenharia tem a crescente necessidade de otimização. Alguns conceitos como a sustentabilidade estão fortemente presentes no cenário econômico atual, nesse sentido, a minimização da quantidade de matéria-prima empregada e do custo de produção são diferenciais almejados pelas grandes corporações em suas linhas de produção. Além disso, a maximização dos lucros também é um requisito desejado.

A otimização topológica é, certamente, a melhor maneira de se chegar a essas características. Exemplos disso são aplicações na indústria aeronáutica onde seria possível a redução do peso da estrutura das aeronaves através da otimização topológica de seus elementos estruturais; na indústria automobilística a otimização dos componentes estruturais e partes do motor trariam melhor desempenho para os projetos e seria possível a exploração de formas e conceitos mais arrojadas para os mesmos; entre muitas outras aplicações.

A motivação desse trabalho está em avançar no campo das aplicações envolvendo o MEC, especialmente, em um domínio onde este é, reconhecidamente, mais eficiente que outros métodos numéricos. Contribuir no desenvolvimento de soluções inovadoras para problemas complexos de engenharia. E iniciar a linha de pesquisa de otimização topológica no Departamento de Engenharia de Estruturas da EESC-USP.

\subsection{DESCRIÇÃO DOS CAPÍTULOS DA DISSERTAÇÃO}

Apresenta-se o conteúdo dos capítulos da dissertação.

O Capítulo 1 introduziu os principais temas tratados, mostrou suas características, vantagens de utilização e aplicabilidade. Bem como, os objetivos e justificativas para a realização desse trabalho.

O Capítulo 2 contém de forma resumida os tópicos relacionados ao Método dos Elementos de Contorno, seus conceitos fundamentais, formulações e hipóteses, aspectos importantes considerados no equacionamento e implementação.

O Capítulo 3 mostra brevemente os conceitos matemáticos relacionados ao Método Level Set, suas diferentes abordagens e tipos de discretização da equação.

O Capítulo 4 apresenta as variáveis de um problema de otimização e os tipos de problema de otimização estrutural existentes. 
O Capítulo 5 é o mais importante e complexo do texto. Apresenta-se a ideia principal do trabalho e contempla o desenvolvimento da formulação de acoplamento MEC-MLS. É realizado o equacionamento e são apresentadas as hipóteses e simplificações adotadas, além de todos os aspectos de implementação computacional relevantes. O capítulo contempla os problemas: mecânico, otimização e reconstrução da estrutura.

O Capítulo 6 testa o código computacional desenvolvido, validando-o através de exemplos e análises dos resultados obtidos.

O Capítulo 7 fecha o texto com as conclusões acerca do tema e mostra perspectivas de trabalhos e investigações futuras envolvendo o tema proposto. 


\section{MÉTODO DOS ELEMENTOS DE CONTORNO}

\subsection{CONCEITOS FUNDAMENTAIS}

Ao se estudar o MEC é necessário o conhecimento de alguns conceitos fundamentais. A seguir, apresentam-se e discutem-se brevemente esses conceitos. Os mesmos são vistos detalhadamente em Brebbia e Dominguez (1992).

\subsubsection{SOLUÇÃO FUNDAMENTAL PARA PROBLEMAS PLANOS}

No desenvolvimento da formulação do MEC é necessário o uso de soluções fundamentais para as variáveis envolvidas.

O problema fundamental da elasticidade consiste na solução da equação diferencial de equilíbrio para um corpo sujeito à ação de carregamentos estáticos. A solução para esse problema em meios isotrópicos foi enunciada por Kelvin em 1848.

Para problemas planos considera-se um domínio infinito sujeito à ação de um carregamento concentrado unitário atuando em um ponto denominado ponto fonte (BREBBIA; DOMINGUEZ, 1992).

Fisicamente, não é possível que o carregamento pontual seja descrito em termos de funções matemáticas clássicas, é intrínseca a existência de uma superfície (área) onde o carregamento exerce sua influência. É conveniente expressar esse carregamento por meio da teoria das distribuições usando a distribuição delta de Dirac.

A distribuição delta de Dirac consegue representar eficientemente a ação pontual de carregamentos concentrados em problemas da elasticidade linear. A teoria das funções generalizadas explica as propriedades da função delta de Dirac. Sua obtenção é dada por meio da função degrau unitário, também denominada Heaviside. A função Delta de Dirac é definida pela Eq. (2.1).

$$
\Delta^{\mathrm{f}}=\left\{\begin{array}{lr}
0, & \text { se } \mathrm{x} \neq 0 \\
\infty, & \text { se } \mathrm{x}=0
\end{array}\right\}
$$


Verificando as propriedades, admite-se que a função $\mathrm{f}(\mathrm{x})$ é conhecida e bem definida no ponto $\mathrm{x}=0$. Por meio do teorema da média para as integrais chega-se a Eq. (2.2).

$$
\int_{-\infty}^{\infty} f(x) \cdot \Delta^{f}(x) d x=f(0)
$$

Essa propriedade pode ser denominada de filtragem da função Delta, ela acontece devido à variação de $\mathrm{f}(\mathrm{x})$ em torno do ponto $\mathrm{x}=0$ ser desprezível. Pela Eq. (2.3) define-se a função Delta em sua forma geral.

$$
\int_{-\infty}^{\infty} f(x) \cdot \Delta^{f}(x-a) d x=f(a)
$$

A Eq. (2.4) contém o conceito da função delta de Dirac expandido para domínios planos.

$$
\Delta^{f}(p, Q)=\left\{\begin{array}{ll}
0, & \text { se } p \neq Q \\
\infty, & \text { se } p=Q
\end{array}\right\}
$$

Então, constrói-se a Eq. (2.5) análoga a Eq. (2.3).

$$
\int_{-\infty}^{\infty} f(Q) \cdot \Delta^{f}(p, Q) d \Omega=f(p)
$$

É importante lembrar que não são aplicáveis os conceitos comuns de função matemática para esta distribuição. Apesar das grandezas representadas por elas não serem funções, as mesmas são tratadas formalmente com tal, permitindo o surgimento dessas propriedades e resultados satisfatórios.

Partindo desse conceito, introduz-se a ideia da distribuição delta de Dirac na teoria do MEC. Quando se leva em conta a condição de equilíbrio, verifica-se que o carregamento do corpo $b_{i}$ deve ser igual a função delta de Dirac, visto na Eq. (2.6) 


$$
\mathrm{b}_{\mathrm{i}}=\Delta^{\mathrm{f}} . \mathrm{e}_{\mathrm{i}}
$$

onde $\Delta^{\mathrm{f}}$ é a função delta de Dirac e $\mathrm{e}_{\mathrm{i}}$ é o versor que define a direção da aplicação do carregamento.

Usando esse resultado e a equação de equilíbrio Eq. (A.2), reescreve-se a mesma em termos de deslocamentos. Emprega-se a Lei de Hooke Generalizada da Eq. (A.5), que relaciona as tensões às deformações, e em seguida aplicam-se as relações deformaçãodeslocamento da Eq. (A.7). A equação de equilíbrio em termos de deslocamento, para material isótropo sob estado plano de deformação pode ser definida pela Eq. (2.7).

$$
\left(\frac{1}{1-2 \cdot v}\right) \cdot u_{i, i j}+u_{j, i i}+\frac{\Delta^{\mathrm{f}} \cdot e_{i}}{\mu}=0
$$

Onde $\mu$ é o módulo de elasticidade transversal. A solução dessa equação representa a solução fundamental para deslocamentos. No estado plano de deformação a solução é dada por:

$$
\mathrm{u}_{\mathrm{lk}}^{*}(\mathrm{f}, \mathrm{c})=\frac{1}{8 \cdot \pi \cdot \mu \cdot(1-v)} \cdot\left[(3-4 \cdot v) \cdot \ln \left(\frac{1}{\mathrm{r}}\right) \cdot \delta_{\mathrm{lk}}+\mathrm{r}_{\mathrm{l}} \cdot \mathrm{r}_{\mathrm{r}, \mathrm{k}}\right]
$$

onde $r_{, k}$ é a derivada da distância, entre o ponto fonte (f) e os pontos onde devem ser avaliados a solução fundamental, pontos campo (c), em relação a direção k.

Destaca-se que o símbolo * representa variáveis associadas ao estado fundamental. Efetuando a diferenciação da Eq. (2.8) é possível obter a expressão para a solução fundamental das deformações. O resultado dessa operação é dado pela Eq. (2.9).

$$
\begin{gathered}
\varepsilon_{\mathrm{ilk}}^{*}(\mathrm{f}, \mathrm{c})=\frac{-1}{8 \cdot \pi \cdot \mu \cdot(1-v) \cdot \mathrm{r}} \cdot\left[(1-2 \cdot v) \cdot\left(\mathrm{r}_{, \mathrm{k}} \cdot \delta_{\mathrm{il}}\right)-\mathrm{r}_{, \mathrm{i}} \cdot \delta_{\mathrm{lk}}\right. \\
\left.+2 \cdot \mathrm{r}_{\mathrm{i}, \mathrm{r}} \cdot \mathrm{r}_{\mathrm{l}, \mathrm{r}} \cdot \mathrm{r}_{\mathrm{k}, \mathrm{k}}\right]
\end{gathered}
$$


A partir da solução fundamental das deformações pode-se aplicar a Lei de Hooke generalizada da Eq. (A.5) e obter-se a expressão para a solução fundamental das tensões conforme apresenta a Eq. (2.10).

$$
\begin{aligned}
\sigma_{\mathrm{ilk}}^{*}(\mathrm{f}, \mathrm{c})=\frac{-1}{4 \cdot \pi \cdot(1-v) \cdot \mathrm{r}} \cdot\left\{(1-2 \cdot v) \cdot\left(\mathrm{r}_{, \mathrm{k}} \cdot \delta_{\mathrm{il}}+\mathrm{r}_{, \mathrm{l}} \cdot \delta_{\mathrm{ik}}-\mathrm{r}_{, \mathrm{i}} \cdot \delta_{\mathrm{lk}}\right)\right. \\
\left.+2 \cdot \mathrm{r}_{, \mathrm{i}} \cdot \mathrm{r}_{, \mathrm{l}} \cdot \mathrm{r}_{\mathrm{,k}}\right\}
\end{aligned}
$$

Por fim, o equilíbrio pode ser efetuado no contorno com o objetivo de calcular a expressão para a solução fundamental das forças de superfície. O procedimento resulta na Eq. (2.11).

$$
\begin{gathered}
\mathrm{P}_{\mathrm{lk}}^{*}(\mathrm{f}, \mathrm{c})=\frac{-1}{4 \cdot \pi \cdot(1-v) \cdot \mathrm{r}} \cdot\left\{\mathrm{r}_{, \mathrm{n}}\left[(1-2 \cdot v) \cdot \delta_{\mathrm{lk}}+2 \cdot \mathrm{r}_{, \mathrm{l}} \cdot \mathrm{r}_{, \mathrm{k}}\right]\right. \\
\left.+(1-2 \cdot v) \cdot\left(\eta_{\mathrm{l}} \cdot \mathrm{r}_{, \mathrm{k}}-\eta_{\mathrm{k}} \cdot \mathrm{r}_{, \mathrm{l}}\right)\right\}
\end{gathered}
$$

Observa-se que as soluções fundamentais apresentadas possuem singularidade na distância entre os pontos fonte e campo. Quando os pontos fonte e campo aproximam-se o valor das soluções fundamentais tendem a infinito. Para evitar esse problema emprega-se o processo de sub-elementação, onde o elemento de contorno considerado é subdividido em elementos menores permitindo um melhor mapeamento das grandezas envolvidas tornando o processo de integração das equações mais preciso.

\subsubsection{EQUACIONAMENTO PARA O PROBLEMA ELÁSTICO PLANO}

O equacionamento do problema elástico via MEC pode ser efetuado com sucesso e de forma expedita empregando-se o princípio da reciprocidade de Betti. Este teorema estabelece que o trabalho realizado pelas tensões de um estado I sobre as deformações de um estado II é igual ao trabalho das tensões do estado II sobre as deformações do estado I admitindo-se o mesmo material em ambos os estados. Esse teorema pode ser representado por meio da Eq. (2.12). 


$$
\int_{\Omega} \sigma_{\mathrm{ij}}^{\mathrm{I}} \cdot \varepsilon_{\mathrm{ij}}^{\mathrm{II}} \mathrm{d} \Omega=\int_{\Omega} \sigma_{\mathrm{ij}}^{\mathrm{II}} \cdot \varepsilon_{\mathrm{ij}}^{\mathrm{I}} \mathrm{d} \Omega
$$

Aplicando esta equação para a formulação do MEC substitui-se um dos estados do problema pelo estado fundamental, ou seja, representado pelas soluções fundamentais. Assim, a Eq. (2.12) pode ser reescrita pela Eq. (2.13).

$$
\int_{\Omega} \sigma_{\mathrm{ilk}}^{*}(\mathrm{f}, \mathrm{c}) \cdot \varepsilon_{\mathrm{lk}}(\mathrm{c}) \mathrm{d} \Omega=\int_{\Omega} \sigma_{\mathrm{lk}}(\mathrm{c}) \cdot \varepsilon_{\mathrm{ilk}}^{*}(\mathrm{f}, \mathrm{c}) \mathrm{d} \Omega
$$

Aplicando a relação deformação-deslocamento, é possível exprimir a relação da Eq. (2.13) em termos de deslocamentos. Observa-se a nova relação na Eq. (2.14).

$$
\int_{\Omega} \sigma_{\text {ilk }}^{*}(f, c) \cdot u_{l k}(c) d \Omega=\int_{\Omega} \sigma_{l k}(c) \cdot u_{i l k}^{*}(f, c) d \Omega
$$

Integrando por partes ambos os termos da Eq. (2.14) e aplicando a condição de equilíbrio de superfície da Eq. (A.3), obtém-se uma expressão envolvendo tensões, deslocamentos e forças de superfície tanto do estado fundamental quanto do problema estudado. Dessa forma, chega-se a Eq. (2.15).

$$
\begin{aligned}
-\int_{\Omega} \sigma_{i l k, k}^{*}(f, c) \cdot u_{l}(c) d \Omega & \int_{\Gamma} P_{i l}^{*}(f, c) \cdot u_{l}(c) d \Gamma \\
& =-\int_{\Omega} \sigma_{l k, k}(c) \cdot u_{i l}^{*}(f, c) d \Omega+\int_{\Gamma} P_{1}(c) \cdot u_{i l}^{*}(f, c) d \Gamma
\end{aligned}
$$

Emprega-se a equação de equilíbrio da Eq. (A.2), tanto no problema real quanto no problema fundamental como forma de substituir os termos de derivada das tensões por forças de corpo. Atenta-se para o fato que no problema fundamental a carga de corpo, $b_{i}$, é igual à função Delta de Dirac, $\Delta^{\mathrm{f}}$. Substituindo-se os termos reescreve-se a Eq. (2.15) por meio da Eq. (2.16). 


$$
\begin{aligned}
\int_{\Omega} \Delta^{\mathrm{f}} \cdot \mathrm{u}_{\mathrm{l}}(\mathrm{c}) \mathrm{d} \Omega & +\int_{\Gamma} \mathrm{P}_{\mathrm{il}}^{*}(\mathrm{f}, \mathrm{c}) \cdot \mathrm{u}_{\mathrm{l}}(\mathrm{c}) \mathrm{d} \Gamma \\
& =\int_{\Omega} \mathrm{b}_{\mathrm{l}}(\mathrm{c}) \cdot \mathrm{u}_{\mathrm{il}}^{*}(\mathrm{f}, \mathrm{c}) \mathrm{d} \Omega+\int_{\Gamma} \mathrm{P}_{\mathrm{l}}(\mathrm{c}) \cdot \mathrm{u}_{\mathrm{il}}^{*}(\mathrm{f}, \mathrm{c}) \mathrm{d} \Gamma
\end{aligned}
$$

Integrando o termo que contém o delta de Dirac obtém-se a Eq. (2.17).

$u_{i}(f)+\int_{\Gamma} P_{i l}^{*}(f, c) \cdot u_{l}(c) d \Gamma=\int_{\Gamma} P_{l}(c) \cdot u_{i l}^{*}(f, c) d \Gamma+\int_{\Omega} u_{i l}^{*}(f, c) \cdot b_{l}(c) d \Omega$

A Eq. (2.17) representa a identidade Somigliana, a qual fornece os valores de deslocamento e tensões em qualquer ponto do domínio dependendo dos valores dos deslocamentos e forças de superfície, conhecidos sobre o contorno, das forças de corpo e das soluções fundamentais (BREBBIA \& DOMINGUEZ, 1992).

Torna-se necessário transformar a Eq. (2.17) válida para todo domínio, em uma equação integral válida somente para valores de contorno, pois o MEC pertence à classe das técnicas de contorno. Admite-se então, a divisão do domínio e do contorno em duas partes, conforme apresenta a Figura 2.1.

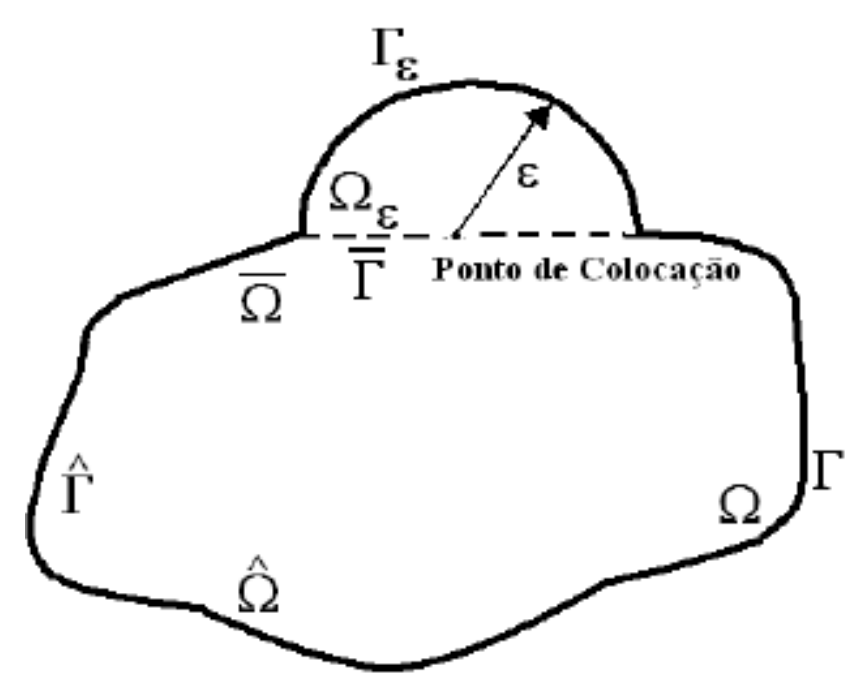

Figura 2.1 - Divisão do domínio e do contorno para determinação da equação integral sobre o contorno. Fonte: Leonel (2009).

Expressam-se as grandezas presentes na Figura 2.1 como: 


$$
\begin{gathered}
\widehat{\Omega}=\Omega-\bar{\Omega}+\Omega_{\varepsilon} \\
\hat{\Gamma}=\Gamma-\bar{\Gamma}+\Gamma_{\varepsilon}
\end{gathered}
$$

$\Omega_{\varepsilon}$ e $\Gamma_{\varepsilon}$ referem-se à introdução de um semicírculo de raio $\overline{\mathrm{r}}$, e no centro desse semicírculo está presente o ponto de colocação. A identidade Somigliana fica avaliada no contorno se as parcelas desta equação referentes à $\Omega_{\varepsilon}$ e $\Gamma_{\varepsilon}$ forem consideradas no limite de $\overline{\mathrm{r}}$, tendendo a zero. Aplicando esse conceito à identidade Somigliana obtém-se a Eq. (2.20).

$$
\begin{gathered}
\mathrm{u}_{\mathrm{i}}(\mathrm{f})=\lim _{\varepsilon \rightarrow 0} \int_{\Gamma-\bar{\Gamma}+\Gamma_{\varepsilon}} \mathrm{P}_{\mathrm{l}}(\mathrm{c}) \cdot \mathrm{u}_{\mathrm{il}}^{*}(\mathrm{f}, \mathrm{c}) \mathrm{d} \Gamma+\lim _{\varepsilon \rightarrow 0} \int_{\Omega-\bar{\Omega}+\Omega_{\varepsilon}} \mathrm{u}_{\mathrm{il}}^{*}(\mathrm{f}, \mathrm{c}) \cdot \mathrm{b}_{1}(\mathrm{c}) \mathrm{d} \Omega \\
\quad-\lim _{\varepsilon \rightarrow 0} \int_{\Gamma-\bar{\Gamma}+\Gamma_{\varepsilon}} \mathrm{P}_{\mathrm{i}}^{*}(\mathrm{f}, \mathrm{c}) \cdot \mathrm{u}_{\mathrm{l}}(\mathrm{c}) \mathrm{d} \Gamma
\end{gathered}
$$

Analisam-se isoladamente os limites da identidade Somigliana. Inicia-se com o primeiro termo do segundo membro da Eq.(2.20).

$$
\begin{aligned}
\lim _{\varepsilon \rightarrow 0} \int_{\Gamma-\bar{\Gamma}+\Gamma_{\varepsilon}} P_{l}(c) \cdot u_{i l}^{*}(f, c) d \Gamma & \\
& =\lim _{\varepsilon \rightarrow 0} \int_{\Gamma-\bar{\Gamma}} P_{l}(c) \cdot u_{i l}^{*}(f, c) d \Gamma+\lim _{\varepsilon \rightarrow 0} \int_{\Gamma_{\varepsilon}} P_{l}(c) \cdot u_{i l}^{*}(f, c) d \Gamma
\end{aligned}
$$

Na análise da solução fundamental de deslocamentos $u_{i l}^{*}$, Portela (1992) classifica a singularidade dessa solução como do tipo fraca. Verifica-se que o segundo termo do segundo membro da Eq. (2.21) é anulado durante a realização do limite. Entretanto, o primeiro termo necessita ser analisado no contorno.

O segundo termo da Eq. (2.20) também é analisado com mais facilidade.

$$
\begin{aligned}
& \lim _{\varepsilon \rightarrow 0} \int_{\Omega-\bar{\Omega}+\Omega_{\varepsilon}} u_{i l}^{*}(f, c) \cdot b_{l}(c) d \Omega \\
& \quad=\lim _{\varepsilon \rightarrow 0} \int_{\Omega-\bar{\Omega}} u_{i l}^{*}(f, c) \cdot b_{l}(c) d \Omega+\lim _{\varepsilon \rightarrow 0} \int_{\Omega_{\varepsilon}} u_{i l}^{*}(f, c) \cdot b_{l}(c) d \Omega
\end{aligned}
$$


Verifica-se que a singularidade fraca presente na solução de deslocamentos $u_{i l}^{*}$, leva o segundo termo da Eq. (2.22) a ser nulo na execução do limite. O primeiro termo de Eq. (2.22) necessita ser avaliado no domínio.

O terceiro termo da Eq. (2.20) também é analisado.

$$
\begin{aligned}
& \lim _{\varepsilon \rightarrow 0} \int_{\Gamma-\bar{\Gamma}+\Gamma_{\varepsilon}} P_{i l}^{*}(f, c) \cdot u_{l}(c) d \Gamma \\
& \quad=\lim _{\varepsilon \rightarrow 0} \int_{\Gamma-\bar{\Gamma}} P_{i l}^{*}(f, c) \cdot u_{l}(c) d \Gamma+\lim _{\varepsilon \rightarrow 0} \int_{\Gamma_{\varepsilon}} P_{i l}^{*}(f, c) \cdot u_{l}(c) d \Gamma
\end{aligned}
$$

A solução fundamental para forças de superfície $P_{i l}^{*}$ está encontra-se na Eq. (2.23). Na singularidade, $1 / r$, o comportamento é diferente da singularidade da solução fundamental para deslocamentos. O primeiro termo da Eq. (2.23) deve ser avaliado tomando a parte finita de Cauchy. Para a sua existência, os deslocamentos prescritos no contorno devem obedecer à condição de continuidade de Hölder, expressa na Eq. (2.24).

$$
\left|u_{(c)}^{j}-u_{(f)}^{j}\right| \leq B \cdot r_{(f, c)}^{v}
$$

Onde $B$, $v$ são constantes reais positivas. $|B|<\infty$ e $v \leq 1$ e $r_{(f, c)}$ é a distância entre os pontos fonte e campo.

Obedecendo a continuidade de Hölder o termo analisado por ser avaliado no contorno do problema. Para o segundo termo do segundo membro da Eq. (2.23) considera-se a expansão em série de Taylor dos deslocamentos, em torno do ponto fonte. Na expansão considera-se apenas o primeiro termo, pois os demais termos anulam-se durante a execução do limite. Obtém-se a Eq. (2.25).

$$
\begin{aligned}
\lim _{\varepsilon \rightarrow 0} \int_{\Gamma_{\varepsilon}} P_{i l}^{*}(f, c) \cdot \mathrm{u}_{l}(c) d \Gamma & \\
& =\lim _{\varepsilon \rightarrow 0} \int_{\Gamma_{\varepsilon}} P_{i l}^{*}(f, c) \cdot u_{l}(c) d \Gamma-\lim _{\varepsilon \rightarrow 0} \int_{\Gamma_{\varepsilon}} P_{i l}^{*}(f, c) \cdot u_{l}(f) d \Gamma \\
& +\lim _{\varepsilon \rightarrow 0} \int_{\Gamma_{\varepsilon}} P_{i l}^{*}(f, c) \cdot u_{l}(f) d \Gamma
\end{aligned}
$$

Simplificando, chega-se a Eq. (2.26). 


$$
\begin{aligned}
\lim _{\varepsilon \rightarrow 0} \int_{\Gamma_{\varepsilon}} P_{i l}^{*}(f, c) & \cdot u_{l}(c) d \Gamma \\
& =\lim _{\varepsilon \rightarrow 0} \int_{\Gamma_{\varepsilon}} P_{i l}^{*}(f, c) \cdot\left(u_{l}(c)-u_{l}(f)\right) d \Gamma \\
& +\lim _{\varepsilon \rightarrow 0} \int_{\Gamma_{\varepsilon}} P_{i l}^{*}(f, c) \cdot u_{l}(f) d \Gamma
\end{aligned}
$$

Considerando a continuidade da função de deslocamentos no ponto fonte, tem-se que o primeiro termo do segundo membro da Eq. (2.26) é nulo, então. Na Eq. (2.27) o termo é eliminado.

$$
\lim _{\varepsilon \rightarrow 0} \int_{\Gamma_{\varepsilon}} P_{i l}^{*}(f, c) \cdot u_{l}(c) d \Gamma=u_{l}(f) \cdot \lim _{\varepsilon \rightarrow 0} \int_{\Gamma_{\varepsilon}} P_{i l}^{*}(f, c) d \Gamma
$$

Verifica-se que a integração e o limite do primeiro segundo termo do segundo membro da Eq. (2.23) gera um termo independente que deve ser inicialmente isolado, e em seguida adicionado ao termo livre de deslocamento presente no primeiro termo da Eq. (2.20).

A identidade Somigliana escrita para o contorno fica na forma da Eq. (2.28).

$$
\begin{aligned}
& c_{i l}(f, c) \cdot u_{l}(f)+f_{\Gamma} P_{i l}^{*}(f, c) \cdot u_{l}(c) d \Gamma=\int_{\Gamma} P_{l}(c) \cdot u_{i l}^{*}(f, c) d \Gamma \\
+ & \int_{\Omega} u_{i l}^{*}(f, c) \cdot \zeta_{l}(c) d \Omega
\end{aligned}
$$

Sendo $\int$ integral da parte finita de Cauchy.

O termo $c_{i l}$, resultante da adição do termo apresentado no primeiro membro da Eq. (2.20) com o termo livre consequente da avaliação do ultimo termo de segundo membro dessa mesma equação do domínio para o contorno, é dependente da geometria do contorno analisado. Apresenta-se um tensor de valores para esse termo na Eq. (2.29).

$$
c_{i l}=\left[\begin{array}{ccc}
\frac{\alpha}{2 \cdot \pi}+\frac{\operatorname{Cos}(2 \cdot \gamma) \cdot \operatorname{Sen}(\alpha)}{4 \cdot \pi \cdot(1-v)} & \frac{\operatorname{Sen}(2 \cdot \gamma) \cdot \operatorname{Sen}(\alpha)}{4 \cdot \pi \cdot(1-v)} \\
\frac{\operatorname{Sen}(2 \cdot \gamma) \cdot \operatorname{Sen}(\alpha)}{4 \cdot \pi \cdot(1-v)} & \frac{\alpha}{2 \cdot \pi}+\frac{\operatorname{Cos}(2 \cdot \gamma) \cdot \operatorname{Sen}(\alpha)}{4 \cdot \pi \cdot(1-v)}
\end{array}\right]
$$


Sendo $\alpha$ e $\gamma$ dependentes da posição do ponto singular sobre o contorno. A obtenção das variáveis é ilustrada pela Figura 2.2.

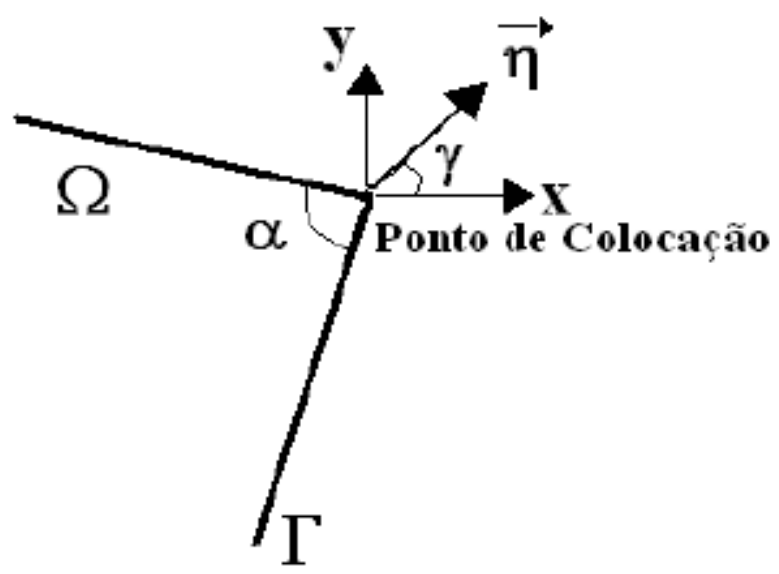

Figura 2.2 - Parâmetros para cálculo da equação integral sobre o contorno. Fonte: Leonel (2009).

Quando o ponto fonte encontra-se exterior ao contorno a matriz $c_{i l}$ é nula:

$$
c_{i l}=\left[\begin{array}{ll}
0 & 0 \\
0 & 0
\end{array}\right]
$$

Quando o ponto fonte encontra-se interior ao contorno a matriz $c_{i l}$ é a identidade:

$$
c_{i l}=\left[\begin{array}{ll}
1 & 0 \\
0 & 1
\end{array}\right]
$$

Em um contorno suave (sem angulosidade), o ponto de colocação torna-se a matriz identidade multiplicada por $1 / 2$ :

$$
c_{i l}=\left[\begin{array}{cc}
1 / 2 & 0 \\
0 & 1 / 2
\end{array}\right]
$$

\subsubsection{APROXIMAÇÕES SOBRE O CONTORNO}


Deduziu-se a equação integral em deslocamentos para pontos sobre o contorno, tornase necessário agora a sua utilização pelo MEC. Para que isso aconteça é preciso que o contorno do problema seja discretizado em elementos de contorno. Os elementos representam a geometria do problema por meio de funções que permitem a aproximação das grandezas envolvidas no problema.

De acordo com o grau de aproximação o problema de elementos de contorno pode classificado como:

- Constante;

- Linear;

- Quadrático;

- Cúbico;

- Ordem superior.

O grau de aproximação pode ser diferente tanto para a geometria quanto para as grandezas envolvidas no problema. Isso conduz a caracterização dos elementos de contorno como:

- Sub-paramétricos;

- Isoparamétricos;

- Super-paramétricos.

Nesse trabalho usam-se elementos de contorno descontínuos lineares isoparamétricos, onde a aproximação da geometria é a mesma utilizada para as grandezas envolvidas.

Desconsiderando as forças de domínio do corpo constrói-se numericamente a identidade Somigliana na Eq. (2.33).

$$
[c]\{u\}^{p}+\sum_{j=1}^{N E}\left(\int_{\Gamma_{j}}\left[P^{*}\right]\{u\} d \Gamma_{j}\right)=\sum_{j=1}^{N E}\left(\int_{\Gamma_{j}}\left[u^{*}\right]\{P\} d \Gamma_{j}\right)
$$

Onde $N E$ é o número de elementos de contorno adotados para a descrição do problema. E $p$ é o ponto fonte considerado (LEONEL, 2009).

\subsubsection{FUNÇÕES DE APROXIMAÇÃO}


O princípio da discretização do contorno é baseado na aproximação da geometria do corpo através de funções matemáticas onde alguns pontos possuem as coordenadas conhecidas.

Os pontos de coordenadas conhecidas são chamados de nós do contorno, e é por meio deles que se delimitam os elementos. As aproximações acontecem através de uma função matemática com valores nodais.

A boa escolha da função aproximadora a ser utilizada na técnica numérica é fundamental para a qualidade dos resultados.

É comum na literatura o uso de elementos constantes e lineares, isso pode ser justificado em sua facilidade para manipulação das integrais e implementação computacional. A solução analítica para as equações integrais anularia a necessidade de tratamento numérico das mesmas.

O uso de elemento de alta ordem costuma ser evitado pelas dificuldades em se desenvolverem as equações integrais analíticas para a obtenção da solução. A implementação para elementos de alta ordem se torna mais fácil usando-se os polinômios de Lagrange e os métodos de integração numérica de Gauss-Legrendre. Esse procedimento foi apresentado por Coda (2000). Através desse procedimento é possível elaborar uma rotina para a generalização da função aproximadora permitindo o uso de elementos curvos e com aproximações de ordem qualquer para as variáveis envolvidas.

É vantajoso o emprego de elementos de alta ordem frente ao uso de elementos de ordem menor. O uso de elementos constantes e lineares exige uma maior discretização das superfícies para obtenção adequada dos resultados. A melhoria desses depende diretamente do refinamento da malha empregada, o que reduz o tamanho dos elementos e consequentemente aumenta o tamanho do sistema a ser calculado.

\subsubsection{POLINÔMIOS DE LAGRANGE}

Numericamente, os polinômios de interpolação de Lagrange são aplicados na determinação das funções de forma do elemento curvo.

Considerando um elemento qualquer $j$ de ordem $n-1$ existem $n$ funções de forma, cada uma representando um nó desse elemento. A aproximação é feita assumindo-se valores para os nós de acordo a função. Dessa forma, cada função de forma $\phi_{i}$ possui valor unitário em $i$ e nulo nos demais nós do elemento. 
Kzam (2009) mostra a formulação de elementos de contorno curvos com qualquer ordem de aproximação. Os elementos de contorno são gerados a partir dos polinômios de Lagrange da Eq. (2.34).

$$
\phi_{i}(x)=\prod_{\substack{j \neq i \\ j=0}}^{n} \frac{\left(\xi-\xi_{j}\right)}{\xi_{i}-\xi_{j}}
$$

Os polinômios de Lagrange resultam do produto de $n$ fatores lineares e satisfazem a partição da unidade, como pode ser visto na Eq. (2.35).

$$
\sum_{i=1}^{n} \phi(\xi)=1
$$

Verifica-se também a veracidade da Eq. (2.36).

$$
\sum_{i=1}^{n} \frac{d \phi_{i}}{d \xi}(\xi)=0
$$

Em pontos específicos do domínio $-1 \leq \xi \leq+1$, a função de forma assume o valor da Eq. (2.37)

$$
\phi_{i}(\xi)=\delta_{i j}
$$

onde $\delta_{i j}$ é o delta de Kronecker.

Kzam (2009) restringe o domínio da função de forma ao intervalo $[-1,+1]$ devido às aplicações da quadradura de Gauss-Legendre que acontecem no problema. A Figura 2.3 mostra um elemento curvo expresso em coordenadas adimensionais. 


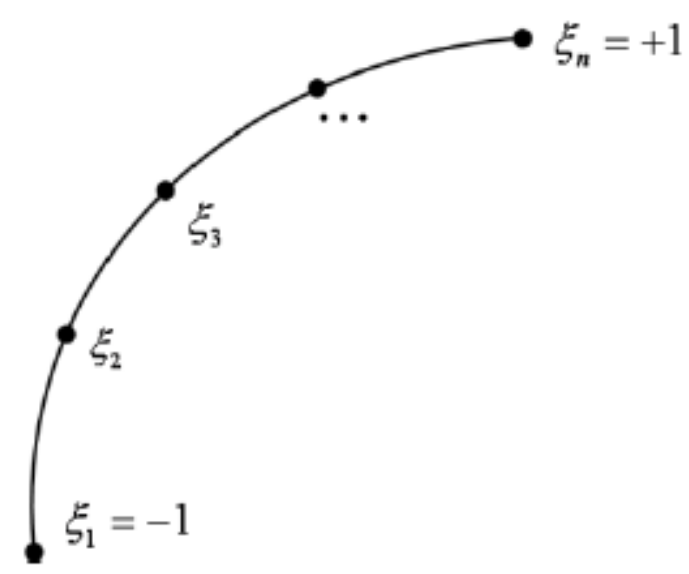

Figura 2.3 - Elemento curvo com coordenadas adimensionais. Fonte: Silva (2010).

Ao se utilizar elementos de contorno curvos na análise de problemas com o MEC, calculam-se os versores normais e tangentes sobre os pontos de colocação, e também sobre os pontos da integração numérica. Essa característica é fundamental para a generalização do grau da aproximação usada na interpolação com esses polinômios. A principal vantagem de se usar os polinômios de Lagrange é a facilidade em se gerarem elementos de contorno isoparamétricos.

Esse artifício é usado com o intuito de facilitar a geração das funções de forma e elaborar uma estratégia de integração numérica geral. Introduz-se um elemento de contorno curvo qualquer, no espaço adimensional da coordenada $\xi$. Para que essa transformação seja escrita corretamente é necessário representar o segmento do contorno $d \Gamma_{n}$ a partir do Jacobiano da transformação:

$$
d \Gamma_{n}=J_{n}(\xi) d \xi
$$

sendo

$$
J_{n}(\xi)=\sqrt{\phi_{m, \xi}(\xi) x_{i}^{n m} \cdot \phi_{m, \xi}(\xi) y_{i}^{n m}}
$$

O Jacobiano da transformação do elemento unidimensional definido no espaço cartesiano bidimensional com $i$ variando de 1 a 2, e $n$ o número do elemento, e $m$ a variação da quantidade de nós por elemento (KZAM, 2009). 
Determinadas as funções de forma para os nós dos elementos, os deslocamentos no interior do elemento são descritos por meio da Eq. (2.40).

$$
\{u\}=\left\{\begin{array}{c}
u_{1} \\
u_{2} \\
\vdots \\
u_{n n}
\end{array}\right\}=\left[\begin{array}{ccccccc}
\phi_{1} & 0 & \phi_{2} & 0 & \phi_{n n} & 0 \\
0 & \phi_{1} & 0 & \phi_{2} & \cdots & 0 & \phi_{n n}
\end{array}\right]\left\{\begin{array}{c}
u_{1}^{1} \\
u_{2}^{1} \\
u_{1}^{2} \\
u_{2}^{2} \\
\vdots \\
u_{1}^{n n} \\
u_{2}^{n n}
\end{array}\right\}=[\phi]\{u\}_{n}^{j}
$$

Analogamente, as forças de superfície são expressas pela Eq. (2.41).

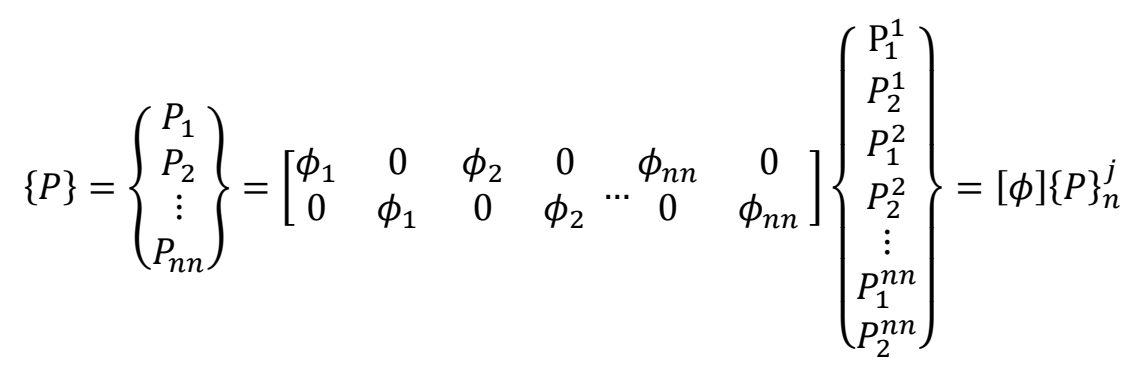

Os termos $u_{l}^{n n}$ e $P_{l}^{n n}$ indicam os deslocamentos e as forças de superfícies atuantes no nó $n n$ segundo a direção $l$.

Os termos $\{u\}_{n}^{j}$ e $\{P\}_{n}^{j}$ representam os deslocamentos e as forças de superfície nodais presentes nos nós pertencentes ao elemento $j$ segundo a direção $n$.

\subsubsection{CONSTRUÇÃO DO SISTEMA DE EQUAÇÕES}

Determinaram-se as equações que relacionam o deslocamento do ponto de colocação considerado, as forças de superfície e deslocamentos nodais dos demais elementos presentes na malha construída. As matrizes resultantes do processo de integração contêm a influência de todos os elementos presentes na malha, estas são denominadas muitas vezes de matrizes de influência.

Escrevem-se então as Eq. (2.42) e (2.43). 


$$
\begin{aligned}
& {\left[\widehat{H}_{I N F}\right]^{p j}=\int_{\Gamma_{j}}\left[P^{*}\right][\phi] d \Gamma_{j}} \\
& {\left[\widehat{G}_{I N F}\right]^{p j}=\int_{\Gamma_{j}}\left[u^{*}\right][\phi] d \Gamma_{j}}
\end{aligned}
$$

Admitindo-se a simplificação por meio da Eq. (2.44), calcula-se a Eq. (2.45).

$$
\begin{gathered}
{\left[H_{I N F}\right]=\left\{\begin{array}{c}
{\left[\widehat{H}_{I N F}\right]^{p j}, \quad \text { se } j \not \subset p} \\
{\left[\widehat{H}_{I N F}\right]^{p j}+[c][\phi]^{p}, \text { se } j \subset p}
\end{array}\right.} \\
\sum_{j=1}^{N E}\left[H_{I N F}\right]^{p j}\{u\}_{n}^{j}=\sum_{j=1}^{N E}\left[G_{I N F}\right]^{p j}\{P\}_{n}^{j}
\end{gathered}
$$

Para problemas elásticos planos, o número de graus de liberdade por nó é quatro, sendo dois deslocamentos e duas forças de superfície. No entanto a metade destes parâmetros é conhecida diretamente por meio da aplicação das condições de contorno do problema. O problema passa a ser resolvido com um número de equações igual a duas vezes o número de nós da malha. Escrevendo as equações para todos os pontos de colocação do modelo tem-se um sistema resultante da ordem de duas vezes o número de nós da malha, dado na forma da Eq. (2.46).

$$
[H]\{u\}=[G]\{P\}
$$

A solução para o sistema apresentado na forma da Eq. (2.46) é realizada aplicando-se as condições de contorno do problema. Na introdução das condições de contorno as matrizes $[H]$ e $[G]$ de tal maneira que as variáveis conhecidas estejam em seu primeiro membro e as incógnitas no segundo. Esse procedimento é realizado por meio da troca das colunas entre as duas matrizes, o sistema resolvido é o da Eq. (2.47). 


$$
[A]\{\operatorname{Inc}\}=[B]\{V P\}
$$

Onde $[A]$ e $[B]$ são as matrizes $[H]$ e $[G]$ modificadas, respectivamente. $\{$ Inc $\}$ é o vetor das incógnitas e $\{V P\}$ o vetor das variáveis prescritas (BREBBIA; DOMINGUEZ, 1992; ALIABADI; HOOKE, 1992).

\subsubsection{GRANDEZAS INTERNAS}

Conhecidos os valores dos deslocamentos e das forças de superfície no contorno do problema, algumas grandezas importantes podem ser calculadas no interior do domínio.

Os deslocamentos nos pontos internos podem ser obtidos empregando-se a identidade Somigliana, que na forma matricial é escrita na Eq. (2.48).

$$
\{u\}^{p i}+\sum_{j=1}^{N E}\left(\int_{\Gamma_{j}}\left[P^{*}\right][\phi] d \Gamma_{j}\right)\{u\}_{n}^{j}=\sum_{j=1}^{N E}\left(\int_{\Gamma_{j}}\left[u^{*}\right][\phi] d \Gamma_{j}\right)\{P\}_{n}^{j}
$$

Para a obtenção dos deslocamentos internos ao domínio, os pontos fonte passam a ser os pontos determinados no interior do domínio. Então, as matrizes $\left[H^{\prime \prime}\right]$ e $\left[G^{\prime \prime}\right]$ recebem o símbolo " para diferenciá-las das matrizes $[H]$ e $[G]$ utilizadas na obtenção dos deslocamentos e forças de superfície no contorno.

As tensões nos pontos internos podem ser obtidas empregando-se a Eq. (A.5), modificada pela introdução da relação entre deformações e deslocamentos da Eq. (A.7). Escreve-se a expressão para as tensões, Eq. (2.49).

$$
\sigma_{i j}^{p i}=\frac{2 \cdot \mu \cdot v}{(1-2 \cdot v)} \cdot \delta_{i j} \cdot u_{l, l}+\mu \cdot\left(u_{i, j}+u_{j, i}\right)
$$

Substituindo a identidade Somigliana na equação das tensões, e desprezando as forças de corpo, obtém-se a Eq. (2.50) para as tensões. 


$$
\begin{array}{r}
\sigma_{i j}^{p i}=\int_{\Gamma}\left\{\frac{2 \cdot \mu \cdot v}{(1-2 \cdot v)} \cdot \delta_{i j} \cdot \frac{\partial u_{l k}^{*}}{\partial x_{l}}+\mu \cdot\left(\frac{\partial u_{i k}^{*}}{\partial x_{j}}+\frac{\partial u_{j k}^{*}}{\partial x_{i}}\right)\right\} P_{k} d \Gamma+ \\
\quad-\int_{\Gamma}\left\{\frac{2 \cdot \mu \cdot v}{(1-2 \cdot v)} \cdot \delta_{i j} \cdot \frac{\partial P_{l k}^{*}}{\partial x_{l}}+\mu \cdot\left(\frac{\partial P_{i k}^{*}}{\partial x_{j}}+\frac{\partial P_{j k}^{*}}{\partial x_{i}}\right)\right\} P_{k} d \Gamma
\end{array}
$$

A Eq. (2.51) é a forma compacta da Eq. (2.50).

$$
\sigma_{i j}^{p i}=\int_{\Gamma} D_{k i j} \cdot P_{k} d \Gamma-\int_{\Gamma} S_{k i j} \cdot U_{k} d \Gamma
$$

Sendo os termos $D_{k i j}$ e $S_{k i j}$ dados pelas Eq. (2.52) e ((2.53).

$$
\begin{gathered}
D_{k i j}=\frac{1}{4 . \pi \cdot(1-v) \cdot r} \cdot\left\{(1-2 \cdot v) \cdot\left(r_{, k} \cdot \delta_{i j}+r_{, j} \cdot \delta_{k i}+r_{, i} \cdot \delta_{j k}\right)\right. \\
\left.+2 \cdot r_{, i} \cdot r_{, j} \cdot r_{, k}\right\}
\end{gathered}
$$

$$
\begin{gathered}
S_{k i j}=\frac{E}{4 \cdot \pi \cdot\left(1-v^{2}\right) \cdot r^{2}} \cdot\left\{2 \cdot r _ { , n } \left[(1-2 \cdot v) \cdot r_{, k} \cdot \delta_{i j}+v \cdot\left(r_{, j} \cdot \delta_{k i}+r_{, i} \cdot \delta_{j k}\right)\right.\right. \\
\left.-4 r_{, i} \cdot r_{, j} \cdot r_{, k} \cdot\right]+2 \cdot v \cdot\left(\eta_{, i} \cdot r_{, j} \cdot r_{, k}+\eta_{, j} \cdot r_{, i} \cdot r_{, k}\right) \\
\left.+(1-2 \cdot v) \cdot\left(2 \cdot \eta_{, k} \cdot r_{, i} \cdot r_{, j}+\eta_{, j} \cdot \delta_{i k}+\eta_{, i} \cdot \delta_{j k}\right)-(1-4 \cdot v) \cdot \eta_{, k} \cdot \delta_{i j}\right\}
\end{gathered}
$$

A Eq. (2.54) é a representação matricial da Eq. (2.50).

$$
\{\sigma\}^{p i}=\left\{\begin{array}{l}
\sigma_{11} \\
\sigma_{12} \\
\sigma_{22}
\end{array}\right\}=\sum_{j=1}^{N E}\left[G^{\prime \prime}{ }_{I N F}\right]\{p\}_{n}^{j}-\sum_{j=1}^{N E}\left[H^{\prime \prime}{ }_{I N F}\right]\{u\}_{n}^{j}
$$

As matrizes $H^{\prime \prime}{ }_{I N F}$ e $G^{\prime \prime}{ }_{I N F}$ indicam as matrizes do processo de integração das variáveis $S_{k i j}$ e $D_{k i j}$, respectivamente sendo o ponto fonte o ponto interno ao domínio. 


\subsubsection{SINGULARIDADES DO MÉTODO DOS ELEMENTOS DE CONTORNO}

A formulação tratada até agora é não-singular, pois existe um raio maior do que zero entre os pontos fonte e os elementos de contorno, ou seja, os pontos fonte não encontram-se sobre o contorno, e a integração numérica resolve adequadamente o problema.

Na condição dos pontos fontes estarem localizados sobre o contorno, o valor do raio utilizado nas soluções fundamentais tem valor nulo, levando a função para um valor infinito.

Emprega-se então o método de subtração de singularidade, o que torna possível a integração numérica dos elementos singulares, sem oferecer prejuízo aos resultados.

A aplicação técnica de subtração de singularidade na matriz $H$ para domínios finitos é evitada usando-se o princípio de movimento de corpo rígido, este trata do deslocamento (translação ou rotação) ocorrido em um corpo sólido na ausência de forças aplicadas, assim, não acontece nenhum deslocamento relativo entre as partículas do corpo. São ausentes deformações e distorções durante o deslocamento, e verifica-se o resultado contido na Eq. (2.55).

$$
[H]\{U\}=0
$$

Isso implica que os somatórios de todos os termos pares e de todos os termos impares das linhas da matriz $H$ devem ser nulos. Para domínios infinitos as somas devem ser iguais à unidade.

Para a matriz $G$ o emprego do princípio de movimento de corpo livre não pode ser utilizado, é necessária então a aplicação da técnica de subtração de singularidade (SILVA, 2010).

Basicamente, a técnica utiliza o processo limite, onde se considera o domínio expandido em torno do ponto fonte de um valor de raio $\varepsilon$ quando esse tende a zero. Removese a singularidade da solução fundamental subtraindo a parte singular da integral imprópria com um integrando de mesma natureza. As demais integrais são resolvidas analiticamente.

A natureza da equação integral é determinada por meio do tipo de singularidade da solução fundamental e não da distância relativa do ponto fonte ao elemento de contorno, sendo essa distância relevante na avaliação da qualidade da integração. 
Aliabadi (1992) discute detalhadamente o método de subtração de singularidade, ele equaciona o método para as subtrações de singularidades de natureza $\ln (r), 1 / r$ e $1 / r^{2}$.

Escrevendo-se uma expansão em série de Taylor sobre o ponto fonte em coordenadas adimensionais $\xi$ imaginando um elemento reto fictício de contorno $\Gamma_{a u x}$ com origem no ponto fonte de coordenada adimensional $\xi_{0}$. A subtração do núcleo integral deve acontecer apenas no primeiro termo da série. A integral regular remanescente deve ser resolvida numericamente e a outra integral resolvida analiticamente. A interpretação geométrica do método pode ser vista na Figura 2.4.

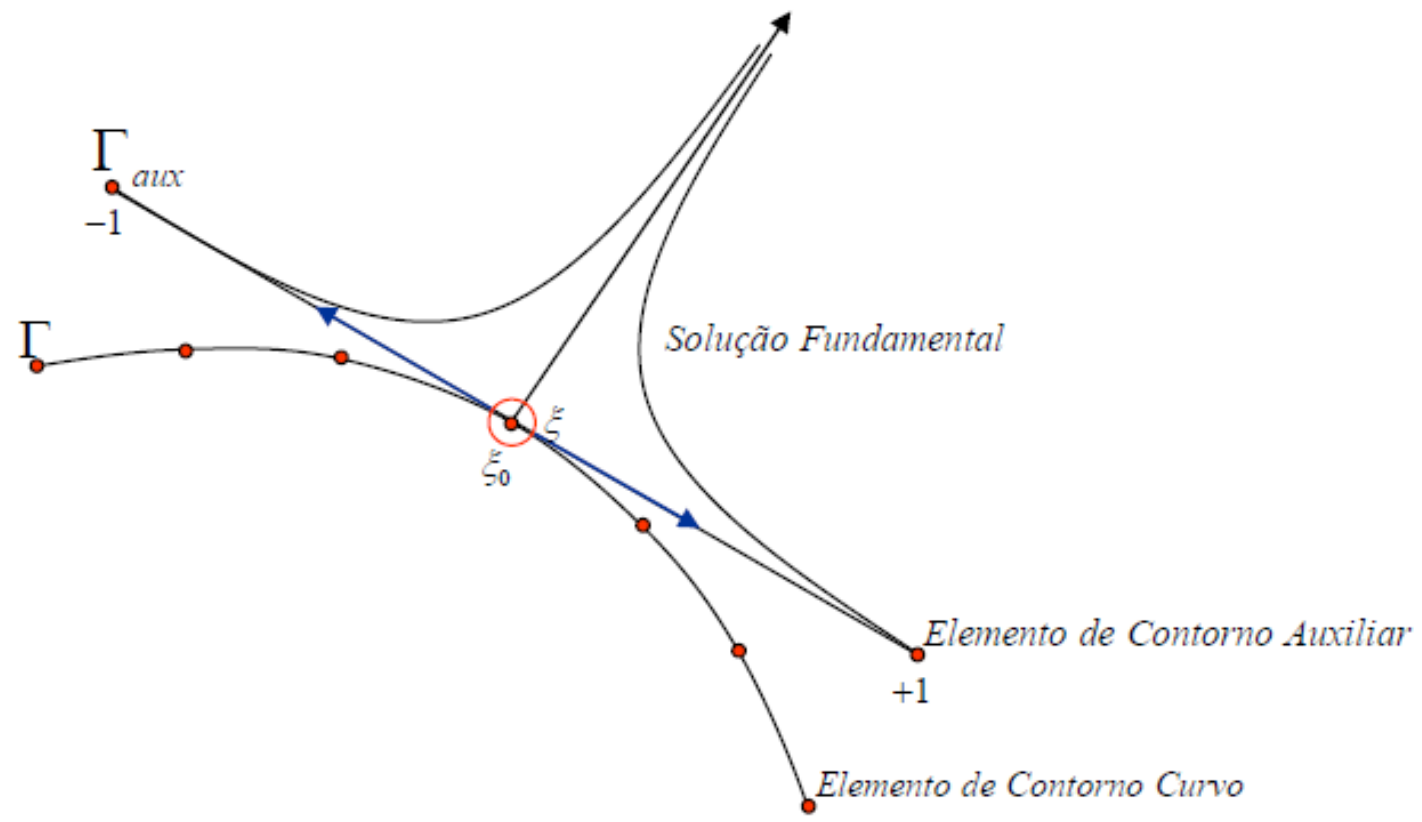

Figura 2.4 - Interpretação geométrica do método de subtração de singularidade. Fonte: Kzam (2009).

As setas azuis indicam o sentido de integração sobre o elemento de contorno auxiliar quando se considera a variável $r^{*}(\xi)$ como referência. A intersecção do círculo com o elemento de contorno curvo indicam os valores vizinhos ao ponto fonte singular $\xi_{0}$ obtido após a expansão em série de Taylor.

A geometria do elemento de contorno curvo é representada por meio dos valores nodais, dados pela Eq. (2.56).

$$
x_{i}(\xi)=\phi_{m}(\xi) x_{i}^{m}
$$

As derivadas são dadas pela Eq. (2.57). 


$$
x_{i, \xi}(\xi)=\phi_{m, \xi}(\xi) x_{i}^{m}
$$

Em série de Taylor em torno de $\xi_{0}$, resulta a Eq. (2.58).

$$
x_{i}(\xi)=x_{i}\left(\xi_{0}\right)+x_{i, \xi}\left(\xi_{0}\right) \varepsilon+O\left(\varepsilon^{\prime \prime}\right)
$$

Onde $\varepsilon$ é o raio que limita os valores na vizinhança do nó singular, $O(\varepsilon ")$ são os termos de ordem superior da série de Taylor que são desprezados.

A distância relativa entre os pontos $\xi$ e $\xi_{0}$ em função das coordenadas do sistema global, é apresentada pelo vetor $\vec{r}$ da Eq. (2.59).

$$
\vec{r}=r_{i}(\xi) \hat{r}_{i}
$$

Sendo $\hat{r}_{i}$ as componentes do vetor unitário que denota a direção e o sentido de vetor $\vec{r}$ e $r_{i}(\xi)=x_{i}(\xi)-x_{i}\left(\xi_{0}\right)$, estas as componentes de vetor $\vec{r}$.

A norma do vetor $\vec{r}$ é dada por $r$, contido na Eq. (2.60).

$$
r=\sqrt{r_{i} r_{i}}
$$

A Eq. (2.60) é reescrita pela Eq. (2.61).

$$
r=\sqrt{\left[x_{i}(\xi)-x_{i}\left(\xi_{0}\right)\right]\left[x_{i}(\xi)-x_{i}\left(\xi_{0}\right)\right]}
$$

Na vizinhança dos pontos fonte é valida a substituição mostrada na Eq. (2.62).

$$
r=\sqrt{x_{i, \xi}\left(\xi_{0}\right) x_{i, \xi}\left(\xi_{0}\right) \varepsilon^{2}}
$$


Então,

$$
r^{*}(\xi)=J\left(\xi_{0}\right)|\varepsilon|
$$

$r^{*}(\xi)$ representa a distância do ponto singular sobre o elemento auxiliar reto. Para $\varepsilon$ não infinitesimal calcula-se $r^{*}(\xi)$ sobre o elemento auxiliar, sendo:

$$
|\varepsilon|=\left|\xi-\xi_{0}\right|
$$

Partindo disso, apresentam-se as formulações considerando a subtração de singularidade (KZAM, 2009).

Reescrevendo as soluções fundamentais de Kelvin:

$$
\begin{gathered}
u_{l k}^{*}(f, c)=\frac{1}{8 \cdot \pi \cdot \mu \cdot(1-v)} \cdot\left[(3-4 \cdot v) \cdot \ln \left(\frac{1}{r}\right) \cdot \delta_{l k}+r_{, l} \cdot r_{, k}\right] \\
P_{l k}^{*}(f, c)=\frac{-1}{4 \cdot \pi \cdot(1-v) \cdot r} \cdot\left\{r_{, n}\left[(1-2 \cdot v) \cdot \delta_{l k}+2 \cdot r_{, l} \cdot r_{, k}\right]\right. \\
\left.+(1-2 \cdot v) \cdot\left(\eta_{l} \cdot r_{, k}-\eta_{\mathrm{k}} \cdot r_{, l}\right)\right\}
\end{gathered}
$$

Para formulação em deslocamentos a subtração de singularidade constrói-se o núcleo contido na Eq. (2.67). Sendo a Eq. (2.68) o VPC.

$$
\begin{aligned}
& \int_{-1}^{+1} \frac{1}{8 \cdot \pi \cdot \mu \cdot(1-v) \cdot\left[(3-4 \cdot v) \cdot \ln \left(\frac{1}{r}\right) \cdot \delta_{l k}+r_{, l}(\xi) \cdot r_{, k} \xi()\right] \cdot J(\xi) \cdot \phi(\xi) d \xi+} \\
& \left.\quad-\int_{-1}^{+1} \frac{1}{8 \cdot \pi \cdot \mu \cdot(1-v)} \cdot\left[-(3-4 \cdot v) \cdot \ln \left(\left|J\left(\xi_{0}\right) \cdot \varepsilon\right|\right) \cdot \delta_{l k}\right)\right] \cdot J\left(\xi_{0}\right) \cdot \phi\left(\xi_{0}\right) d \xi+V P C
\end{aligned}
$$




$$
\begin{gathered}
V P C=\frac{-(3-4 \cdot v) \cdot \delta_{l k}}{8 \cdot \pi \cdot \mu \cdot(1-v)} \cdot\left[\left(1+\xi_{0}\right) \cdot \ln \left(\left|J\left(\xi_{0}\right) \cdot\left(1+\xi_{0}\right)\right|\right)\right. \\
\left.+\left(1-\xi_{0}\right) \cdot \ln \left(\left|J\left(\xi_{0}\right) \cdot\left(1-\xi_{0}\right)\right|\right)-2\right]
\end{gathered}
$$

Para formulação em forças de superfície a subtração de singularidade constrói-se o núcleo contido na Eq. (2.69). Sendo a Eq. (2.70) o VPC.

$$
\begin{aligned}
& \int_{-1}^{+1} \frac{-1}{4 \cdot \pi \cdot(1-v) \cdot r} \cdot\left\{\begin{array}{c}
r_{, n}\left[(1-2 \cdot v) \cdot \delta_{l k}+2 \cdot r_{, l} \cdot r_{, k}\right]+ \\
+(1-2 \cdot v) \cdot\left(\eta_{l} \cdot r_{, k}-\eta_{k} \cdot r_{, l}\right)
\end{array}\right\} \cdot J(\xi) \cdot \phi(\xi) d \xi+ \\
& +\int_{-1}^{+1} \frac{-1}{4 \cdot \pi \cdot(1-v) \cdot \varepsilon \cdot J\left(\xi_{0}\right)} \cdot\left\{(1-2 \cdot v) \cdot\left(\eta_{l}{ }^{*} \cdot r_{, k}{ }^{*}-\eta_{k}{ }^{*} \cdot r_{, l}{ }^{*}\right)\right\} \cdot J\left(\xi_{0}\right) \cdot \phi\left(\xi_{0}\right) d \xi+V P C \\
& V P C=\frac{-(1-2 \cdot v) \cdot\left(\eta_{l}^{*} \cdot r_{, k}{ }^{*}-\eta_{k}{ }^{*} \cdot r_{, l}^{*}\right)}{4 \cdot \pi \cdot(1-v)} \cdot\left\{\ln \left(\left|\left(1-\xi_{0}\right)\right|\right)\right. \\
& \left.-\ln \left(\left|\left(1+\xi_{0}\right)\right|\right)\right\}
\end{aligned}
$$

Ambas as formulações são válidas para os casos onde o ponto fonte não se encontra nos extremos do elemento, ou seja, onde $\xi_{0}= \pm 1$. 


\section{MÉTODO LEVEL SET}

\subsection{CONCEITOS FUNDAMENTAIS}

O desenvolvimento do MLS está intimamente ligado a alguns conceitos fundamentais como: leis de conservação, entropia, curvas características e formação de choques, equações de diferenças finitas, convergência e estabilidade.

Sethian (1999) e Osher e Fedkiw (2003) discutem meticulosamente esses conceitos. Napolitano (2004) apresenta brevemente o assunto. Baseado nestes e em outros estudiosos, faz-se a seguir uma discussão.

Os conceitos aqui abordados, não são aplicados diretamente no equacionamento da dissertação, entretanto, é importante esclarecer o método level set (MLS), mostrar sua raiz e particularidades matemáticas, bem como, citar algumas aplicações onde o mesmo demonstra grande eficiência.

\subsubsection{MOVIMENTOS DE UM CAMPO DE VELOCIDADE GERADO EXTERNAMENTE}

\subsubsection{CONVECÇÃO}

Supondo que a velocidade de cada ponto em uma função seja dada por $\vec{V}(\vec{x})$, e que esta seja conhecida em todos os pontos $\vec{x}$ onde $\phi(\vec{x})=0$. Para um campo de velocidade $V=\langle u, v, w\rangle$, deseja-se mover todos os pontos na superfície com esta velocidade.

$$
\frac{d \vec{x}}{d t}=\vec{V}(\vec{x})
$$

A Eq. (3.1) é denominada aproximação Lagrangeana ou explícita. É a maneira mais simples para representação de movimentos no contorno. Nesse modelo são delimitados nós que se conectam através de segmentos de reta. A interface resultante é chamada snake e recebe esse nome devido à similaridade da avaliação do contorno com o movimento de uma 
cobra. O método trabalha no movimento dos nós de acordo com uma velocidade $\vartheta$ através da resolução de sistemas de equações diferenciais ordinárias (EDOs).

O contorno tem uma representação paramétrica e o método é baseado na ideia de minimização de energia. Para uma dada função, considera-se que a cada instante de tempo $t$ a mesma esteja em um ponto diferente do espaço. A procura do mínimo para essas funções é realizada através de métodos numéricos clássicos como: steepest descent, gradientes conjugados, método simplex, entre outros.

A fim de evitar problemas com instabilidades, deformação da superfície, entre outras, usa-se a função implícita $\phi$ para representar o contorno e desenvolver a superfície em questão.

Definindo a evolução da função $\phi$, usa-se a equação de advecção, mais conhecida como equação de convecção, apresenta-se a mesma na Eq. (3.2).

$$
\phi_{t}+\vec{V} \cdot \nabla \phi=0
$$

O índice $t$ subscrito denota a derivada parcial no tempo. $\nabla$ é o operador gradiente, calculado na Eq. (3.3).

$$
\vec{V} \cdot(\nabla \phi)=u \phi_{x}+v \phi_{y}+w \phi_{z}
$$

Esta equação diferencial parcial (EDP) define o movimento de um contorno onde $\phi(\vec{x})=0$, é a representação Euleriana da evolução da interface.

A Eq. (3.2) é chamada de equação level set (LS), e é usada para a evolução numérica de interfaces.

Um caso popular de utilização dessa equação é a equação de combustão, denominada de equação-G, a mesma pode ser vista na Eq. (3.4).

$$
G_{t}+\vec{V} \cdot \nabla G=0
$$

$G(\vec{x})=0$ é o contorno usado para representar implicitamente a superfície de reação de uma frente de evolução das chamas.

Em um grid cartesiano é dificultoso o processo de implementação da equação LS, pois o campo de velocidade pode estar definido apenas na interface. Assim, supõe-se que para a 
Eq. (3.2), o campo de velocidade $\vec{V}$ seja válido também em pontos fora da interface, admitindo-se a definição em uma banda próxima a mesma.

\subsubsection{DIFERENÇA UPWIND}

Uma vez que $\phi$ e $\vec{V}$ sejam definidos em todo grid cartesiano ou pelo menos suficientemente próximos a interface, aplicam-se métodos numéricos para desenvolver $\phi$ no tempo e movimentar a interface pelo grid. Em um tempo $t$, diz-se tempo $t^{n}$, e $\phi^{n}=\phi\left(t^{n}\right)$ representa o valor corrente de $\phi$. Atualizando $\phi$ encontram-se novos vallores para $\phi$ em todo o grid após um incremento de tempo $\Delta t$. Então, $\phi^{n+1}=\phi\left(t^{n+1}\right)$, onde $t^{n+1}=t^{n}+\Delta t$.

Um simples e preciso método de primeira ordem para discretização da Eq. (3.2) no tempo é o método de Euler adiantado (Forward Euler Method), representado na Eq. (3.5).

$$
\frac{\phi^{n+1}-\phi^{n}}{\Delta t}+\vec{V}^{n} \cdot \nabla \phi^{n}=0
$$

$\vec{V}^{n}$ é um dado campo externo de velocidade no tempo $t^{n}$, e $\nabla \phi^{n}$ avalia o operador gradiente usando os valores de $\phi$ no tempo $t^{n}$.

A avaliação das derivadas espaciais de $\phi$ pode ser realizada usando-se diferenças finitas de primeira ordem: adiantadas $\left(D^{+} \phi\right)$, atrasadas $\left(D^{-} \phi\right)$ e centrais $\left(D^{0} \phi\right)$. Dadas pelas Eq. (3.6), (3.7) e (3.8), respectivamente.

$$
\begin{gathered}
\frac{\partial \phi}{\partial x} \approx \frac{\phi_{i+1}-\phi_{i}}{\Delta x} \\
\frac{\partial \phi}{\partial x} \approx \frac{\phi_{i}-\phi_{i-1}}{\Delta x} \\
\frac{\partial \phi}{\partial x} \approx \frac{\phi_{i+1}-\phi_{i-1}}{2 \Delta x}
\end{gathered}
$$

Contudo, esta aproximação pode falhar. Em geral, é preciso cuidado ao se tratar de métodos numéricos para discretização de equações diferenciais parciais.

Expande-se a Eq. (3.5) como mostrado na Eq. (3.9). 


$$
\frac{\phi^{n+1}-\phi^{n}}{\Delta t}+u^{n} \phi_{x}^{n}+v^{n} \phi_{y}^{n}+w^{n} \phi_{z}^{n}=0
$$

Analisando em $1 D$ considera-se apenas a direção $x$ da Eq. (3.9).

$$
\frac{\phi^{n+1}-\phi^{n}}{\Delta t}+u^{n} \phi_{x}^{n}=0
$$

Indica-se com $u^{n}$ os valores de $\phi$ estão se movendo para a direita ou esquerda. Desde que $u^{n}$ possa variar espacialmente, foca-se no ponto $x_{i}$, escrevendo-se a Eq. (3.11), em que $\left(\phi_{x}\right)_{i}$ denota a derivada espacial de $\phi$ no ponto $x_{i}$.

$$
\frac{\phi_{i}^{n+1}-\phi_{i}^{n}}{\Delta t}+u_{i}^{n}\left(\phi_{x}\right)_{i}^{n}=0
$$

Se $u_{i}>0$, os valores de $\phi$ se deslocam da esquerda para direita, o método determina que se adotem valores à esquerda de $x_{i}$ para cálculo de quais valores de $\phi$ pousarão no ponto $x_{i}$.

Analogamente, se $u_{i}<0$, os valores se movem da direita para a esquerda, o método determina que se adotem os valores à direita de $x_{i}$ para se determinar valores apropriados de $\phi_{i}$ no tempo $t^{n+1}$.

Esse método de escolha da aproximação para as derivadas espaciais baseadas no sinal de $u$ é conhecido como upwinding ou upwind difference. Geralmente, os métodos de aproximação upwinding derivam da diferença finita na direção de onde vem a informação característica.

Para a discretização upwind em cada ponto define-se $\phi_{x}^{-}$como $D^{-} \phi$ e $\phi_{x}^{+}$como $D^{+} \phi$. Se $u_{i}>0$, aproxima-se $\phi_{x} \operatorname{com} \phi_{x}^{+}$. Se $u_{i}<0$, aproxima-se $\phi_{x} \operatorname{com} \phi_{x}^{-}$. Quando $u_{i}=0$, o termo $u_{i}\left(\phi_{x}\right)_{i}$ desaparece e $\phi_{x}$ não necessita ser aproximado. Esta é uma discretização de primeira ordem do operador espacial, desde que $D^{-} \phi$ e $D^{+} \phi$ sejam aproximações de primeira ordem da derivada e o erro seja $O(\Delta x)$.

A combinação da discretização adiantada de Euler no tempo com esquema de diferenças upwind é uma aproximação por diferença finita consistente para a Eq. (3.2), desde que o erro da aproximação convirja para zero quando $\Delta t \rightarrow 0$ e $\Delta x \rightarrow 0$. 
De acordo com o teorema da equivalência de Lax-Richtmyer uma aproximação por diferença finita para equações diferenciais parciais lineares é convergente. A correta solução é obtida quando $\Delta t \rightarrow 0$ e $\Delta x \rightarrow 0$, se e somente se o esquema é, simultaneamente, consistente e estável.

A estabilidade garante que os pequenos erros na aproximação não sejam propagados. Verifica-se a mesma através da condição de Courant-Friedreichs-Lewy (condição CFL). Esta condição afirma que uma 'onda numérica' deve propagar-se tão rápido quando as 'ondas físicas'. Isso significa que a velocidade da 'onda numérica' $\Delta x / \Delta t$ deve ter ao menos a velocidade da 'onda física' $|u|$, ou seja, $\Delta x / \Delta t>|u|$. Através da Eq. (3.12) é obtida a restrição de tempo CFL, onde $\max \{|u|\}$ é o maior valor de $|u|$ em todo o grid Cartesiano.

$$
\Delta t=\frac{\Delta x}{\max \{|u|\}}
$$

Na realidade necessita-se do maior valor de $|u|$ na interface. Os valores serão os mesmos se o campo de velocidade for definido como velocidade de pontos mais próximos à interface. A Eq. (3.12) é usualmente dada por um número $\alpha$ CFL como na Eq. (3.13).

$$
\Delta t\left(\frac{\max \{|u|\}}{\Delta x}\right)=\alpha
$$

Uma escolha próxima a ideal é $\alpha=0,9$, e uma comum escolha conservadora é $\alpha=0,5$. Sendo $0<\alpha<1$ o intervalo limite.

Empregam-se também as diferenças finitas centrais para a discretização, entretanto, elas são instáveis quando a condição CFL tem $\Delta t \sim \Delta x$. A estabilidade pode ser alcançada usando uma condição CFL mais restrita com $\Delta t \sim(\Delta x)^{2}$, onde o custo computacional passa ser maior. Outra maneira de se atingir a estabilidade é usando uma discretização temporal diferente, como o método Runge-Kutta de terceira ordem (discutido posteriormente). Uma terceira maneira de se chegar à estabilidade, consiste em adicionar algumas dissipações artificiais do lado direito da Eq. (3.2), a Eq. (3.14) mostra a inserção da dissipação.

$$
\phi_{t}+\vec{V} \cdot \nabla \phi=\mu \Delta \phi
$$


O coeficiente de viscosidade $\mu$ é escolhido proporcionalmente a $\Delta x(\mu \sim \Delta x)$, desde que a viscosidade artificial desapareça quando $\Delta x \rightarrow 0$, determinando a consistência do método.

\subsubsection{HAMILTON-JACOBI ENO}

A ideia do método é a interpolação polinomial Essencially Nonoscillatory (ENO) para soluções numéricas de leis de conservação. Basicamente, trata-se de computar funções de fluxo numérico usando funções polinomiais mais suaves possíveis. Osher e Sethian (1988) descobriram que as equações de Hamilton-Jacobi em $1 D$ são integrais das leis de conservação. Eles usaram esse fato para estender o método ENO para discretização numérica das leis de conservação para equações de Hamilton-Jacobi na forma da Eq. (3.2).

O método Hamilton-Jacobi ENO (HJ ENO) permite estender diferenças upwind de primeira ordem para ordens superiores fornecendo melhores aproximações para $\phi_{x}^{-}$ou $\phi_{x}^{+}$.

Usando o polinômio de interpolação o mais suave possível, encontra-se $\phi$ e depois se diferencia a fim de obter $\phi_{x}$. Através do polinômio de interpolação de Newton o termo zero de $\phi$ é definido nos nós do grid como na Eq. (3.15), em cada nó $i$ (locado em $x_{i}$ ).

$$
D_{i}^{0} \phi=\phi_{i}
$$

A primeira diferença de $\phi$ é definida no meio dos nós através da Eq. (3.16).

$$
D_{i+1 / 2}^{1} \phi=\frac{D_{i+1}^{0} \phi-D_{i}^{0} \phi}{\Delta x}
$$

Assume-se que o espaçamento da malha seja uniformemente $\Delta x$. Nota-se que $D_{i-1 / 2}^{1} \phi=\left(D^{-} \phi\right)_{i}$ e $D_{i+1 / 2}^{1} \phi=\left(D^{+} \phi\right)_{i}$, a primeira diferença é a aproximação de diferenças atrasadas e adiantadas das derivadas. A segunda diferença é definida no grid de nós e é mostrada na Eq. (3.17). A terceira diferença é apresentada na Eq. (3.18).

$$
D_{i}^{2} \phi=\frac{D_{i+1 / 2}^{1} \phi-D_{i-1 / 2}^{1} \phi}{2 \Delta x}
$$




$$
D_{i+1 / 2}^{3} \phi=\frac{D_{i+1}^{2} \phi-D_{i}^{2} \phi}{3 \Delta x}
$$

As diferenças são empregadas para reconstrução de um polinômio na forma da Eq. (3.19), pode ser diferenciado e avaliado em $x_{i}$ para encontrar $\left(\phi_{x}^{-}\right)_{i}$ e $\left(\phi_{x}^{+}\right)_{i}$ por meio da Eq. (3.20).

$$
\begin{gathered}
\phi(x)=Q_{0}(x)+Q_{1}(x)+Q_{2}(x)+Q_{3}(x) \\
\phi_{x}\left(x_{i}\right)=Q_{1}{ }^{\prime}\left(x_{i}\right)+Q_{2}{ }^{\prime}\left(x_{i}\right)+Q_{3}{ }^{\prime}\left(x_{i}\right)
\end{gathered}
$$

Para encontrar $\phi_{x}^{-}$e $\phi_{x}^{+}$inicia-se com $k=i-1$ e $k=i$, respectivamente. Chega-se então às Eq. (3.21) e (3.22).

$$
\begin{gathered}
Q_{1}(x)=\left(D_{k+1 / 2}^{1} \phi\right)\left(x-x_{i}\right) \\
Q_{1}^{\prime}\left(x_{i}\right)=D_{k+1 / 2}^{1} \phi
\end{gathered}
$$

A contribuição de $Q_{1}{ }^{\prime}\left(x_{i}\right)$ na Eq. (3.20) é a diferença atrasada no caso de $\phi_{x}^{-}$e a diferença adiantada no caso de $\phi_{x}^{+}$. Em outras palavras, a interpolação polinomial de primeira ordem é exatamente a diferença upwind de primeira ordem. Melhorias são obtidas incluindo os termos $Q_{2}{ }^{\prime}\left(x_{i}\right)$ e $Q_{3}{ }^{\prime}\left(x_{i}\right)$ na Eq. (3.20), levando para segunda e terceira ordem, respectivamente.

\subsubsection{HAMILTON-JACOBI WENO}

Quando se calcula $\left(\phi_{x}^{-}\right)_{i}$, o esquema HJ ENO de terceira ordem usa um subconjunto de $\left\{\phi_{i-3}, \phi_{i-2}, \phi_{i-1}, \phi_{i}, \phi_{i+1}, \phi_{i+2}\right\}$ que depende de como o estêncill é escolhido. Há três possíveis aproximações para $\left(\phi_{x}^{-}\right)_{i}$. Definindo $v_{1}=D^{-} \phi_{i-2}, v_{2}=D^{-} \phi_{i-1}, v_{3}=D^{-} \phi_{i}$, $v_{4}=D^{-} \phi_{i+1}$ e $v_{5}=D^{-} \phi_{i+2}$, o que permite escrever as Eq. (3.23), (3.24), e (3.25) como as três potenciais aproximações HJ ENO para $\phi_{x}^{-}$. 


$$
\begin{gathered}
\phi_{x}^{1}=\frac{v_{1}}{3}-\frac{7 v_{2}}{6}+\frac{11 v_{3}}{6} \\
\phi_{x}^{2}=-\frac{v_{2}}{6}+\frac{5 v_{3}}{6}+\frac{v_{4}}{3} \\
\phi_{x}^{3}=\frac{v_{3}}{3}+\frac{5 v_{4}}{6}-\frac{v_{5}}{6}
\end{gathered}
$$

O objetivo da HJ ENO é escolher uma aproximação com menor erro, através da função polinomial de interpolação $\phi$ mais suave possível.

Utilizar ENO em regiões onde os dados são bem comportados pode ser exagerado. Então, Liu et al. (1994) propuseram o método Weight Essencially Nonoscillatory (WENO) que toma uma combinação convexa das três aproximações. Posteriormente, foram realizadas modificações nesse método, o que alcançou precisão de até quinta ordem para as regiões suaves das funções. Jiang e Peung (1997) estenderam o método WENO para as equações de Hamilton-Jacobi, criando o Hamilton-Jacobi WENO (HJ WENO), que pode ser uma opção muito útil para a Eq. (3.2), desde que isso reduza os erros existentes no método HJ ENO.

A aproximação HJ ENO de $\left(\phi_{x}^{-}\right)_{i}$ é uma combinação convexa das Eq. (3.23), (3.24) e (3.25) dada pela Eq. (3.26), onde $0 \leq \omega_{k} \leq 1$ são os pesos com $\omega_{1}+\omega_{2}+\omega_{3}=1$.

$$
\phi_{x}=\omega_{1} \phi_{x}^{1}+\omega_{2} \phi_{x}^{2}+\omega_{3} \phi_{x}^{3}
$$

A chave para obtenção de precisões de alta ordem em regiões suaves é que os pesos valham $\omega_{1}=0.1, \omega_{2}=0.6$ e $\omega_{3}=0.3$, esses valores resultam na aproximação ótima para aproximações de quinta ordem para $\phi_{x}$. Em regiões não suaves esses valores de pesos podem resultar em resultados ruins, então se utilizam aproximações para $\phi_{x}$ pelo método HJ ENO. Existem diversas bibliografias que apontam diferentes maneiras de se obter os valores para os pesos.

A função $\left(\phi_{x}^{+}\right)_{i}$ e construída com o subconjunto $\left\{\phi_{i-2}, \phi_{i-1}, \phi_{i}, \phi_{i+1}, \phi_{i+2}, \phi_{i+3}\right\}$. Definindo $\quad v_{1}=D^{+} \phi_{i+2}, \quad v_{2}=D^{+} \phi_{i+1}, \quad v_{3}=D^{+} \phi_{i}, \quad v_{4}=D^{+} \phi_{i-1} \quad$ e $\quad v_{5}=D^{+} \phi_{i-2}$ permitindo o uso das Eq. (3.23), (3.24) e (3.25) como as três aproximações HJ ENO para $\left(\phi_{x}^{+}\right)_{\mathrm{i}}$

A combinação convexa para a aproximação HJ ENO é dada pela Eq. (3.26). 


\subsubsection{TVD RUNGE-KUTTA}

Há casos em que uma discretização temporal de alta ordem é necessária para obter precisas soluções numéricas. Shu e Osher (1988) propuseram método Total Variation Diminishing (TVD) Runge-Kutta (RK) para aumentar a precisão para um método de aproximação de linhas em discretização temporal. O método de aproximação de linhas assume que a discretização espacial pode ser separada de uma discretização temporal que permita a discretização temporal da EDP ser tratada independentemente como uma EDO.

O TVD RK garante que hipotéticas oscilações sejam produzidas como consequência da discretização temporal de alta ordem, e que elas sejam tão longas quanto às oscilações não hipotéticas produzidas com as construções adiantadas de Euler.

\subsubsection{MOVIMENTO ENVOLVENDO CURVATURA PRINCIPAL}

\subsubsection{EQUAÇÃO DE MOVIMENTO}

Trata-se aqui de movimento da interface gerados por um campo de velocidade $\vec{V}$ que depende diretamente da função LS. Considera-se o movimento através da curvatura principal onde a interface se move na direção normal com velocidade proporcional a esta curvatura, ou seja, $\vec{V}=-b \kappa \vec{N}$, onde $b>0$ é uma constante e $\kappa$ é a curvatura.

Quando $b>0$, a interface se move na direção da concavidade, de modo que a curva encolha a um único ponto e desapareça. Quando $b<0$, a interface se move na direção da convexidade e, ao invés de encolher, a curva aumenta. Esse efeito de crescimento leva a pequenas perturbações, incluindo erros de arredondamento.

O campo velocidade para movimento pela curvatura contém apenas uma componente na direção normal, a componente tangencial é identicamente igual à zero. Desde que $\vec{N}$ e $\Delta \phi$ estejam na mesma direção, $\vec{T} \cdot \nabla \phi=0$ para qualquer vetor $\vec{T}$, implicando que a velocidade tangencial desapareça quando presente na equação LS, isso apresentado nas Eq. (3.27) e (3.28). 


$$
\begin{gathered}
\phi_{t}+\left(V_{n} \vec{N}+V_{t} \vec{T}\right) \cdot \nabla \phi=0 \\
\phi_{t}+V_{n} \vec{N} \cdot \nabla \phi=0
\end{gathered}
$$

Na Eq. (3.29) analisa-se o termo $\vec{N} . \nabla \phi$. E na Eq. (3.30) reescreve-se a Eq. (3.28) segundo essa análise.

$$
\begin{gathered}
\vec{N} \cdot \nabla \phi=\frac{\nabla \phi}{|\nabla \phi|} \cdot \nabla \phi=\frac{|\nabla \phi|^{2}}{|\nabla \phi|}=|\nabla \phi| \\
\phi_{t}+V_{n}|\nabla \phi|=0
\end{gathered}
$$

Verifica-se que $V_{n}$ é a componente da velocidade na direção normal, conhecida como velocidade normal. O movimento através da curvatura principal é caracterizado por $V_{n}=$ $-b \kappa$.

A Eq. (3.30) é conhecida como a equação do MLS. Como a Eq. (3.2) é usada para campos de velocidade gerados externamente, enquanto a Eq. (3.30) é usada para campos de velocidade gerados internamente (autogerados). Métodos numéricos mais complicados do que os apresentados para resolver a Eq. (3.2), são empregados para resolver a Eq. (3.30).

Utilizando o termo $V_{n}=-b \kappa$ na Eq. (3.30) e levando-o para o lado direito da equação, chega-se na Eq. (3.31).

$$
\phi_{t}=b \kappa|\nabla \phi|
$$

Nota-se que $b \kappa|\nabla \phi|$ é um termo parabólico que não pode ser discretizado com uma aproximação upwind. Quando $\phi$ é função distância com sinal, a Eq. (3.31) se torna a equação de calor dada pela Eq. (3.32) onde $\phi$ é a temperatura e $b$ é a condutibilidade térmica. A equação de calor é a mais básica equação do modelo parabólico.

$$
\phi_{t}=b \Delta \phi
$$

Quando $\phi$ é função distância com sinal, $b \kappa|\nabla \phi|$ e $b \Delta \phi$ são iguais, e quaisquer dessas podem ser usadas para se calcular a Eq. (3.31). Contudo, uma vez que, a parcela do lado 
direito da equação seja combinada com as equações de Euler adiantadas no tempo, os novos valores de $\phi$ não são mais sinais da função distância, e as Eq. (3.31) e (3.32) não podem ser intercambiadas. Entretanto, se esse novo valor de $\phi$ é reinicializado piara a função distância com sinal, o termo $b \Delta \phi$ pode ser empregado no lugar do termo $b \kappa|\nabla \phi|$.

\subsubsection{DISCRETIZAÇÃO NUMÉRICA}

Equações parabólicas necessitam discretização utilizando diferenças finitas centrais desde que o domínio de dependência inclua informações sobre todas as direções espaciais, em oposição às equações hiperbólicas como a Eq. (3.2), em que as informações são dadas apenas na direção analisada. Assim, discretiza-se o termo $\Delta \phi$ da Eq. (3.32) usando a aproximação de segunda ordem dada pela Eq. (3.33).

$$
\frac{\partial^{2} \phi}{\partial x^{2}}=\frac{\phi_{i+1}-2 \phi_{i}+\phi_{i-1}}{\Delta x^{2}}
$$

Para cada direção espacial verifica-se a Eq. (3.34).

$$
\Delta \phi=\phi_{x x}+\phi_{y y}+\phi_{z z}
$$

Uma aproximação similar poderia ser utilizada para discretizar a Eq. (3.31). A curvatura $\kappa$ é discretizada usando uma diferença central de segunda ordem delimitada pela Eq. (3.35).

$$
\begin{gathered}
\kappa=\left(\phi_{x}^{2} \phi_{y y}-2 \phi_{x} \phi_{y} \phi_{x y}+\phi_{y}^{2} \phi_{x x}+\phi_{x}^{2} \phi_{z z}-2 \phi_{x} \phi_{z} \phi_{x z}+\right. \\
\left.\phi_{z}^{2} \phi_{x x}+\phi_{y}^{2} \phi_{z z}-2 \phi_{y} \phi_{z} \phi_{y z}+\phi_{z}^{2} \phi_{y y}\right) /|\nabla \phi|^{3}
\end{gathered}
$$

O termo $\nabla \phi$ é discretizado usando a diferença central de segunda ordem dada pela Eq. (3.8) aplicada independentemente das direções espaciais. Enquanto estas discretizações são apenas precisões de segunda ordem no espaço, a natureza dissipativa das equações torna essas aproximações suficientes. 
A diferença central de $\Delta \phi$ na Eq. (3.32) combinada com a discretização temporal de Euler adiantada requer a restrição da Eq. (3.36) para manter a estabilidade do algoritmo numérico.

$$
\Delta t\left(\frac{2 b}{(\Delta x)^{2}}+\frac{2 b}{(\Delta y)^{2}}+\frac{2 b}{(\Delta z)^{2}}\right)<1
$$

Aqui $\Delta t$ é $O\left((\Delta x)^{2}\right)$, na qual é significantemente mais rigoroso do que no caso hiperbólico, onde $\Delta t$ é $O(\Delta x)$. A Eq. (3.31) pode ser discretizada usando um intervalo de tempo de Euler adiantado com a condição CFL na Eq. (3.36).

A rigorosa restrição no tempo $O\left((\Delta x)^{2}\right)$ resulta da discretização de Euler adiantada, pode ser aliviada usando a solução para equações diferenciais ordinárias com uma grande região de estabilidade, como por exemplo, um método implícito.

A diferença de Euler atrasada aplicada à Eq. (3.32) obtém a Eq. (3.37), na qual não tem restrição de estabilidade no tamanho de $\Delta t$.

$$
\frac{\phi^{n+1}-\phi^{n}}{\Delta t}=b \Delta \phi^{n+1}
$$

Isso significa que $\Delta t$ pode ser escolhido por razões de precisão. Nota-se que fixado $\Delta t=O(\Delta x)$ ao contrário de $\Delta t=O\left((\Delta x)^{2}\right)$, reduz a precisão geral de $O(\Delta x)$. Isso pode ser melhorado usando a regra trapezoidal da Eq. (3.38), onde está $O\left((\Delta t)^{2}\right)$ no tempo e assim $O\left((\Delta x)^{2}\right)$ global mesmo quando $\Delta t=O(\Delta x)$.

$$
\frac{\phi^{n+1}-\phi^{n}}{\Delta t}=b\left(\frac{\Delta \phi^{n}+\Delta \phi^{n+1}}{2}\right)
$$

Esta combinação da regra trapezoidal com a diferença central de um operador espacial parabólico é denominado esquema Crank-Nicolson.

O preço que se paga por um largo intervalo de tempo usando a Eq. (3.37) ou (3.38) é que o sistema linear de equações deve ser resolvido em cada passo de tempo para obter $\phi^{n+1}$. Felizmente, isto não é difícil, dada a simples estrutura linear de $\Delta \phi^{n+1}$. Porém, uma discretização implícita da Eq. (3.31) requer consideração de termos não lineares complicados como, $\kappa^{n+1}\left|\Delta \phi^{n+1}\right|$. 
Mesmo se $\phi^{n}$ é inicialmente a função distância com sinal, $\phi^{n+1}$ não será uma função distância após a resolução do sistema linear. Isso significa que $\Delta \phi^{n+1}$ não é uma boa aproximação para $\kappa^{n+1}\left|\Delta \phi^{n+1}\right|$, mesmo com $\Delta \phi^{n}$ sendo exatamente igual a $\kappa^{n}\left|\Delta \phi^{n}\right|$.

\subsubsection{EQUAÇÃO DE CONVECÇÃO-DIFUSÃO}

A equação de convecção-difusão é mostrada na Eq. (3.39). Esta inclui ambos os efeitos de um campo de velocidade externo e um termo difusivo.

$$
\phi_{t}+\vec{V} \cdot \nabla \phi=b \Delta \phi
$$

A versão LS dessa equação é a Eq. (3.40).

$$
\phi_{t}+\vec{V} \cdot \nabla \phi=b_{\kappa} \Delta \phi
$$

As Eq. (3.39) e (3.40) podem ser intercambiadas se mantiverem a forma da função distância com sinal para $\phi$ fora da interface. Estas equações podem ser resolvidas usando o método upwind no termo $\vec{V} . \nabla \phi$ e uma diferença central no termo parabólico $b \Delta \phi$ ou no termo $b \kappa|\nabla \phi|$. Uma discretização temporal TVD RK pode ser usada com um intervalo de tempo como na Eq. (3.41) satisfeita em todos os pontos.

$$
\Delta t\left(\frac{|u|}{\Delta x}+\frac{|v|}{\Delta y}+\frac{|w|}{\Delta z} \frac{2 b}{(\Delta x)^{2}}+\frac{2 b}{(\Delta y)^{2}}+\frac{2 b}{(\Delta z)^{2}}\right)<1
$$

Supondo termo $O(1)$ que é $b$ ser substituído por um $O(\Delta x)$ de tamanho $\epsilon$ que é eliminado quando a malha é refinada com $\Delta x \rightarrow 0$. Então a Eq. (3.39) torna-se a Eq. (3.42), que assintoticamente aproxima a Eq. (3.2) quando $\epsilon \rightarrow 0$.

$$
\phi_{t}+\vec{V} \cdot \nabla \phi=\epsilon \Delta \phi
$$

A adição de um termo artificial $\epsilon \Delta \phi$ do lado direito da Eq. (3.2) é chamado de método da viscosidade artificial. 
A viscosidade artificial é usada por muitos autores para estabilizar uma aproximação por diferenças centrais para o termo convectivo $\nabla \phi$ da Eq. (3.2). Isso surge na dinâmica computacional, onde termos de $\epsilon \Delta \phi$ são adicionados do lado direito da equação de convecção para escolher soluções de viscosidade que desaparecem quando $\epsilon \rightarrow 0$. As viscosidades eliminadas escolhem soluções fracas fisicamente corretas quando soluções clássicas não existem.

Sethian (1999) sugeriu uma condição de entropia que requer curvas para fluxos nas quinas, e ele melhorou numericamente para mostrar que esta condição de entropia produz corretas soluções fracas. A condição de entropia de Sethian indica que $\epsilon \kappa|\nabla \phi|$ é a melhor forma para eliminar a viscosidade, ao invés de se trabalhar com $\epsilon \Delta \phi$. Este conceito é usado por Osher e Sethian (1988), eles mostraram que se tratando do MLS a Eq. (3.43) é a melhor escolha a ser feita.

$$
\phi_{t}+\vec{V} \cdot \nabla \phi=\epsilon \kappa|\nabla \phi|
$$

Entretanto, as Eq. (3.39) e (3.40) só podem ser intercambiadas quando $\phi$ representa o sinal da função distância.

\subsubsection{EQUAÇÕES DE HAMILTON-JACOBI}

O MLS caracteriza-se por representar um caso particular das equações de HamiltonJacobi, a forma geral dessas é dada pela Eq. (3.44) onde $H$ pode ser a função para espaço e tempo.

$$
\phi_{t}+H(\nabla \phi)=0
$$

A convecção de um campo de velocidade gerado externamente (Eq. (3.2)) é um exemplo da equação de Hamilton-Jacobi, onde $H(\nabla \phi)=\vec{V} \cdot \nabla \phi$. A equação LS (Eq. (3.30)) é outro exemplo da equação de Hamilton-Jacobi com $H(\nabla \phi)=V_{n} \cdot|\nabla \phi|$, onde $V_{n}$ pode depender de $\vec{x}, t$ ou mesmo $\nabla \phi /|\nabla \phi|$.

A Eq. (3.31) para movimento através da curvatura principal não é uma equação do tipo Hamilton-Jacobi, as frentes de velocidade dependem das derivadas segundas de $\phi$. Nas 
equações de Hamilton-Jacobi dependem da primeira derivada de $\phi$, e são hiperbólicas. A equação para movimento através da curvatura principal são parabólicas.

\subsubsection{CONEXÃO COM AS LEIS DE CONSERVAÇÃO}

Considera-se a lei de conservação escalar em 1D na Eq. (3.45) onde $u$ é a quantidade conservada e $F(u)$ é função fluxo.

$$
u_{\mathrm{t}}+F(u)_{x}=0
$$

Uma lei de conservação bem conhecida é a equação de continuidade para conservação de massa, vista na Eq. (3.46) onde $\rho$ é a densidade do material.

$$
\rho_{t}+(\rho u)_{x}=0
$$

Essa lei é largamente utilizada na dinâmica dos fluidos computacional (Computacional Fluid Dynamics - CFD). A equação de continuidade é combinada com as equações de conservação de momentum e conservação de energia para obter as equações compressíveis de Navier-Stokes. Quando os efeitos viscosos são ignorados, as equações de Navier-Stokes são reduzidas para equações de Euler.

A presença de descontinuidades nas equações de Euler força a consideração de soluções fracas onde as derivadas das soluções variáveis, $\rho_{x}$, podem não existir.

As equações de Euler podem não conter soluções únicas, e uma condição de entropia é usada para escolher a solução fisicamente correta.

Outro exemplo das leis de conservação são as equações de Burger, Eq. (3.47).

$$
u_{t}+\left(\frac{u^{2}}{2}\right)_{x}=0
$$

Esta é lei de conservação que possui propriedades não lineares interessantes contendo as equações de Euler mais complexas. As equações de Burger desenvolvem descontinuidades de dados inicialmente suaves e exibem expansões dos choques não físicas (descontinuidades) se a solução de viscosidade não é usada para forçar torna-las ondas suaves. 
Muitas dos métodos numéricos desenvolvidos para resolver as equações de Burger podem ser estendidas para tratar problemas uni ou multidimensionais das equações de Euler para gases dinâmicos.

Na Eq. (3.48) considera-se a equação de Hamilton-Jacobi em $1 D$.

$$
\phi_{t}+H\left(\phi_{x}\right)=0
$$

Analisando em $\phi_{x}$ a Eq. (3.48) torna-se a Eq. (3.49).

$$
\left(\phi_{x}\right)_{t}+H\left(\phi_{x}\right)_{x}=0
$$

E fazendo $u=\phi_{x}$ a Eq. (3.49) fica como na Eq. (3.50), representando uma lei de conservação escalar.

$$
u_{t}+H(u)_{x}=0
$$

Em $1 D$ é possível fazer uma correspondência entre as equações de Hamilton-Jacobi e as leis de conservação. A solução $u$ para a lei de conservação é a derivada da solução $\phi$ para a equação Hamilton-Jacobi. Reciprocamente, a solução $\phi$ para a equação de Hamilton-Jacobi é a integral da solução $u$ para a lei de conservação. É possível levantar uma série de características relevantes. Na descontinuidade na primeira derivada, a solução da equação de Hamilton-Jacobi pode ser desenvolvida mesmo se os dados inicialmente suaves. Além disso, as soluções para as equações de Hamilton-Jacobi não podem ser geradas desenvolvendo uma descontinuidade, a não ser que a lei de conservação correspondente desenvolva uma função delta. Assim, a solução da Eq. (3.44) é sempre contínua. A lei de conservação pode ter soluções não únicas, condições de entropia são necessárias para assinalar soluções relevantes.

\subsubsection{DISCRETIZAÇÃO NUMÉRICA}

Uma discretização temporal de Euler adiantada pode ser escrita como na Eq. (3.51). E $\widehat{H}\left(\phi_{x}^{-}, \phi_{x}^{+} ; \phi_{y}^{-}, \phi_{y}^{+} ; \phi_{z}^{-}, \phi_{z}^{+}\right)$é a aproximação numérica de $H\left(\phi_{x}, \phi_{y}, \phi_{z}\right)$. 


$$
\frac{\phi^{n+1}+\phi^{n}}{\Delta t}+\widehat{H}^{n}\left(\phi_{x}^{-}, \phi_{x}^{+} ; \phi_{y}^{-}, \phi_{y}^{+} ; \phi_{z}^{-}, \phi_{z}^{+}\right)=0
$$

A função $\widehat{H}$ é chamada de Hamiltoniana numérica, precisa ser consistente no sentido que $\widehat{H}\left(\phi_{x}^{-}, \phi_{x}^{+} ; \phi_{y}^{-}, \phi_{y}^{+} ; \phi_{z}^{-}, \phi_{z}^{+}\right)=H\left(\phi_{x}, \phi_{y}, \phi_{z}\right)$.

Analisando-se $H\left(\phi_{x}, \phi_{y}\right)$, um esquema é considerado monotônico (monotone) quando $\phi^{n+1}$ definido na Eq. (3.51) é uma função não decrescente em todos os $\phi^{n}$.

Crandall e Lion (1983) provaram que esses esquemas convergem para a solução correta, embora eles sejam apenas precisões de primeira ordem. Com a associação da Hamiltoniana numérica a esquemas monotônicos importantes resultados são obtidos.

Como já foi discutido anteriormente, a discretização temporal de Euler adiantada da Eq. (3.51) pode ser estendida para TVD Runge Kutta de alta ordem. A condição CFL para a Eq. (3.51) é dada pela Eq. (3.52). Em que $H_{1}, H_{2}$ e $H_{3}$ são as derivadas parciais de $H$ com relação a $\phi_{x}, \phi_{y}$ e $\phi_{z}$, respectivamente.

$$
\Delta t \max \left\{\frac{\left|H_{1}\right|}{\Delta x}+\frac{\left|H_{2}\right|}{\Delta y}+\frac{\left|H_{3}\right|}{\Delta z}\right\}<1
$$

\subsection{ESQUEMAS LAX-FRIEDRICHS}

A primeira aproximação para $\widehat{H}$ a ser considerada é o esquema Lax-Friedrichs (LF) dado na Eq. (3.53).

$$
\widehat{H}=H\left(\frac{\phi_{x}^{-}+\phi_{x}^{+}}{2}, \frac{\phi_{y}^{-}+\phi_{y}^{+}}{2}\right)-\alpha^{x}\left(\frac{\phi_{x}^{+}-\phi_{x}^{-}}{2}\right)-\alpha^{y}\left(\frac{\phi_{y}^{+}-\phi_{y}^{-}}{2}\right)
$$

Onde $\alpha^{x}$ e $\alpha^{y}$ são coeficientes dissipativos que controlam a quantidade de viscosidade numérica. Esses coeficientes de dissipação são apresentados na Eq. (3.54) e (3.55). Sua escolha é baseada nas derivadas parciais de $H$.

$$
\alpha^{x}=\max \left|H_{1}\left(\phi_{x}, \phi_{y}\right)\right|
$$




$$
\alpha^{y}=\max \left|H_{1}\left(\phi_{x}, \phi_{y}\right)\right|
$$

A escolha dos coeficientes de dissipação da Eq. (3.54) e (3.55) pode ser bastante sutil. Em uma implementação tradicional do esquema LF, o máximo é escolhido ao longo de todo domínio computacional. Primeiro, os valores de máximo e mínimo de $\phi_{x}$ são identificados considerando todos os valores de $\phi_{x}^{-}$e $\phi_{x}^{+}$em um eixo cartesiano. Em seguida identifica-se o intervalo $I^{x}=\min \left[\phi_{x}^{\min }, \phi_{x}^{\max }\right]$. Um procedimento similar é feito para definir $I^{y}=$ $\min \left[\phi_{y}^{\min }, \phi_{y}^{\max }\right]$. Os coeficientes $\alpha^{x}$ e $\alpha^{y}$ são o conjunto de máximos valores possíveis de $\left|H_{1}\left(\phi_{x}, \phi_{y}\right)\right|$ e $\left|H_{2}\left(\phi_{x}, \phi_{y}\right)\right|$, respectivamente, com $\phi_{x} \in I^{x}$ e $\phi_{y} \in I^{y}$.

Para a Eq. (3.2) $H_{1}=u$ e $H_{2}=v$ são independentes de $\phi_{x}$ e $\phi_{y}$, então $\alpha^{x}$ e $\alpha^{y}$ são definidos como $|u|$ e $|y|$ no eixo cartesiano.

Para a Eq. (3.30) $H_{1}=V_{n} \phi_{x} /|\nabla \phi|$ e $H_{2}=V_{N} \phi_{y} /|\nabla \phi|$, essas são as derivadas parciais somente se $V_{N}$ é independente de $\phi_{x}$ e $\phi_{y}$, isso torna os coeficientes $\alpha^{x}$ e $\alpha^{y}$ mais difíceis de serem avaliados. Um caso especial acontece quando $|\nabla \phi|=1$, simplifica-se $H_{1}=V_{n} \phi_{x}$ e $H_{2}=V_{n} \phi_{y}$, com $V_{n}$ variando espacialmente, o trabalho torna-se dificultoso. É possível considerar $V_{n}$ constante, os valores de $\left|H_{1}\right|$ e $\left|H_{2}\right|$ são determinados apenas com os pontos finais de $I_{x}$ e $I_{y}$, respectivamente.

Na determinação dos valores de $\alpha^{x}$ e $\alpha^{y}$, chegar-se a valores mais elevados do que o ideal, o que aumenta a dissipação numérica.

Aumentar $\alpha$ eleva a dissipação artificial, diminuindo a qualidade da solução. É benéfico escolher $\alpha$ tão pequeno quanto possível, sem a indução de oscilações ou outros fenômenos não físicos na solução.

Em regiões onde a velocidade é elevada, valores elevados de $\alpha$ representam boas soluções, entretanto, nas regiões onde as velocidades são pequenas, os valores elevados para $\alpha$ produzem dissipação numérica.

Para a redução dessa dissipação, emprega-se o esquema chamado de Stencil LaxFriedrichs (SLF), este determina o coeficiente de dissipação usando apenas a vizinhança dos pontos que são parte do estêncil usado ara determinar $\phi^{x}$ e $\phi^{y}$.

O esquema Local Lax-Friendrichs (LLF) proposto por Shu e Osher (1989) não observa ponto na vizinhança do grid quando calcula os coeficientes de dissipação em uma dada direção. Eles interpretaram que $\alpha^{x}$ é determinado em casa ponto do grid usando apenas os valores de $\phi_{x}^{-}$e $\phi_{x}^{+}$para se chegar ao intervalo $I^{x}$. O intervalo $I^{y}$ é obtido de forma análoga. 
Osher e Shu (1989) também propuseram o esquema Local Local Lax-Friedrichs (LLLF) com ainda menos dissipação numérica. Em casa ponto do grid $I^{x}$ é determinado usando valores de $\phi_{x}^{-}+\phi_{x}^{+}$. I $I^{y}$ é determinado usando valores de $\phi_{y}^{-}+\phi_{y}^{+}$. Ambos os intervalos são usados para determinar os valores de $\alpha^{x}$ e $\alpha^{y}$. Quando $H$ é separável, $H\left(\phi_{x}, \phi_{y}\right)=H^{x}\left(\phi_{x}\right)+H^{y}\left(\phi_{y}\right)$, o esquema LLLF se reduz ao esquema LLF, desde que $\alpha^{x}$ e $\alpha^{y}$ sejam independentes de $\phi_{x}$ e $\phi_{y}$, respectivamente. Caso $H$ não seja separável, os esquemas LLLF e LLF são totalmente distintos.

Usualmente, o esquema LLF trabalha melhor do que qualquer outra opção. Os esquemas LF e SLF são usualmente dissipativos, enquanto o esquema LLLF não é dissipativo suficiente para superar os problemas introduzidos usando aproximações médias para $\phi_{x}$ e $\phi_{y}$ na avaliação de $H$ na Eq. (3.53). Nota-se que o esquema LLF é do tipo monotônico.

\subsection{ESQUEMA ROE-FIX}

Como já foi abordado, a escolha da quantidade apropriada de dissipação artificial para avaliar $H$ na Eq. (3.53) é um processo complexo. Para as leis de conservação, Shu e Osher (1989) propuseram usando o método upwind de Roe com uma correção de entropia em pontos sônicos onde a violação de entropia poderia ser formada. A dissipação proveniente da correção de entropia LLF força a expansão dos choques em ondas de rarefação contínuas. Assim, o esquema Roe-Fix (RF) pode ser escrito para as equações de Hamilton-Jacobi na forma da Eq. (3.56).

$$
\widehat{H}=H\left(\phi_{x}^{\star}, \phi_{y}^{\star}\right)-\alpha^{x}\left(\frac{\phi_{x}^{+}-\phi_{x}^{-}}{2}\right)-\alpha^{y}\left(\frac{\phi_{y}^{+}-\phi_{y}^{-}}{2}\right)
$$

Onde $\alpha^{x}$ e $\alpha^{y}$ são identicamente iguais à zero para remover a dissipação numérica do método. No esquema RF, $I^{x}$ e $I^{y}$ são inicialmente determinados usando apenas o valor nodal pra $\phi_{\bar{x}}^{ \pm}$e $\phi_{\bar{y}}^{ \pm}$como no esquema LLLF. Para estimar o potencial para upwind, olha-se nas derivadas parciais $H_{1}$ e $H_{2}$. Se $H_{1}\left(\phi_{x}, \phi_{y}\right)$ tem o mesmo sinal para todo $\phi_{x} \in I^{x}$ e todo $\phi_{y} \in I^{y}$, conhece-se o caminho por onde flui a informação e pode ser aplicado o esquema upwind. O mesmo acontece para $H_{2}\left(\phi_{x}, \phi_{y}\right)$. Se ambos $H_{1}$ e $H_{2}$ não mudarem o sinal, fixa-se 
$\alpha^{x}$ e $\alpha^{y}$ iguais à zero. Se $H_{1}>0$ a informação flui da esquerda para direita, e $\phi_{x}^{\star}=\phi_{x}^{-}$. Se $H_{1}<0, \phi_{x}^{\star}=\phi_{x}^{+}$. Analogamente, $H_{2}>0$ indica $\phi_{y}^{\star}=\phi_{y}^{-}$, e $H_{2}<0$ indica $\phi_{y}^{\star}=\phi_{y}^{+}$.

Se $H_{1}$ ou $H_{2}$ mudam de sinal, o problema encontra na vizinhança de um ponto sônico onde o autovalor é identicamente igual zero. Isso significa que um potenciial dificulta com soluções não únicas, e dissipação artificial é necessária para conseguir soluções viscosas fisicamente corretas. Essa dissipação é obtida usando o esquema LFF. Se há um ponto sônico em apenas uma direção ( $x$ ou $y$ ), não é conveniente utilizar o amortecimento em ambas às direções. Assim, observa-se somente para pontos sônicos em cada direção e utiliza-se amortecimento apenas onde for necessário. Isso é feito usando $I^{x}$ e $I^{y}$ como definidos no esquema LLF.

Se $H_{1}\left(\phi_{x}, \phi_{y}\right)$ não muda de sinal para todo $\phi_{x} \in I_{L L F}^{x}$ e todo $\phi_{y} \in I_{L L F}^{y}$, $\phi_{x}^{\star}$ é igual a $\phi_{x}^{-}$ou $\phi_{x}^{+}$dependendo do sinal de $H_{1}$. Com $\alpha^{x}$ igual a zero remove-se a dissipação artificial na direção $x$. Ao mesmo tempo, isso significa que o ponto sônico poderia ocorrer em $\mathrm{H}_{2}$, então se aplica o esquema LLF na direção $y$, fazendo $\phi_{y}^{\star}=\left(\phi_{y}^{-}+\phi_{y}^{+}\right) / 2$ e escolhendo $\alpha^{y}$ como regido pelo esquema LLF.

Um algoritmo similar é executado se $H_{2}\left(\phi_{x}, \phi_{y}\right)$ não muda de sinal para todo $\phi_{x} \in I_{L L F}^{x}$ e todo $\phi_{y} \in I_{L L F}^{y}$. Define-se $\phi_{y}^{\star}$ como $\phi_{y}^{-}$ou $\phi_{y}^{+}$, dependendo de sinal de $H_{2} \cdot \alpha^{y}$ é zero e o esquema LLF é aplicado na direção $x$, fazendo $\phi_{x}^{\star}=\left(\phi_{x}^{-}+\phi_{x}^{+}\right) / 2$ enquanto $\alpha^{x}$ for regido pelo esquema LLF.

Caso ambos, $H_{1}$ e $H_{2}$, mudarem de sinal, tem-se pontos sônicos nas duas direções e o procedimento utilizado é o padrão do esquema LLF.

Com o esquema RF, upwind na direção $x$ dita podem ser empregados $\phi_{x}^{-}$ou $\phi_{x}^{+}$, porém não ambos. Similarmente, upwind na direção $y$ utiliza $\phi_{y}^{-}$ou $\phi_{y}^{+}$, mas não ambos. Desde a avaliação de $\phi_{\bar{x}}^{ \pm}$e $\phi_{\bar{y}}^{ \pm}$usando esquemas de alta ordem como HJ ENO ou HJ WENO é bastante custosa, e parece desperdício realizar o trabalho duas vezes. Infelizmente, uma vez não é suficiente para determinar se upwind pode ser utilizada sem computar $\phi_{x}^{ \pm}$e $\phi_{\bar{y}}^{ \pm}$. Para redução do custo computacional, pode-se calcular $\phi_{\bar{x}}^{ \pm}$e $\phi_{\bar{y}}^{ \pm}$através das diferenças adiantadas e atrasadas. Essas aproximações mais simples decidem a utilização do esquema LLF ou upwinding.

\subsection{ESQUEMA GODUNOV}


Godunov (1959) propôs um método numérico que fornece a solução exata para o problema de Riemann para leis de conservação em $1 D$, com partes constantes nos dados iniciais. A formulação Hamilton-Jacobi multidimensional desse esquema é escrita como na Eq. (3.57).

$$
\widehat{H}=\operatorname{ext}_{x} \operatorname{ext}_{y} H\left(\phi_{x}, \phi_{y}\right)
$$

Esta foi enunciada por Bardi e Osher (1991). É um esquema monotônico (monotone) canônico. Definindo os intervalos $I^{x}$ e $I^{y}$ no LLLF usando apenas valores de $\phi_{\bar{x}}^{ \pm}$e $\phi_{\bar{y}}^{ \pm}$nos nós do grid considerados. Se $\phi_{x}^{-}<\phi_{x}^{+}$, então $e x t_{x} H$ leva o mínimo valor de $H$ para todo $\phi_{x} \in I^{x}$. Se $\phi_{x}^{-}>\phi_{x}^{+}$, então $e x t_{x} H$ leva o máximo valor de $H$ para todo $\phi_{x} \in I^{x}$. Por outro lado, se $\phi_{x}^{-}=\phi_{x}^{+}$, então $\operatorname{ext}_{x} H$ simplesmente se conecta $\phi_{x}^{-}\left(=\phi_{x}^{+}\right)$em $H$ para $\phi_{x}$. Analogamente, se $\phi_{y}^{-}<\phi_{y}^{+}$, então $e x t_{y} H$ leva o mínimo valor de $H$ para todo $\phi_{y} \in I^{y}$. Se $\phi_{y}^{-}>\phi_{y}^{+}$, então $\operatorname{ext}_{y} H$ leva o máximo valor de $H$ para todo $\phi_{y} \in I^{y}$. Por outro lado, se $\phi_{y}^{-}=\phi_{y}^{+}$, então $e x t_{y} H$ simplesmente se conecta $\phi_{y}^{-}\left(=\phi_{y}^{+}\right)$em $H$ para $\phi_{y}$. Em geral ext $t_{x} e x t_{y} H \neq e x t_{y} e x t_{x} H$, então diferentes versões do esquema de Godunov são obtidas dependendo da ordem das operações. Em muitos casos, incluindo quando $H$ é separável, ext $t_{x} e x t_{y} H=e x t_{y} e x t_{x} H$ o que não é um problema.

\subsection{METODOLOGIA ESCOLHIDA}

Nota-se que existem várias metodologias para a representação e a discretização do MLS. Verifica-se o elevado nível matemático para cada um dos métodos apresentados.

Para o caso de otimização topológica estudado nesse trabalho constata-se que a velocidade presente na movimentação da estrutura origina-se de um campo externo, ou seja, não há grandezas internas capazes de gerar movimento nas interfaces. Assim para a evolução durante o processo de otimização escolhe-se o método diferença upwind apresentado no item 3.1.1.2, este possui a abordagem mais tradicional e simples apresentadas nas bibliografias e é suficiente para as aplicações tratadas.

Anteriormente ao acoplamento do MLS ao MEC, optou-se por implementar e testar separadamente o método diferença upwind. Os itens 3.2.1 e 3.2.2 ilustram a eficiência do método para evolução de curvas e superfícies. 


\subsubsection{EXEMPLO 1}

Tradicionalmente, as bibliografias apresentam a Figura 1.6 como principal exemplo da função LS representando o nível zero da curva ou superfície analisada. Esse exemplo testa o caso clássico do MLS a fim de validar o algoritmo do método diferença upwind. As figuras apresentadas nessa seção foram geradas através do software GNUplot.

A Figura 3.1 contém a superfície inicial que representa um cone e observa-se no plano $x y$ as curvas de nível para a superfície, o nível zero é dado pelo círculo amarelo.

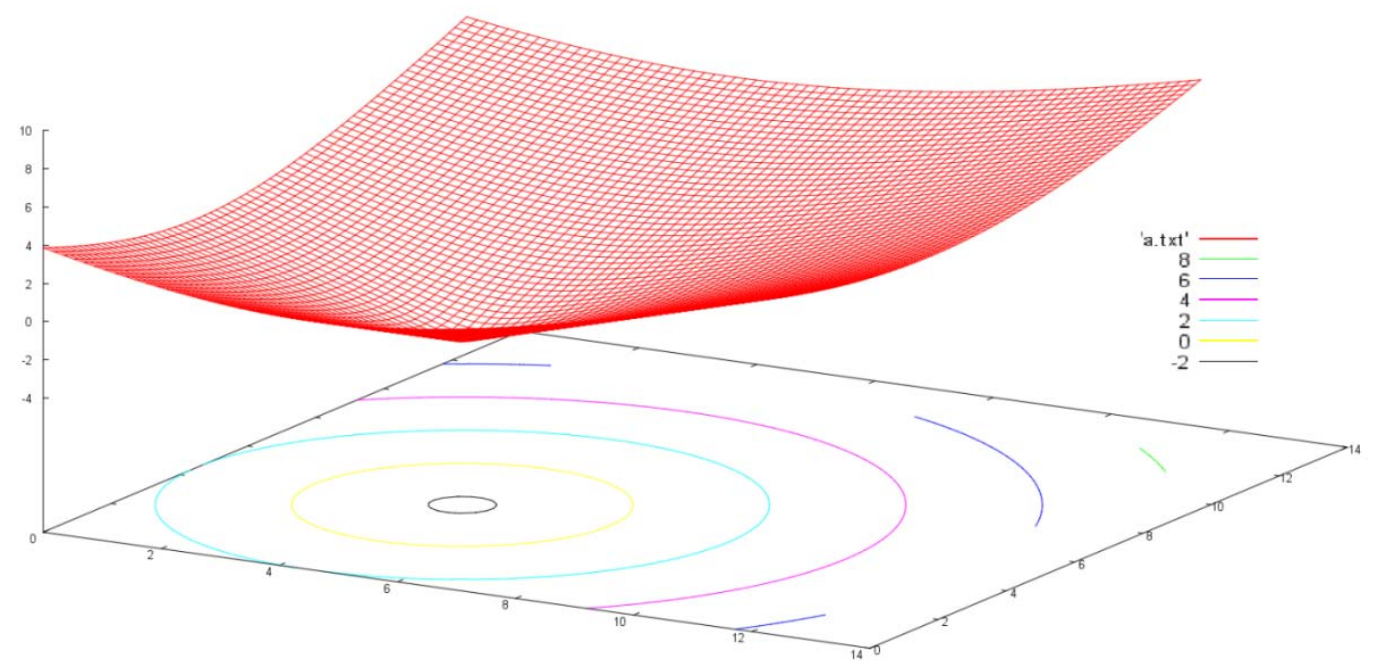

Figura 3.1 - Configuração inicial do círculo representado implicitamente.

A fim de verificar a eficiência do método diferença upwind, aplicam-se velocidades arbitrárias ao mesmo. Define-se o grid Euleriano fixo na origem dos eixos coordenados, com $72 x 72$ pontos, $\Delta x$ e $\Delta y$ iguais a $0,175 m$ e $\Delta t$ fictício igual a 0,005 .

Na Figura 3.2 compara-se a figura inicial com a figura final após 100 evoluções. Nota-se que há a movimentação das curvas de nível, a nova superfície está sobreposta à superfície inicial da Figura 3.1, assim observa-se que as novas curvas de nível aparecem com uma pequena distância para o interior das curvas de nível iniciais.

Apesar da pequena movimentação verifica-se que o método diferença upwind consegue captar os resultados apresentados pela bibliografia. 


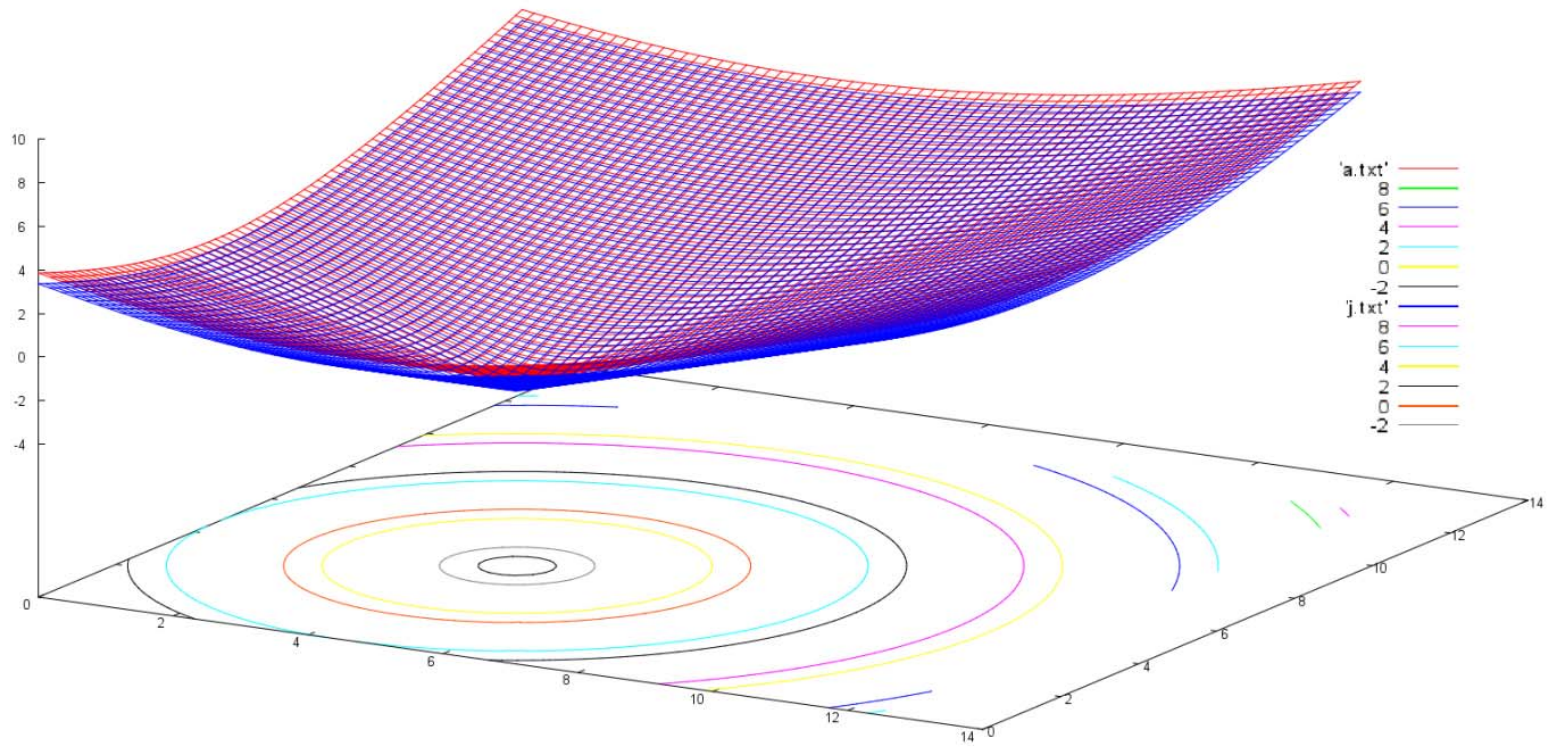

Figura 3.2 - Movimentação do círculo através do método diferença upwind.

\subsubsection{EXEMPLO 2}

O exemplo 2 testa a evolução de curvas e superfícies com maior complexidade. A Figura 3.3 contém a superfície inicial que representa a flor e observa-se no plano $x y$ as curvas de nível para a superfície, o nível zero é dado pela cor rosa.

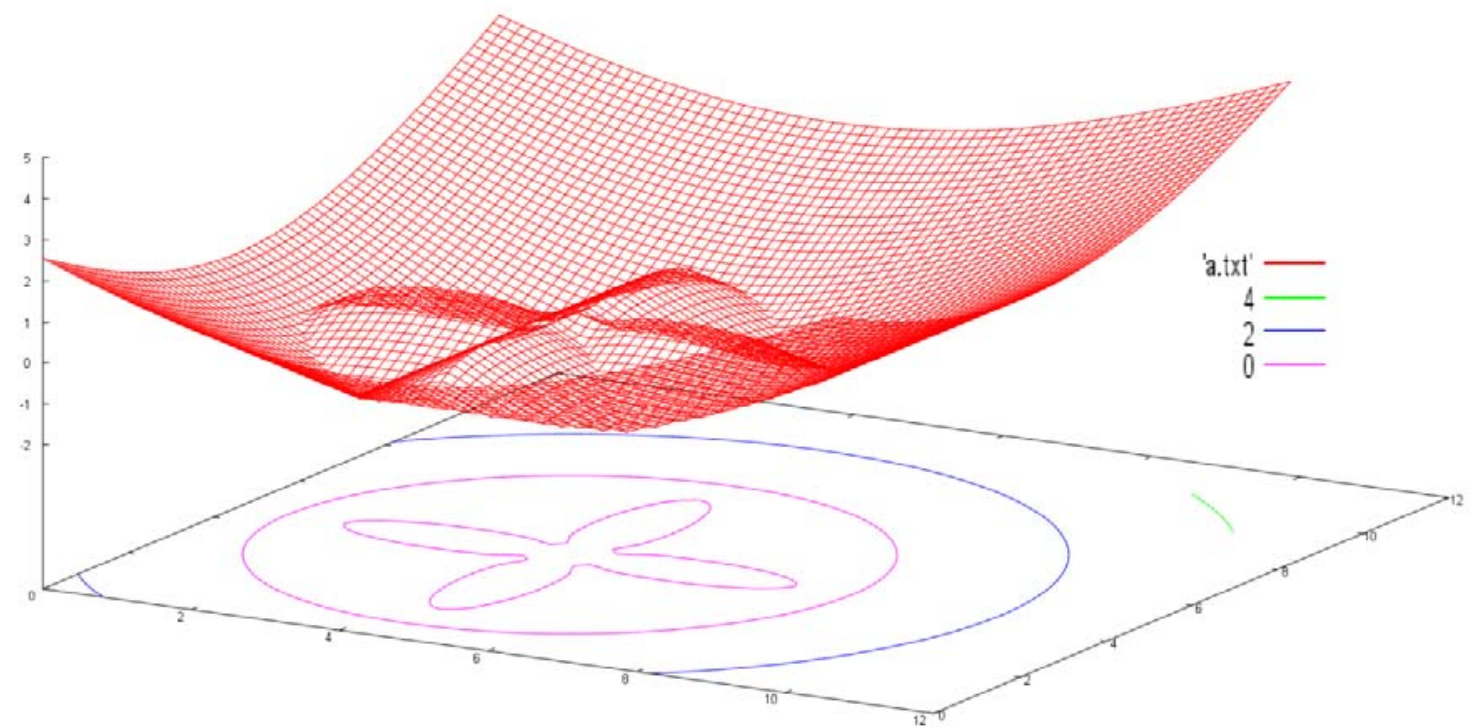

Figura 3.3 - Configuração inicial da flor representada implicitamente.

A fim de verificar a eficiência do método diferença upwind para curva de maior complexidade, aplicam-se velocidades arbitrárias ao mesmo. Define-se o grid Euleriano fixo 
na origem dos eixos coordenados, com $72 x 72$ pontos, $\Delta x$ e $\Delta y$ iguais a $0,15 \mathrm{~m}$ e $\Delta t$ fictício igual a 0,005 .

Na Figura 3.4 compara-se a figura inicial com a figura final após 100 evoluções. Nota-se que há a movimentação das curvas de nível, as superfícies azul e vermelha estão sobrepostas, observa-se que as novas curvas de nível aparecem com uma pequena distância para o interior das curvas de nível iniciais.

Apesar da pequena movimentação verifica-se que o método diferença upwind consegue captar os resultados movimentando curvas de maior complexidade.

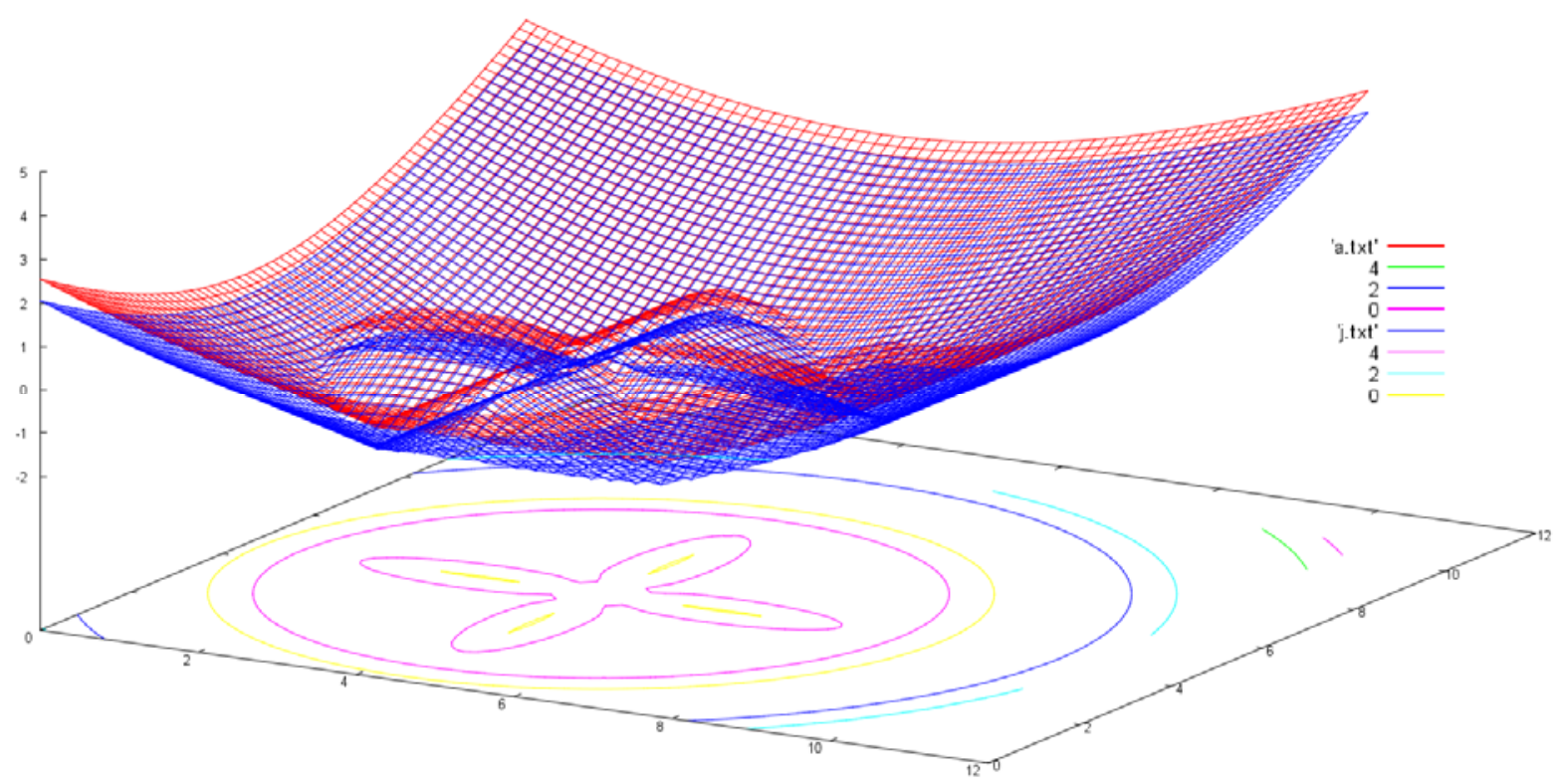

Figura 3.4 - Movimentação da flor através do método diferença upwind. 


\section{OTIMIZAÇÃO ESTRUTURAL}

Nesse capítulo mostra-se de maneira simples e sucinta os conceitos básicos presentes no processo de otimização (definição dos termos e componentes) e também os principais tipos de otimização estrutural existentes.

Segundo Secchi (2001), em uma indústria típica a busca pelo ótimo acontece em três níveis principais:

- Nível gerencial:

- Nível de projeto e especificações de equipamentos;

- Nível operacional.

A otimização estrutural aparece no contexto de otimização em nível de projeto.

Para abordar a otimização estrutural é necessário conhecer alguns conceitos básicos, a seguir apresenta-se esses conceitos.

\subsection{CONCEITOS BÁSICOS}

A formulação de problema de otimização é apresentada através dos componentes:

- Função objetivo;

- Modelo do processo;

- Restrições.

De forma geral, a função objetivo representa lucro, custo, energia, produção, distância, etc., em termos das variáveis de decisão do processo ou sistema em análise. O modelo do processo e as restrições descrevem as inter-relações entre estas variáveis.

\subsubsection{VARIÁVEIS DE PROJETO}

As variáveis de projeto são parâmetros que descrevem o projeto de um sistema ou estrutura (ARORA, 1989). Estas variáveis podem ser de natureza discreta, assumindo valores isolados dentro de um conjunto, como na Eq. (4.1).

$$
\left\{x \in X \mid x=\left(k_{1}, k_{2}, \ldots, k_{3}\right)\right\}
$$


Ou podem ser de natureza contínua, onde assumem qualquer valor dentro de um intervalo, como na Eq. (4.2).

$$
\left\{x \in X \mid k_{\text {inf }} \leq x \leq k_{\text {sup }}\right\}
$$

Se os valores especificados não satisfazem todas as restrições do problema, o projeto é dito não admissível. Quando o projeto é viável, o sistema executa corretamente todas as funções para o qual foi projetado dentro das hipóteses de análise. É importante que as variáveis sejam escolhidas de forma que sejam independentes umas em relação às outras, para evitar complicações adicionais ao problema (ARORA, 1989).

\subsubsection{FUNÇÃO OBJETIVO}

Para se chegar a um determinado ótimo existem diversos projetos viáveis, sendo alguns melhores que outros. Estabelece-se então, um critério numérico que relacione um dado conjunto de variáveis de projeto. Esse critério é denominado função objetivo (FO) ou função custo. A seleção da FO é uma etapa importante na formulação do problema de otimização.

Na otimização estrutural é usual que o funcional a ser minimizado represente o volume da estrutura. Minimizando-se o volume, otimiza-se a quantidade de material a ser gasto, que pode acarretar uma considerável diminuição nos custos com matéria-prima e produção da estrutura.

\subsubsection{RESTRIÇÕES DE PROJETO}

Muitas vezes em um dado processo de otimização, os valores encontrados para as variáveis de projeto são absurdos ou fisicamente impossíveis, não se adequando à realidade. Por isso, é comum impor limites aos valores das variáveis para que os mesmos recebam resultados dentro de uma faixa adequada. Esses limites são chamados de restrições de projeto.

Em um projeto de estruturas, as restrições laterais são o caso mais simples, impõem-se limites superiores e inferiores para os valores admissíveis da geometria de elementos 
estruturais, custos e resistências nominais de materiais. Em casos complexos estão as restrições tecnológicas, que limitam valores para tensões, flexibilidades e rigidezes.

As restrições podem ser de desigualdade ou igualdade. As restriições de igualdade que estão sempre presentes em problemas de otimização estrutural são as equações de equilíbrio. As demais restrições geralmente aparecem na forma de desigualdades.

\subsubsection{TIPOS DE PROBLEMAS}

Autores como Sant’Anna (2002), Mosmann (2003), Mundstock (2006) tratam a otimização estrutural subdividida em 3 tipos:

- Otimização dimensional;

- Otimização de forma;

- Otimização topológica.

\subsubsection{OTIMIZAÇÃO DIMENSIONAL}

O domínio do problema é fixo. As variáveis de projeto descrevem características da estrutura (área da seção transversal, momento de inércia, etc). Busca-se a melhor distribuição de áreas, visando a minimização ou maximização da FO (peso, flexibilidade, tensão, etc), respeitando as restrições do problema (limite admissível para deslocamentos, tensões, frequências, comprimento de flambagem, etc). A Figura 4.1 ilustra a otimização dimensional, onde a área de algumas barras são otimizadas de acordo com a FO.
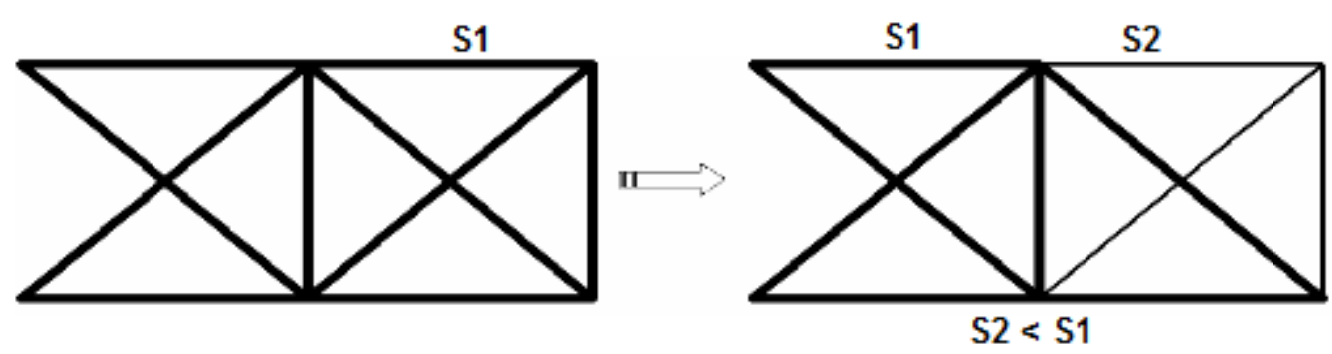

Figura 4.1 - Otimização Dimensional. Fonte: Fonseca (2008)

\subsubsection{OTIMIZAÇÃO DE FORMA}


O domínio do problema é variável, o objetivo é a determinação do domínio ótimo, ou seja, a melhor forma da estrutura. As variáveis de projeto podem ser pontos de controle do polinômio que definem o contorno da estrutura (problemas contínuos) ou as coordenadas dos pontos nodais (problemas discretos). Esse tipo de otimização é mais complexo, pois pode gerar distorções nas malhas escolhidas, levando a problemas de convergência da solução. Além das restrições usuais podem ainda ser incorporadas restrições que evitem soluções hipostáticas. A Figura 4.2 mostra a otimização de forma, as barras da estrutura são rearranjadas para a melhor configuração de acordo com a otimização da FO.
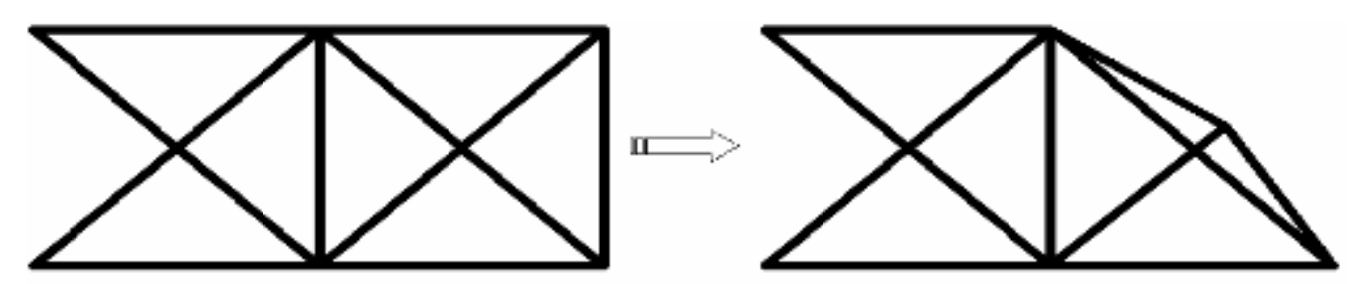

Figura 4.2 - Otimização de Forma. Fonte: Fonseca (2008).

\subsubsection{OTIMIZAÇÃO TOPOLÓGICA}

Busca-se a melhor distribuição de material no domínio do projeto. Nesse caso, a variável de projeto está associada à distribuição de material. Para problemas contínuos tem-se inserção de furos e reforço de pontos. No caso das estruturas discretas, determina-se a presença ou ausência de determinados elementos. Nesse tipo de otimização, é necessária a verificação de estabilidade física e numérica do problema, pois a ausência de determinados elementos torna a estrutura hipostática. A Figura 4.3 ilustra a otimização topológica, a estrutura passa a ter apenas as barras que garantam a resistência mínima para suportar os esforços aplicados.
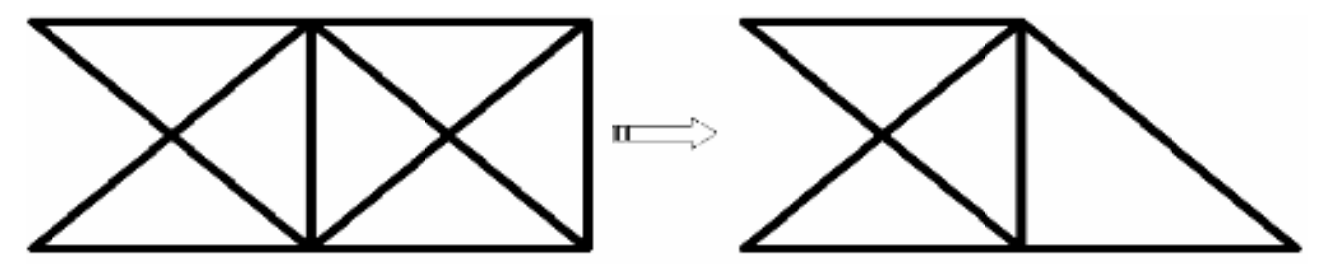

Figura 4.3 - Otimização Topológica. Fonte: Fonseca (2008). 
Nessa dissertação é empregado o conceito de otimização topológica. Visto que esse modelo apresenta como principal vantagem a modificação no domínio da estrutura ou componente estrutural a ser otimizado.

Além dos três tipos de otimização estrutural citados, alguns autores como Fonseca (2008) trabalham com mais dois tipos de otimização para as estruturas:

- Otimização simultânea;

- Otimização com multiobjetivos.

\subsubsection{OTIMIZAÇÃO SIMULTÂNEA}

O domínio do problema é variável, pois o objetivo é determinar o domínio ótimo e a melhor distribuição de áreas. É a junção da otimização dimensional à otimização de forma. As variáveis de projeto são as coordenadas dos pontos nodais (problemas discretos) e as áreas das seções transversais dos elementos. Além das restrições usuais, consideram-se as restrições que evitem soluções hipostáticas. A Figura 4.4 ilustra a otimização simultânea, onde acontece a mudança na geometria de algumas barras e também a reconfiguração para seu posicionamento ótimo.
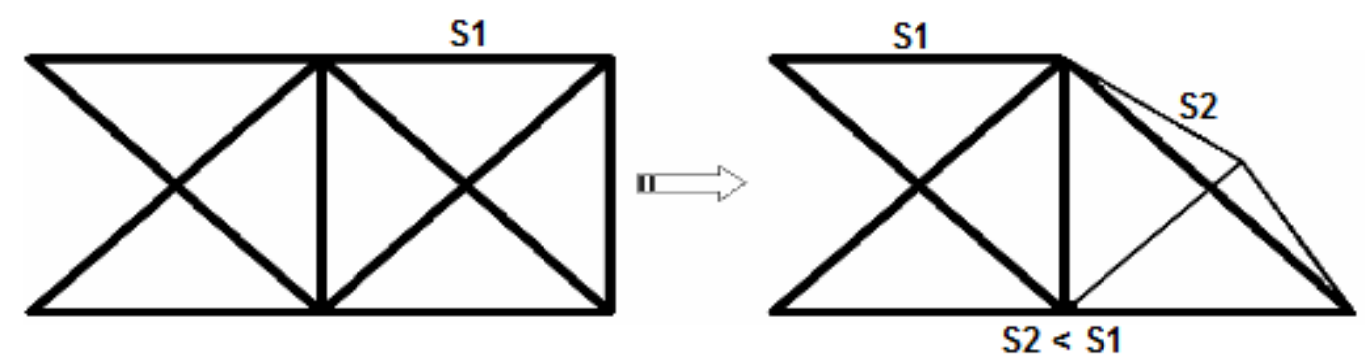

Figura 4.4 - Otimização Simultânea. Fonte: Fonseca (2008).

\subsubsection{OTIMIZAÇÃO COM MULTIOBJETIVOS}

Problemas de otimização podem conter uma ou mais FO. A solução de problemas com duas ou mais funções é chamada otimização com multi-objetivos. Quanto maior o número de FO, maior a dificuldade de se chegar a solução. A fim de eliminar esse problema, identifica-se a variável mais relevante para se tornar a FO, as demais variáveiis transformam-se em restrições. 


\section{OTIMIZAÇÃO TOPOLÓGICA ATRAVÉS DO ACOPLAMENTO MEC-MLS}

Os capítulos anteriores deram um panorama geral da evolução no tempo, vantagens e algumas particularidades de cada método a ser empregado.

Por meio da Figura 5.1, é possível relacionar os temas empregados de acordo com sua evolução no tempo até o presente trabalho.

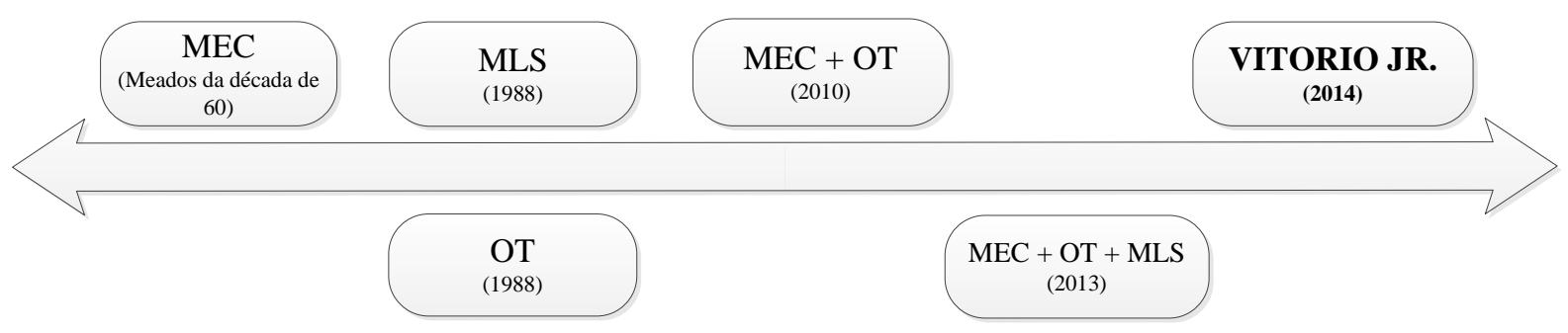

Figura 5.1 - Linha do tempo para os assuntos estudados.

Os estudos do MEC tiveram maior relevância a partir de meados dos anos 60. Nesse período a otimização já era estudada em meio acadêmico. Em 1988, Osher e Sethian propuseram o MLS como forma de representar curvas e superfícies implicitamente. No mesmo ano, Bendsøe e Kikuchi difundiram a técnica de OT através de métodos de homogeneização, estudos nessa área ganharam representatividade utilizando essa abordagem para modelos mecânicos calculados através do MEF. No final da década de 90, alguns pesquisadores investiram em acoplar a OT a modelos calculados com o MEC. No ano de 2003, diversas obras foram publicadas mostrando artifícios para a resolução do problema de OT para modelos mecânicos calculados através do MEC. Durante esse tempo o MLS desenvolveu-se paralelamente para solucionar problemas em diversas aplicações, a OT foi uma das aplicações mais promissoras encontradas para o método, a curva de nível dada pelo MLS representa a estrutura ótima. Os primeiros modelos de OT empregando o MLS foram implementados considerando o acoplamento com o MEF. Apesar dos avanços, o acoplamento MEF-MLS apresentou diversos problemas e limitações, principalmente, em função da malha utilizada. Após o ano de 2010, os estudos foram dirigidos para o acoplamento MEC-MLS.

Quando os assuntos são tratados separadamente, nota-se que existem campos onde os mesmos são reconhecidamente mais eficazes do que outras abordagens. Apesar do MEC possuir muitos anos de uso, o seu acoplamento ao MLS para cálculo da OT é atual, este se 
mostra eficiente e viável de ser implementado, contudo, ainda há melhorias e descobertas a serem realizadas.

No cenário nacional poucos pesquisadores tem estudado o MLS, como Napolitano (2004) no campo da física com a definição da forma ótima de cristais e Emmendoerfer Jr. (2011) que resolve o problema de otimização estrutural com acoplamento MEF-MLS. Após vasta pesquisa na área, acredita-se que o Departamento de Engenharia de Estruturas SETEESC/USP seja pioneiro no Brasil com a introdução da linha pesquisa em OT utilizando acoplamento MEC-MLS.

\subsection{VISÃO GERAL DO ACOPLAMENTO MEC-MLS}

A proposta desse trabalho é desenvolver uma formulação constituída pelo acoplamento do MEC ao MLS, a fim de definir a topologia ótima de uma estrutura ou componente estrutural. A dissertação iniciou-se com estudos das formulações do MEC, da OT e do MLS, a fim de verificar os possíveis pontos de intersecção entre os métodos.

Analisando a abordagem de acoplamento do MEF-MLS, observa-se que a formulação do MLS é inserida diretamente nas equações que regem o problema mecânico solucionado pelo MEF. Apesar de ser iterativo, o problema é resolvido de forma única, o cálculo das tensões e deformações do problema é obtido simultaneamente aos valores que representam a estrutura ótima. É necessária a análise de sensibilidade para a atualização das variáveis e verificação da influência da mudança de forma no projeto. O processo é realizado até que todas as variáveis atendam aos valores das restrições, com tensões e deformações adequadas. Emmendoerfer Jr. (2011) apresenta esse procedimento em seu trabalho.

Tentou-se de forma análoga interferir na formulação do MEC e gerar o sistema final que fornecesse tensões, deformações e valores de coordenadas para a nova estrutura. Pesquisas minuciosas buscaram bases para a manipulação adequada da formulação, no entanto, ainda não há trabalhos utilizando a abordagem de interferir diretamente no equacionamento do MEC para a determinção da geometria ótima através do MLS. Verificouse que a ligação entre os métodos realizada por Emmendoerfer Jr. (2011) para o MEF não poderia ser realizada de maneira similar para o MEC no tempo disponível para conclusão do mestrado. 
Nas bibliografias internacionais disponíveis realiza-se o acoplamento de fronteira entre o MEC e o MLS, o problema é tratado com a utilização de uma malha Euleriana responsável por auxiliar o processo de mudança de geometria da estrutura.

Primeiramente, reproduziu-se o algoritmo proposto por Yamada et al. (2013). Eles determinam a OT de estruturas em 3D através do acoplamento MEC-MLS. A função LS controla o contorno da estrutura. As condições de contorno são impostas explicitamente e variam ao longo do contorno. Eles propõem a existência de um problema adjunto que juntamente ao problema real é parte do funcional a ser otimizado. A parcela de regularização contendo a função LS e as restrições de volume também fazem parte do funcional. A análise de sensibilidade é realizada para atualização da função LS e dos multiplicadores de Lagrange presentes. O processo é repetido até que as restrições sejam atendidas e os valores para a função LS sejam praticamente constantes de uma iteração para a outra.

Apesar do êxito encontrado por Yamada et al. (2013), o presente trabalho não obteve resultados consistentes para o algoritmo reproduzido. O principais problemas enfrentados estavam relacionados a possíveis instabilidades do MLS acoplado aos problemas real e adjunto, e a complexidade da derivada topológica. Além disso, a busca exaustiva de parâmetros da formulação também foram pontos de dificuldade.

Pela falta de resultados satisfatórios na implementação do algoritmo de Yamada et al. (2013), optou-se em modificar a estratégia de trabalho e seguir a metodologia desenvolvida por Ullah, Trevelyan e Matthews (2014).

Ullah et al. (2014) utilizam uma abordagem evolucionária de otimização topológica aplicada ao acoplamento MEC-MLS. Durante o processo de otimização, o método introduz furos automaticamente. O zero level set descreve as geometrias interna e externa da estrutura. O contorno é representado através da abordagem NURBS para curvas suaves na malha do MEC. Realiza-se a inserção de furos em pontos onde a tensão de von Mises esteja abaixo dos limites estabelecidos. O método proposto gera geometrias ótimas para estruturas em duas dimensões, os resultados são validados através de exemplos de referência presentes na literatura.

Reproduz-se a ideia da inserção de furos baseado no critério de tensão de von Mises, aplica-se o MLS discretizado através do método diferença upwind e realiza-se a reconstrução da estrutura por meio de um algoritmo de remalhamento. Mostra-se a seguir o equacionamento e análise da análise LS para OT de estruturas planas utilizando o MEC. 


\subsection{FORMULAÇÃO DO ACOPLAMENTO MEC-MLS}

Para se determinar a estrutura ótima necessita-se que o algoritmo proposto solucione 3 problemas:

- Problema mecânico;

- Problema de otimização;

- Problema de remalhamento.

No problema mecânico determinam-se as tensões e deslocamentos para os pontos do contorno da estrutura. O MEC necessita da discretização da estrutura por meio de nós e elementos. As condições de contorno em deslocamentos e forças de superfícies no contorno são explicitadas.

Para o problema de otimização necessita-se de uma malha Euleriana definida por um grid retangular. Para cada ponto do grid a função LS representa o domínio sob otimização, ela é definida como a distância na direção normal entre os pontos do grid e o contorno da estrutura. Calculam-se valores de $\phi(x)$ negativos para os pontos do grid internos ao contorno, valores de $\phi(x)$ positivos para pontos exteriores ao contorno e valores de $\phi(x)$ nulos para pontos coincidentes ao contorno. Assume-se que a estrutura projetada existe dentro de $D$. Assim, a função $\phi(x)$ é escrita como a Eq. (5.1), onde $\partial \Omega=\Gamma$.

$$
\left\{\begin{array}{c}
0<\phi(x) \quad \text { para } \forall x \in \Omega \backslash \partial \Omega \\
\phi(x)=0 \quad \text { para } \forall x \in \partial \Omega \\
\phi(x)<0 \quad \text { para } \forall x \in D \backslash \Omega
\end{array}\right.
$$

A imersão no grid significa que a estrutura passa ter suas coordenadas expressas como parte da malha Euleriana, assim, a inicialização da função LS é realizada e as distâncias orientadas representam as distâncias na direção normal entre os pontos do grid e o contorno da estrutura.

Na estratégia de inserção de furos, os pontos exteriores ao contorno têm tensão de von Mises nula, para os pontos interiores e pontos coincidentes ao contorno a tensão é calculada de acordo com os valores de suas tensões principais. Os furos são inseridos no interior da estrutura em pontos de mínima tensão de von Mises. Em cada análise insere-se no um furo circular centrado no ponto de mínima tensão de von Mises, o entorno desse ponto deve atender a alguns critérios de tensão estabelecidos para que o furo seja inserido. A malha de elementos de contorno é atualizada. 
O MLS é utilizado para evoluir a estrutura após a inserção dos furos. A equação LS é discretizada através do método diferença upwind e a velocidade para cada ponto do grid é calculada de acordo com o valor de tensão de von Mises. O método diferença upwind calcula as derivadas parciais da função LS em relação a $x$ e $y$, e realiza a aproximação por meio do método das diferenças finitas adiantadas ou atrasadas, esse critério é escolhido automaticamente através do sinal velocidade calculada por meio da tensão de von Mises. O intervalo de tempo utilizado pelo método é considerado fictício, o valor é parâmetro de entrada, e influencia diretamente na evolução da estrutura. Outro parâmetro importante é a quantidade de evoluções realizadas em cada iteração.

A estrutura evoluída pelo MLS necessita ser atualizada, ou seja, a malha anterior deve ser destruída e um novo número de nós e elementos deve ser calculado, para isso um algoritmo de remalhamento é desenvolvido. Consideram-se as coordenadas dos nós do grid e o valor da função LS para cada um desses pontos. O algortimo é capaz de reconhecer a quantidade de curvas presentes na estrutura (contorno exterior e contorno dos furos existentes no interior da estrutura) e encontrar o nível zero como contorno final, este é discretizado em nós e elementos de contorno para a nova análise do MEC. O processo é repetido até que a área final desejada seja atingida.

A seguir, discute-se em detalhes as partes constituintes do algoritmo de otimização desenvolvido.

\subsubsection{GEOMETRIA INICIAL DA ESTRUTURA, CARREGAMENTOS E CONDIÇÕES DE CONTORNO}

O processo inicia-se com a escolha da estrutura a ser otimizada, a estrutura inicial é arbitrária e representada através de um polígono. Como já foi dito anteriormente, é necessário o uso de uma malha Euleriana para auxiliar a movimentação do contorno até se atingir a estrutura ótima. O grid adotado é retangular e deve ser maior do que a estrutura, para que haja espaço suficiente para a movimentação da estrutura. O problema deve ser convertido, a imersão garante que a estrutura passe a ter suas coordenadas expressas em função das coordenadas presentes no grid, nesse ponto cria-se a relação direta entre as variáveis do MEC e do MLS.

A estrutura e o grid são inseridos através do arquivo de entrada do programa. Fixa-se o grid em sua origem e estipula-se a quantidade de pontos nas direções $x$ e $y$. Escolhe-se em 
seguida as medidas de passo no espaço para $x$ e $y$, ou seja, os valores de $\Delta x$ e $\Delta y$. A Figura 5.2 apresenta um exemplo de grid construído.

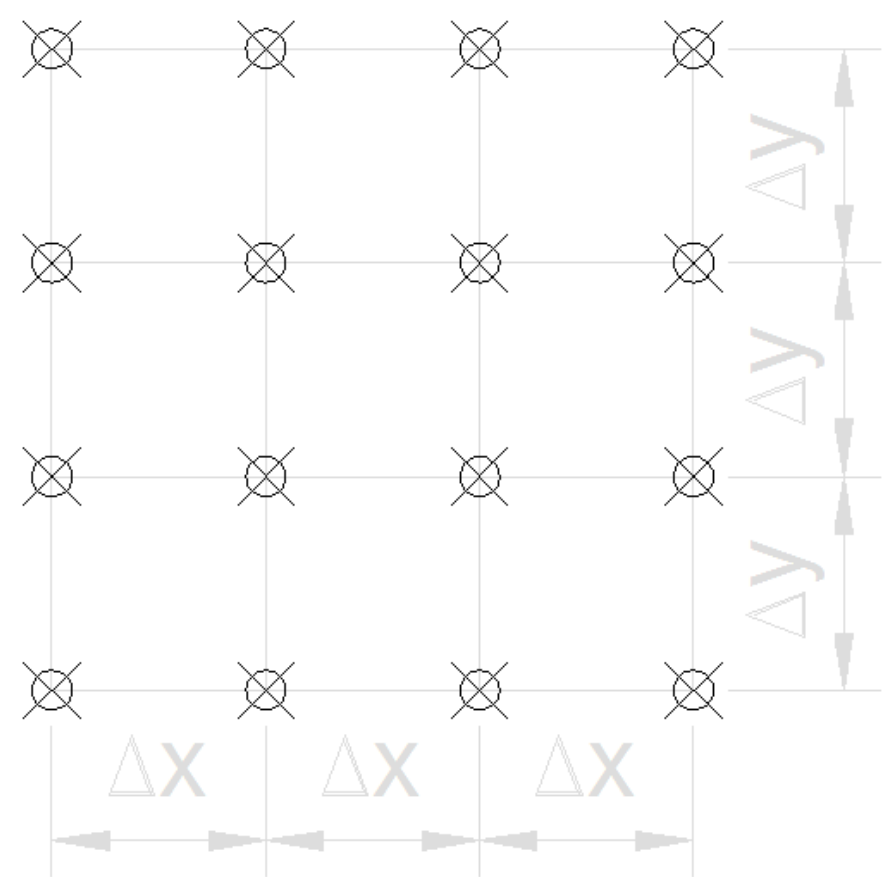

Figura 5.2 - Grid de pontos.

Também são dados de entrada as propriedades do material da estrutura, a quantidade de nós e elementos de contorno, a ordem de aproximação dos elementos, as coordenadas cartesianas dos pontos de contorno, a conectividade dos elementos e o tipo de equacionamento do MEC utilizado (singular ou hiper-singular). As condições de contorno contém os elementos com deslocamentos e carregamentos prescritos. Todos os elementos são lineares e descontínuos, essa escolha facilita o remalhamento. A Figura 5.3 contém um exemplo de estrutura imersa no grid de pontos. 


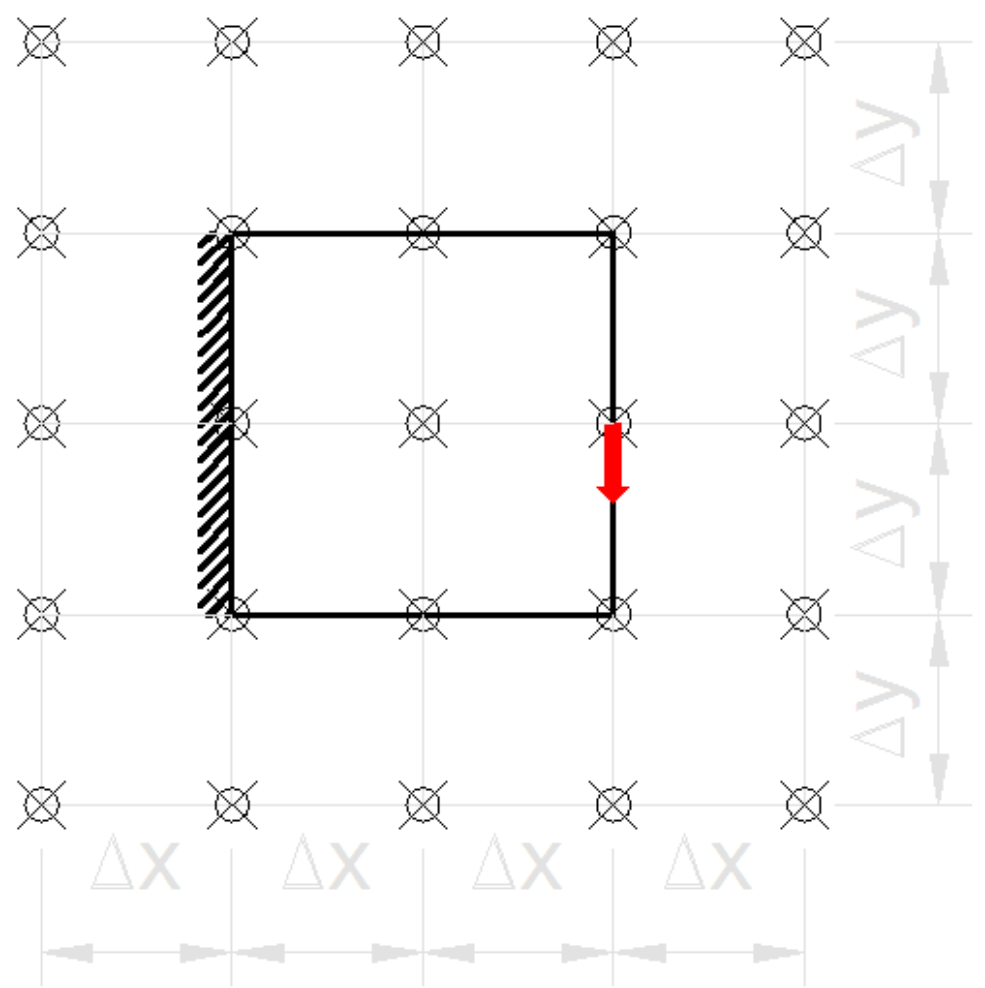

Figura 5.3 - Estrutura imersa no grid de pontos.

A quantidade de evoluções para o método diferença upwind, o volume final desejado, o tempo fictício e o fator de redução para a evolução também são dados presentes no arquivo de entrada e seus valores são apresentados no capítulo 6, onde estão presentes os exemplos que validam a formulação.

\subsubsection{ATUALIZAÇÃO DA GEOMETRIA}

Com a estrutura definida e convertida para as coordenadas do grid, o cálculo mecânico é ser executado. O algoritmo ELAST-2D desenvolvido pelo Prof. Edson Denner Leonel calcula os valores de deslocamentos e tensões do problema. Em seguida, calculam-se as tensões principais e as tensões de von Mises para cada um dos pontos do grid. A tensão de von Mises é calculada através da Eq. (5.2), onde $\sigma_{1}, \sigma_{2}$ e $\sigma_{3}$ são as tensões principais no ponto analisado.

$$
\sigma_{v m}=\frac{1}{\sqrt{2}} \sqrt{\left(\sigma_{1}-\sigma_{2}\right)^{2}+\left(\sigma_{2}-\sigma_{3}\right)^{2}+\left(\sigma_{1}-\sigma_{3}\right)^{2}}
$$


A otimização realizada baseia-se na aproximação bidirecional do material, ou seja, a adição e remoção do material acontece simultaneamente durante as iterações, tornando-se similar ao processo de otimização evolucionária citada anteriormente. O MEC calcula as tensões de von Mises em cada ponto do grid e os locais de material ineficiente é removido progressivamente. As regiões que satisfazem a Eq. (5.3) são analisadas para a remoção de material.

$$
\sigma_{v m}<R R \sigma_{\max }
$$

Onde $R R$ é o módulo de redução de material e $\sigma_{\max }$ é a máxima tensão de von Mises da estrutura inicial. Similarmente, identificam-se as regiões onde material deve ser adicionado considerando a Eq. (5.4).

$$
\sigma_{v m}>\min \left(\sigma_{\max }, \sigma_{y}\right)
$$

Sendo $\sigma_{y}$ a tensão de escoamento do material em questão.

\subsubsection{INSERÇÃO E REMOÇÃO DE MATERIAL}

Para a movimentação do contorno da estrutura é necessária a determinação da velocidade para cada um dos pontos de grid. Este cálculo é relacionado diretamente às tensões de von Mises, delimitam-se intervalos de tensão e relacionam-se os mesmos às velocidades. Os intervalos são caracterizados em função de $\sigma_{v m}, R R, \sigma_{y}$ e $\sigma_{\max }$, estes podem ser vistos na Eq. (5.5).

$$
\begin{gathered}
\sigma_{v m} \in\left[0, \sigma_{t 1}\right]: \sigma_{t 1}=0,5 R R \sigma_{\max }, \quad V N=-1 \\
\sigma_{v m} \in\left[\sigma_{t 1}, \sigma_{t 2}\right]: \sigma_{t 2}=0,9 R R \sigma_{\max }, \quad V N \in[-1 ; 0] \\
\sigma_{v m} \in\left[\sigma_{t 2}, \sigma_{t 3}\right]: \sigma_{t 3}=0,95 \min \left(\sigma_{\max }, \sigma_{y}\right), \quad V N=0 \\
\sigma_{v m} \in\left[\sigma_{t 3}, \sigma_{t 4}\right]: \sigma_{t 4}=\min \left(\sigma_{\max }, \sigma_{y}\right), \quad V N \in[0 ; 1] \\
\sigma_{v m} \in\left[\sigma_{t 4}, \infty\right]: V N=1
\end{gathered}
$$


A velocidade $V N$ negativa caracteriza o movimento na direção normal para o interior do contorno, eliminando material ineficiente. Da mesma maneira, o movimento na direção normal para o exterior do contorno representa velocidade $V N$ positiva aumentando a quantidade de material. A velocidade $V N$ nula mantém os pontos parados. É possível verificar os intervalos de tensão e as suas respectivas faixas de velocidade na Figura 5.4.

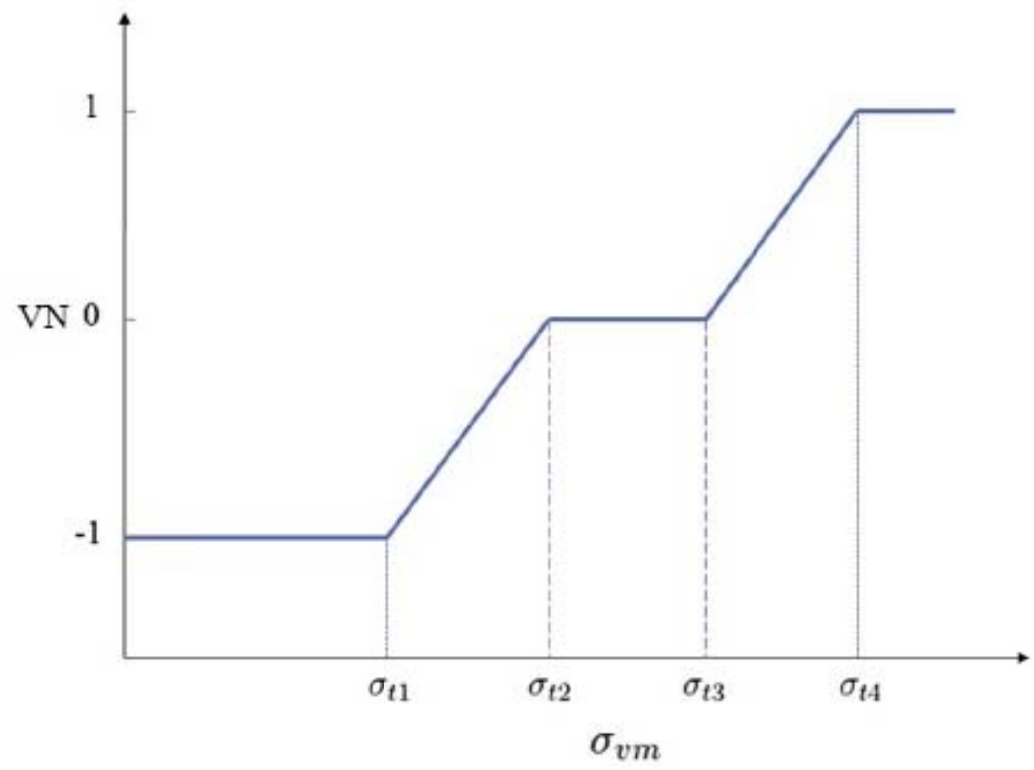

Figura 5.4 - Conversão da tensão de von Mises para velocidade. Fonte: Ullah (2014).

\subsubsection{INSERÇÃO DE FUROS}

O material ineficiente também pode ser removido através da inserção de furos em pontos de baixa tensão de von Mises no interior da estrutura. Para a inserção de furos identificam-se os pontos da estrutura que satisfaçam a Eq. (5.6).

$$
\sigma_{i} \leq R R \sigma_{t 1}
$$

Onde $\sigma_{i}$ é a tensão de von Mises no ponto. Para cada iteração escolhe-se apenas um ponto de menor tensão pra a inserção do furo. Quando o ponto é identificado analisam-se os pontos existentes no entorno do mesmo. Para que a inserção do furo seja realizada, necessitase que pelo menos 5 dos 8 pontos presentes no entorno atendam ao critério da Eq. (5.6). Caso 
isso aconteça um furo circular é inserido. O mesmo é centrado no ponto de menor tensão e seu raio é equivalente a $0,8 \Delta x$, onde $\Delta x$ é passo no espaço adotado para a contrução do grid. Esse valor é adotado para facilitar a modificação da malha de contorno e evitar que furos sejam inseridos em pontos onde possa haver contato entre os contornos, considera-se que a função de evoluir, fundir ou separar curvas é do método diferença upwind, ou seja, exclusiva do MLS. Após a inserção de cada furo circular, são acrescidos 16 nós e 8 elementos lineares descontínuos à malha de elementos de contorno. O processo é repetido até que as tensões presentes sejam todas superiores a faixa de análise da Eq. (5.6). A Figura 5.5 mostra um furo inserido no grid de pontos.

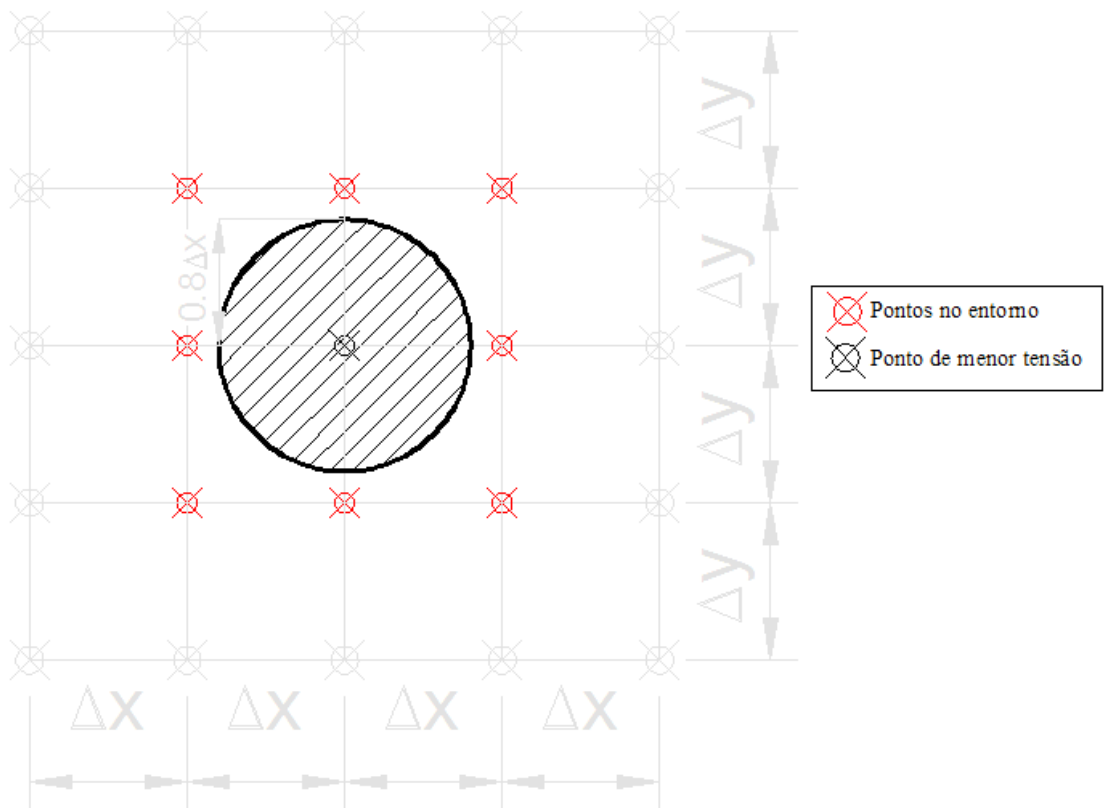

Figura 5.5 - Furo inserido no grid de pontos.

\subsubsection{INICIALIZAÇÃO DA FUNÇÃO LS}

A malha Euleriana é fundamental para a análise da otimização topológica proposta. É através dela que a estrutura evolui e atinge a sua geometria ótima. Para cada ponto do grid calcula-se a distância orientada ao contorno da estrutura, esta representa a distância na direção normal ao contorno, o sinal determina a posição do ponto em relação ao contorno do corpo. Os pontos do grid com distância nula são coincidentes ao contorno da estrutura. Os pontos com distâncias positivas são exteriores ao contorno e os pontos com distância negativa são interiores ao contorno. 


\subsubsection{ATUALIZAÇÃO DA FUNÇÃO LS}

Após o cálculo das velocidades a equação LS é atualizada através do método diferença upwind descrito no item 3.1.1.2. O intervalo de tempo fictício $(\Delta t)$ e os valores de passo no espaço $(\Delta x e \Delta y)$ adotados atendem à condição de estabilidade Courant-Friedrichs-Lewy (CFL) também descrita no item 3.1.1.2.

Em cada iteração é desejável eliminar uma quantidade superior de material, entretanto, a condição CFL controla a quantidade de material a ser removida de acordo com as carcterísticas do grid empregado.

Durante as análises, verificou-se que o método diferença upwind é bastante sensível a modicação dos parâmetros $\Delta x, \Delta y$ e $\Delta t$. Ajustou-se o tamanho do grid e o valor de tempo fictício para atender a condição CFL.

\subsubsection{ATUALIZAÇÃO DA ESTRUTURA}

A solução da equação LS modifica o valor da função LS em cada ponto do grid. Com a atualização dos valores de $\phi$, torna-se necessária a atualização das posições dos pontos onde o valor de $\phi$ é nulo. A mudança na posição do contorno torna a estrutura a ser avaliada na iteração posterior ser diferente da estrutura analisada na iteração atual.

A primeira estrutura é introduzida no programa manualmente por meio do arquivo de entrada. A quantidade desconhecida de iterações necessárias para se atingir a estrutura ótima torna inviável a introdução manual de novas estruturas. Realiza-se então o remalhamento automático.

O novo nível zero é traçado eficientemente através do algoritmo de remeshing, essa ferramenta é capaz de construir a nova estrutura. A partir das coordenadas dos pontos do grid e do valor da função LS em cada ponto, o remeshing recalcula o número de nós e elementos, enumerando e conectando-os no sentido adequado, aplicando as condições de contorno e introduzindo os dados no programa automaticamente. As condições de contorno em deslocamento e forças permanecem nos mesmos lugares independentemente da nova configuração da estrutura.

\subsubsection{CRITÉRIO DE PARADA}


O critério de parada é analisado a partir do volume da estrutura, entretanto, como o caso aqui estudado trata-se de um problema em duas dimensões, considera-se a área como critério final da convergência do algoritmo.

Calcula-se a área inicial e a cada iteração calcula-se a área restante na estrutura. A solução final é encontrada quando a área calculada é igual ao valor estipulado no arquivo de entrada, este é expresso em porcentagem da área inicial. Os valores aqui utilizados estão especificados no capítulo 6.

\subsection{FLUXOGRAMA DO PROGRAMA}

A Figura 5.6 apresenta o fluxograma do acoplamento MEC-MLS para otimização topológica de estruturas planas.

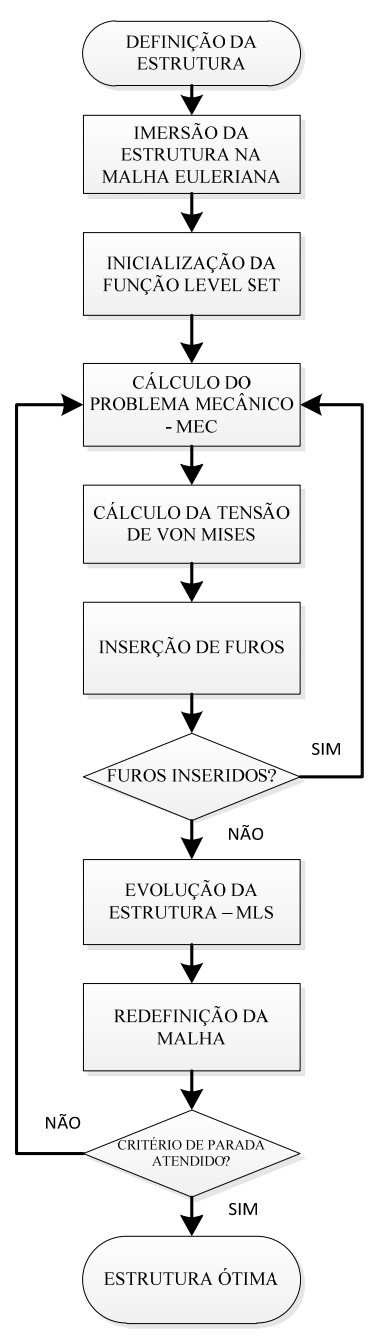

Figura 5.6 - Fluxograma do acoplamento MEC-MLS para otimização topológica de estruturas planas. 


\section{RESULTADOS}

A validade e eficiência do método de otimização proposto é testado através de um exemplo de referência encontrado no trabalho de Ullah et al. (2014). As propriedades do material utilizadas foram: módulo de elasticidade $E=210 \mathrm{GPa}$, coeficiente de Poisson $v=0,3$ e tensão de escoamento $\sigma_{y}=280 \mathrm{MPa}$.

Os exemplos 1, 2 e 3 são variações da mesma estrutura inicial, uma viga retangular engastada com razão de 1,6 entre as medidas de suas faces. Os deslocamentos da estrutura são restringidos no topo e na base de sua extremidade esquerda. No meio da extremidade direita aplica-se a força de $3 K N$. No exemplo 1 o carregamento é de tração e nos exemplos 2 e 3 o carregamento é de cisalhamento. A geometria inicial da viga pode ser vista na Figura 6.1.

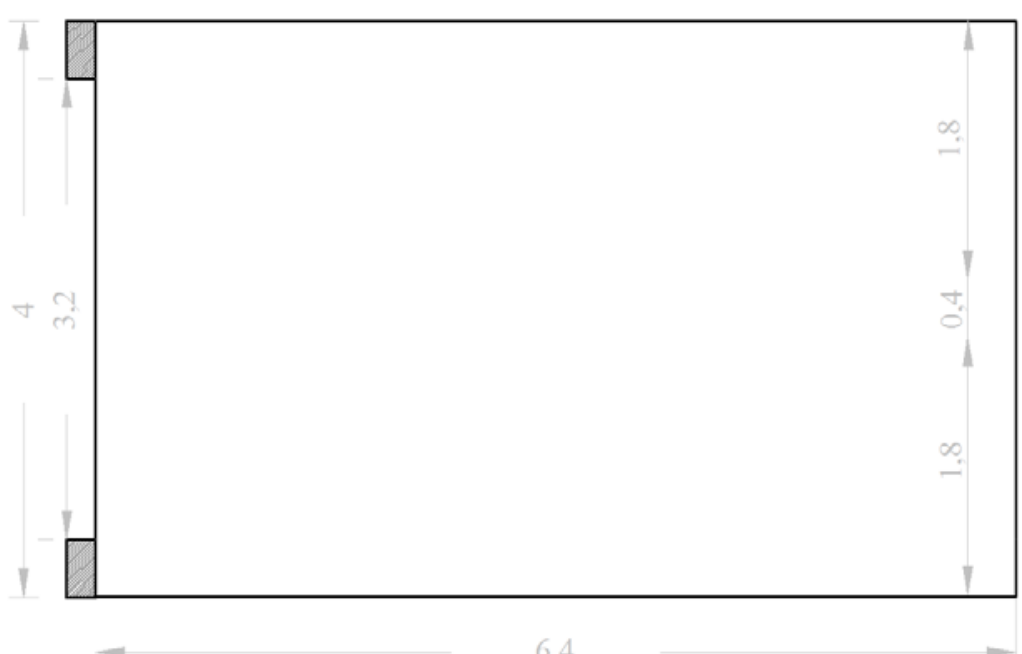

Figura 6.1 - Estrutura original.

\subsection{EXEMPLO 1}

O primeiro exemplo tem como objetivo validar a formulação proposta para o presente algoritmo de otimização topológica. Baseia-se no exemplo 3 do trabalho de Ullah et al. (2014). Trata-se de uma viga engastada submetida a um carregamento de tração. A Figura 6.2 ilustra a estrutura inicial do exemplo. 


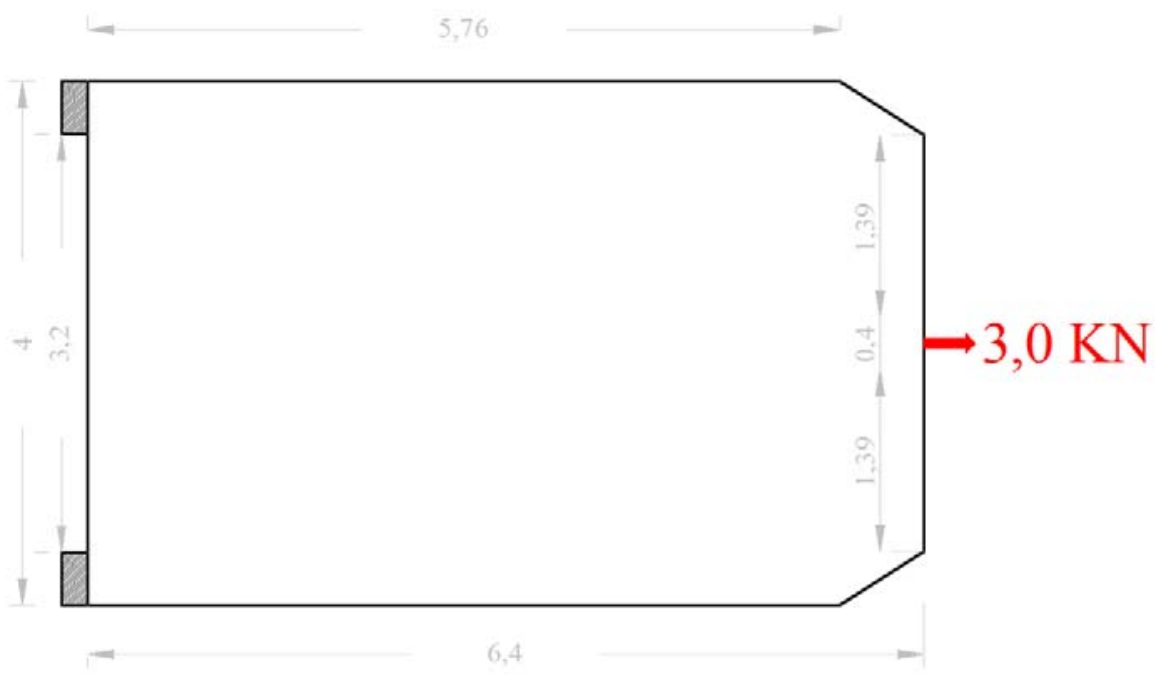

Figura 6.2 - Viga engastada submetida a tração.

O fator de redução utilizado foi de $R R=0,1$, adotaram-se 10 evoluções para cada etapa do método diferença upwind. O tempo fictício utilizado é de $\Delta t=0,003$. O grid é composto por $67 \times 45$ pontos, ou seja, 3015 pontos. Os valores de $\Delta x$ e $\Delta y$ são iguais a $0,1 \mathrm{~m}$. Optou-se pela introdução de chanfros nas quinas da extremidade direita da estrutura, o objetivo é reduzir a concentração de tensão existente nesses locais. Necessita-se que a estrutura otimizada contenha $40 \%$ da área inicial.

A Figura 6.3 mostra a evolução da estrutura até sua chegada à estrutura ótima. 

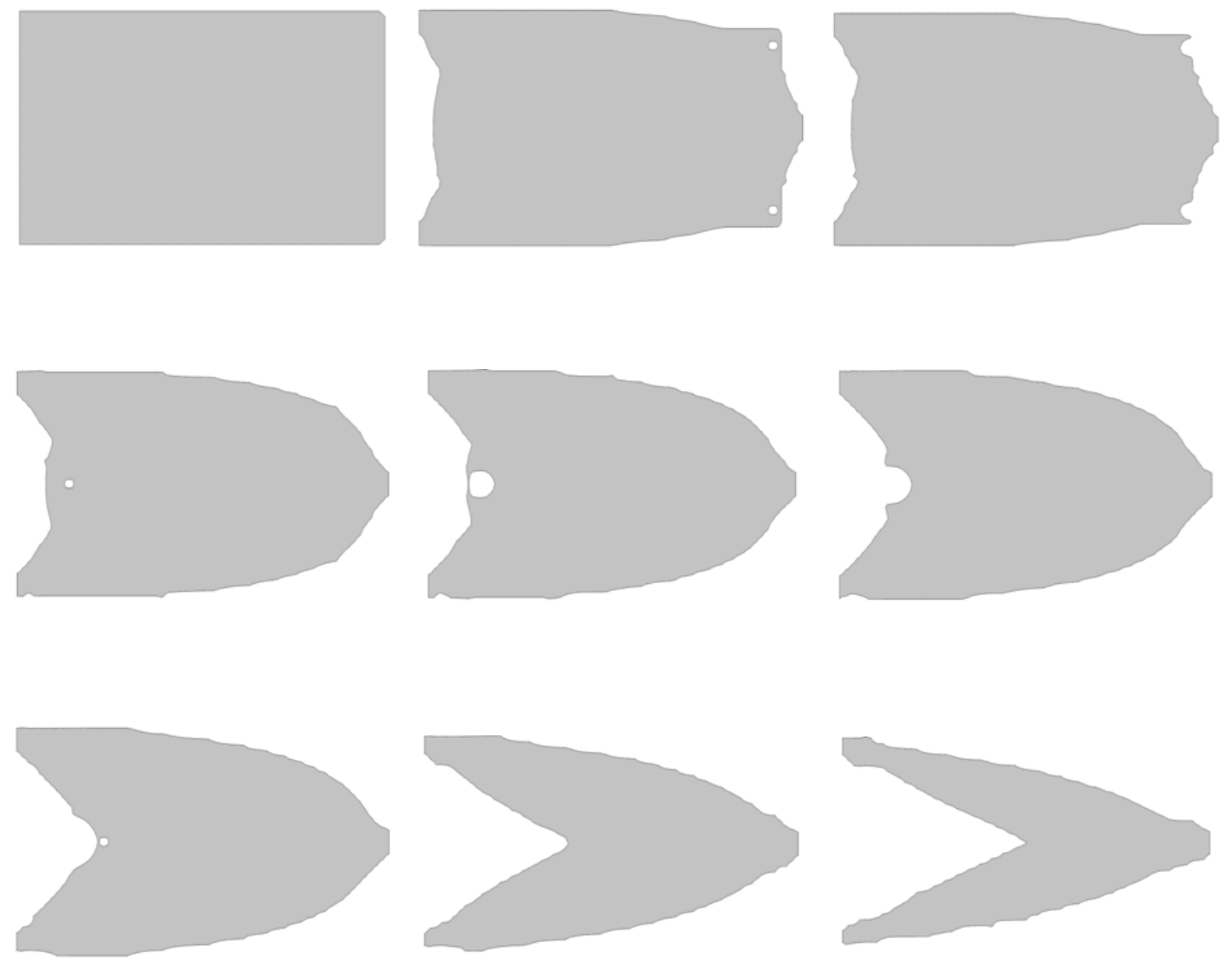

Figura 6.3 - Processo de otimização do exemplo 1.

A Figura 6.4 compara a estrutura inicial a estrutura otimizada. É possível observar a simetria e a permanência das condições de contorno até a estrutura final. Comparando-se com o exemplo 3 de Ullah et al. (2014), verifica-se a convergência do método e valida-se o algoritmo proposto.

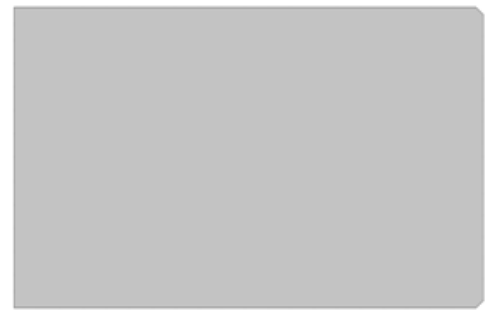

Estrutura inicial

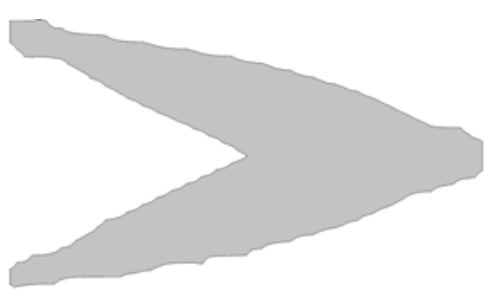

Estrutura final

Figura 6.4 - Comparação estruturas exemplo 1: inicial e final.

A Figura 6.5 ilustra a redução da área durante o processo iterativo. 


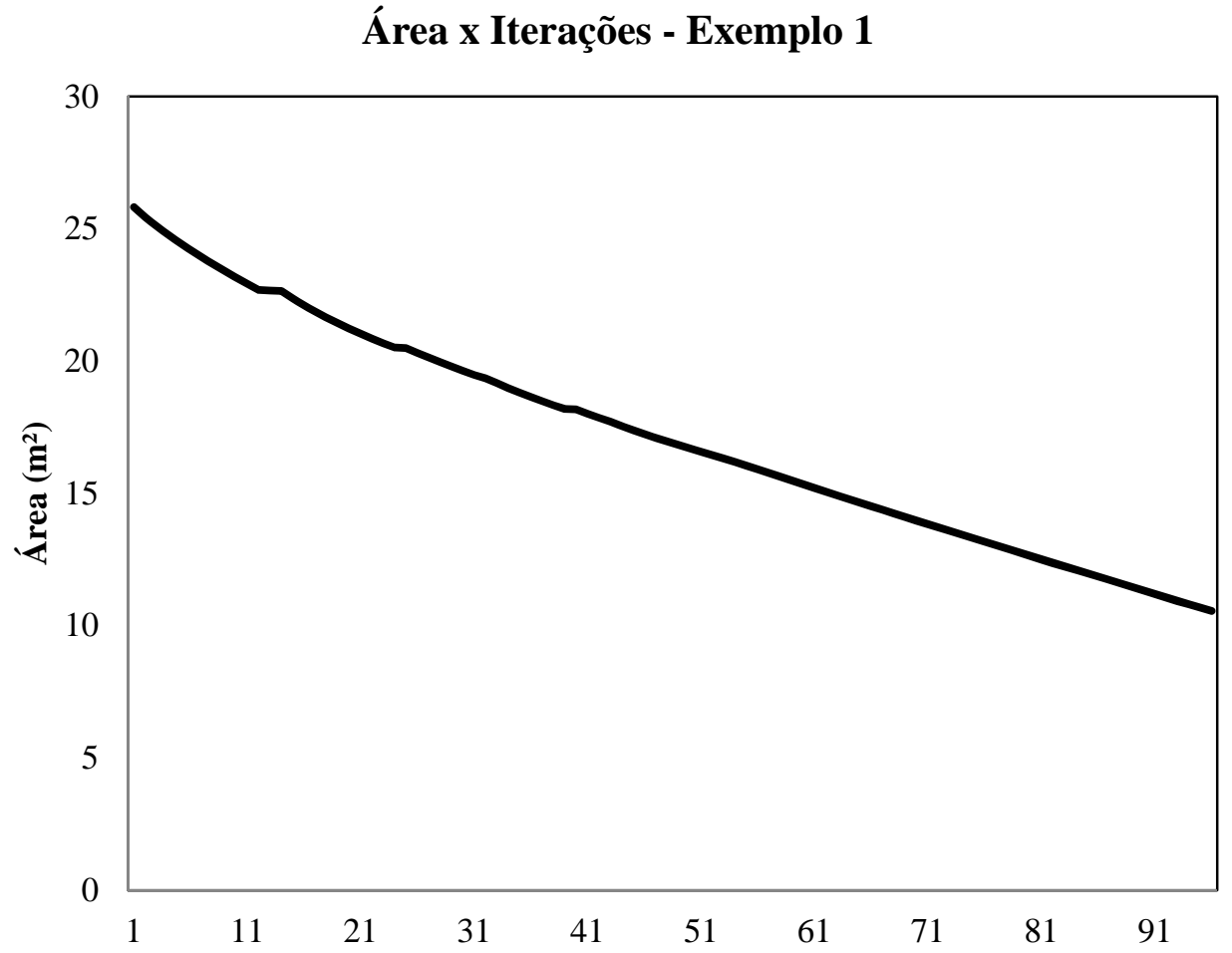

Figura 6.5 - Redução da área da estrutura de acordo com a iteração - Exemplo 1.

A Figura 6.6 ilustra a evolução da estrutura até a chegada a estrutura ótima por meio das superfícies e as curvas de nível. 

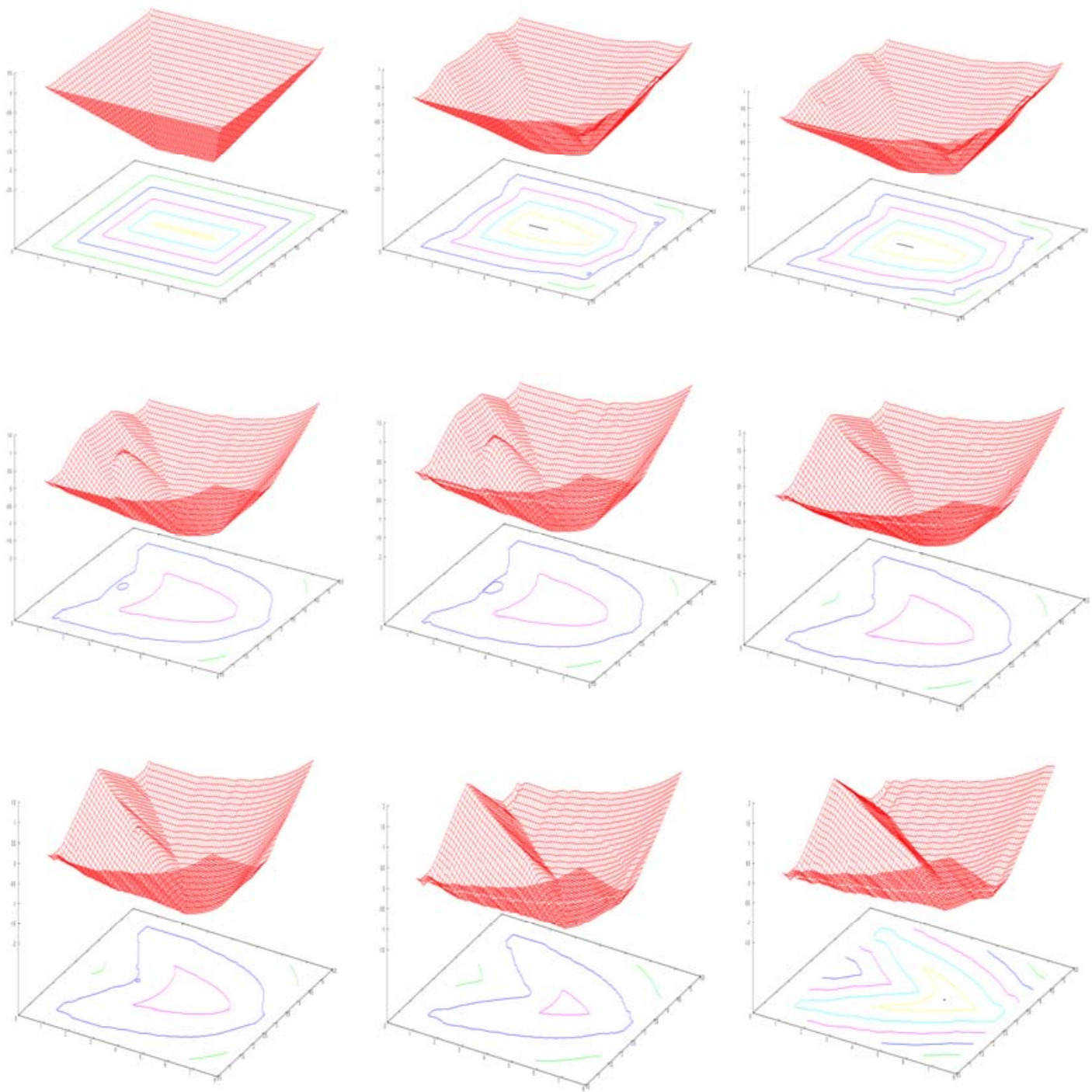

Figura 6.6 - Processo de otimização do exemplo 1 - superfícies.

A Figura 6.8 ilustra a superfície e as curvas de nível da estrutura final, o nível zero representa a estrutura ótima.

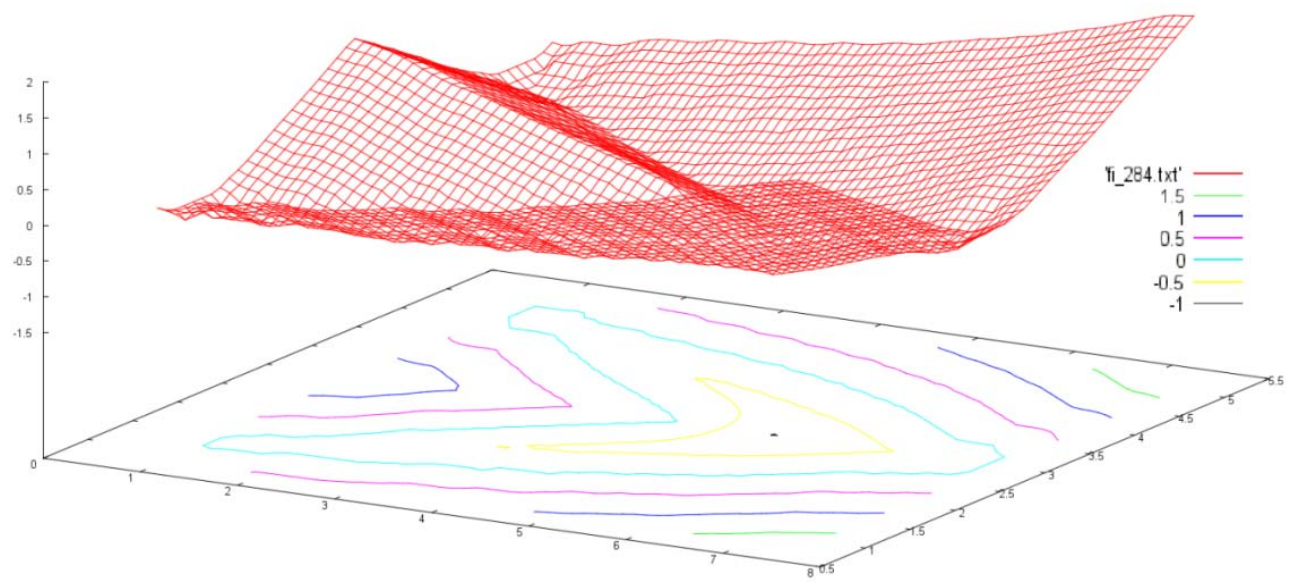

Figura 6.7 - Superfície e curvas de nível do exemplo 1. 


\subsection{EXEMPLO 2}

Trata-se de uma viga engastada submetida a um carregamento de cisalhamento. A Figura 6.8 ilustra a estrutura inicial do exemplo.

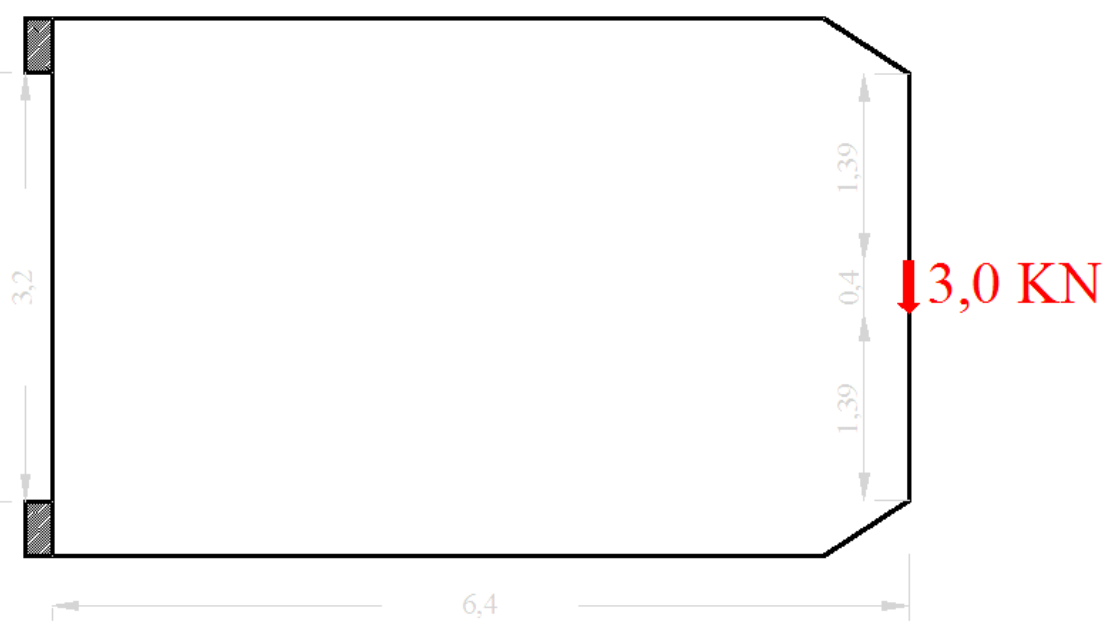

Figura 6.8 - Viga engastada submetida a flexão.

O fator de redução utilizado foi de $R R=0,05$, adotou-se 10 a quantidade de evoluções para cada etapa do método diferença upwind. O tempo fictício utilizado é de $\Delta t=0,003$. O grid é composto por $67 \times 45$ pontos, ou seja, 3015 pontos. Os valores de $\Delta x \mathrm{e}$ $\Delta y$ são iguais a $0,1 m$

As principais referências no campo da otimização topológica demonstram a unicidade de solução para os problemas de otimização, ou seja, aplicando-se as mesmas condições de contorno é possível determinar a geometria ótima de uma estrutura independentemente de sua forma inicial, é usual a inserção de furos ou descontinuidades para a demonstração da eficiência do algoritmo. Utilizando esse conceito, a estrutura é modificada com a inserção de 4 furos em seu domínio. Também são introduzidos chanfros nas quinas da extremidade direita, o objetivo é reduzir a concentração de tensão existente nesses locais.

Para esse exemplo, calcula-se a estrutura otimizada contendo $50 \%$ da área inicial (Figura 6.8). A Figura 6.9 ilustra o ponto da partida da estrutura a ser otimizada. 


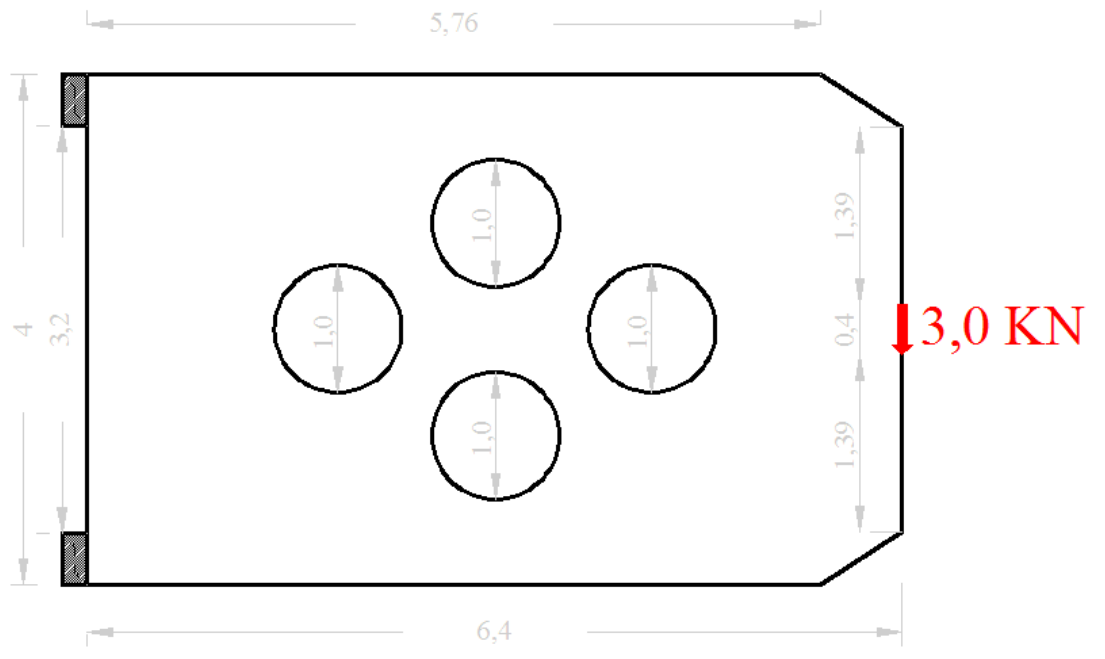

Figura 6.9 - Inserção de furos iniciais na estrutura.

A Figura 6.10 contém a evolução da estrutura até sua chegada a estrutura ótima.
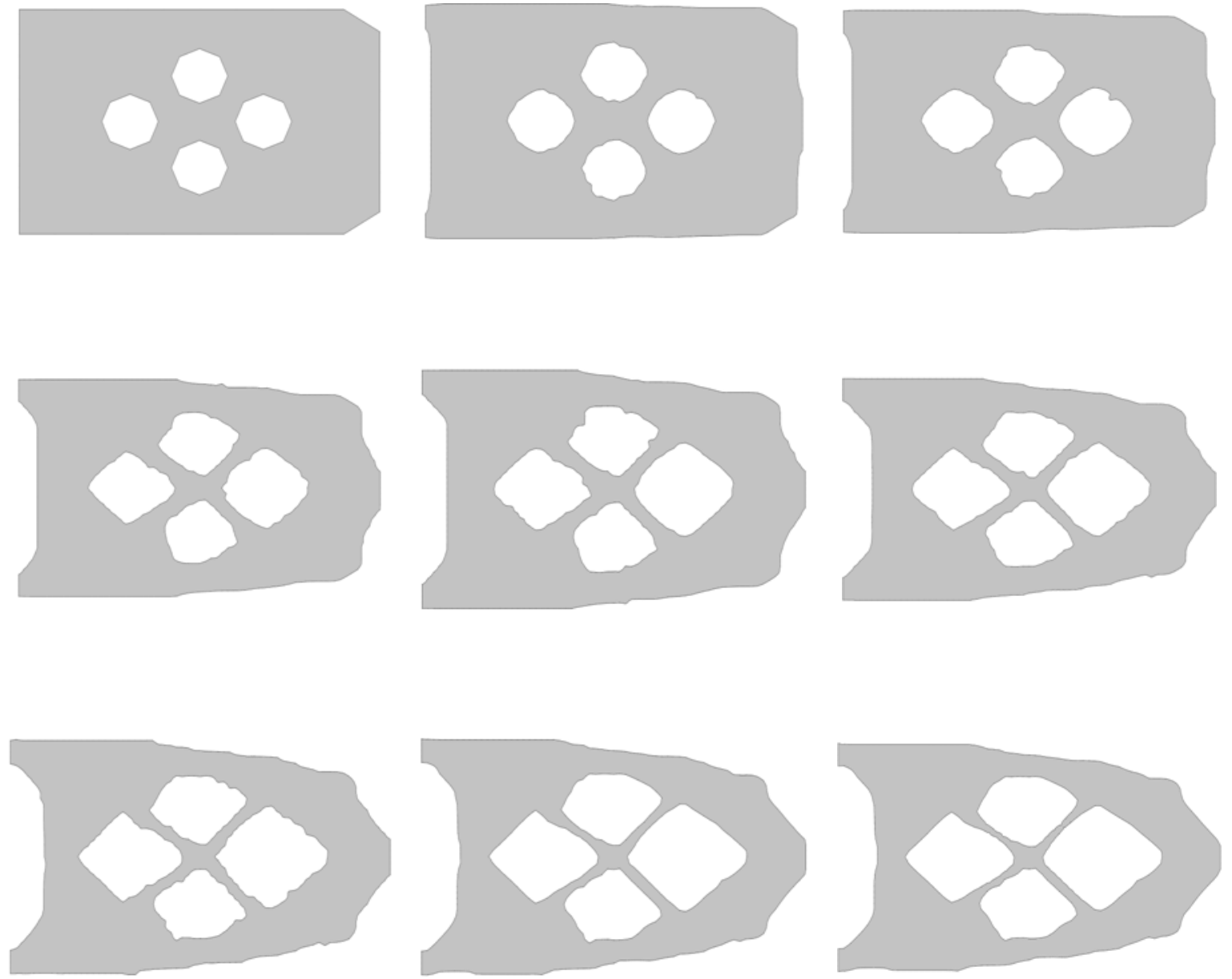

Figura 6.10 - Processo de otimização do exemplo 2. 
A Figura 6.11 compara a estrutura inicial a estrutura otimizada.

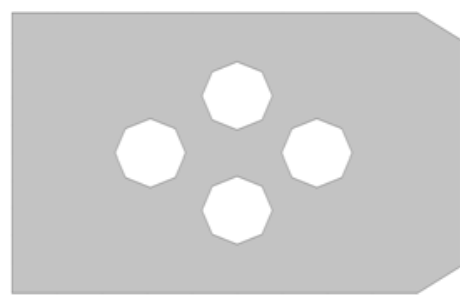

Estrutura inicial

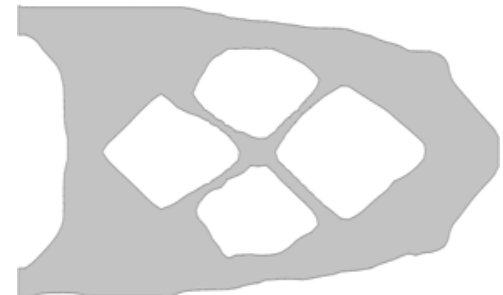

Estrutura final

Figura 6.11 - Comparação estruturas exemplo 2: inicial e final.

A Figura 6.12 ilustra a redução da área durante o processo iterativo.

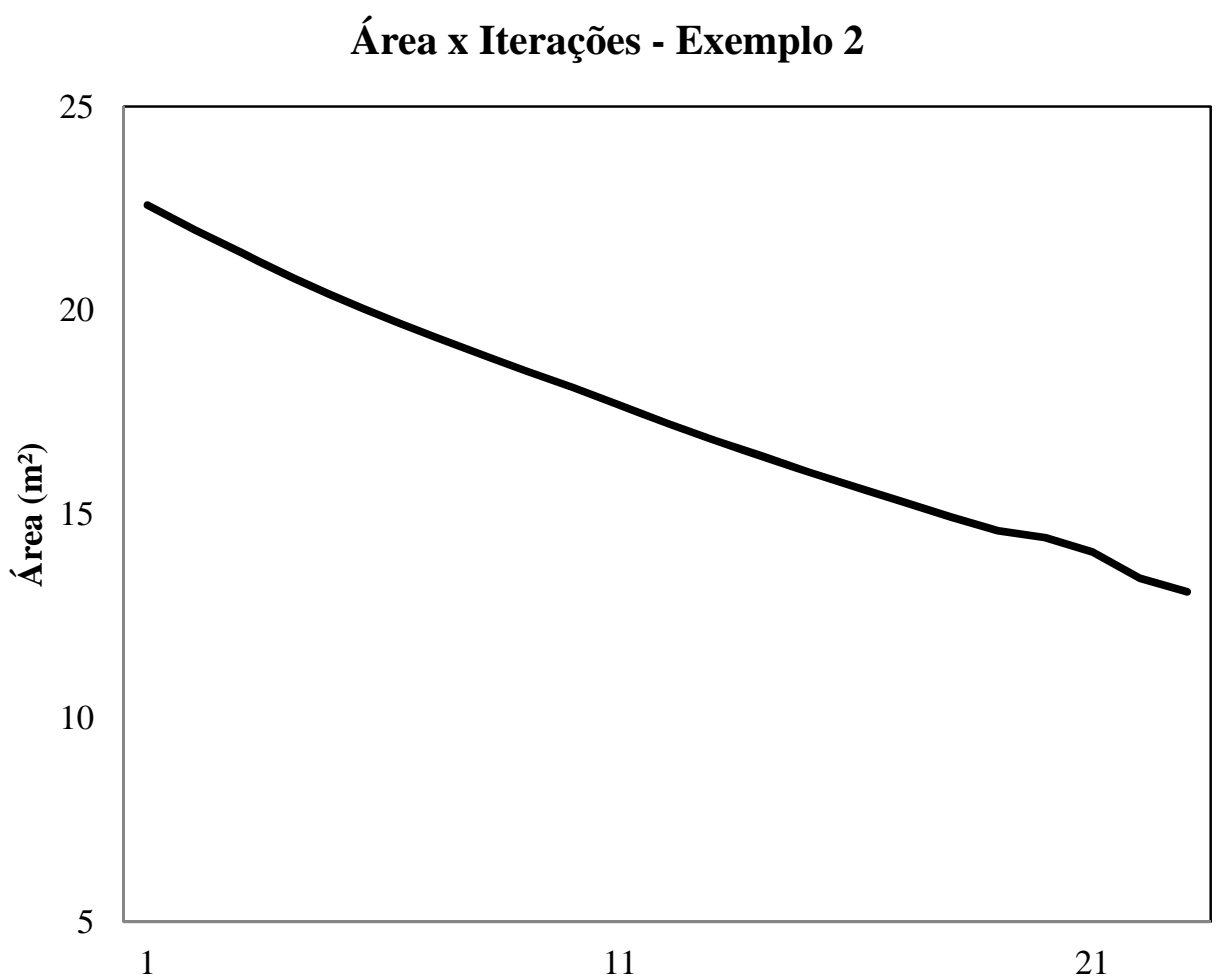

Figura 6.12 - Redução da área da estrutura de acordo com a iteração - Exemplo 2.

A Figura 6.13 ilustra a evolução da estrutura até a chegada a estrutura ótima por meio das superfícies e as curvas de nível. 

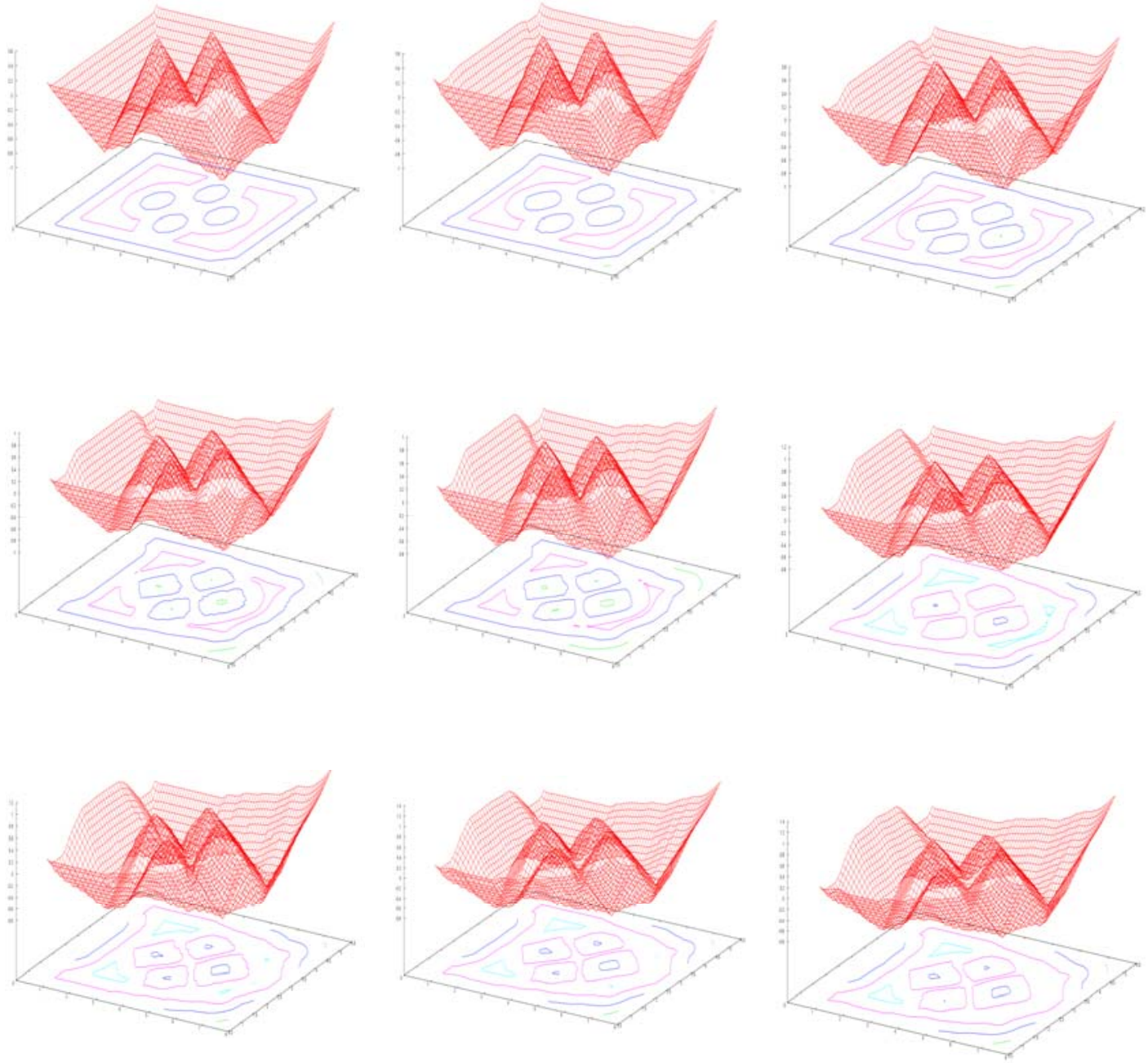

Figura 6.13 - Processo de otimização do exemplo 2 - superfícies.

A Figura 6.14 ilustra a superfície e as curvas de nível da estrutura final, o nível zero representa a estrutura ótima.

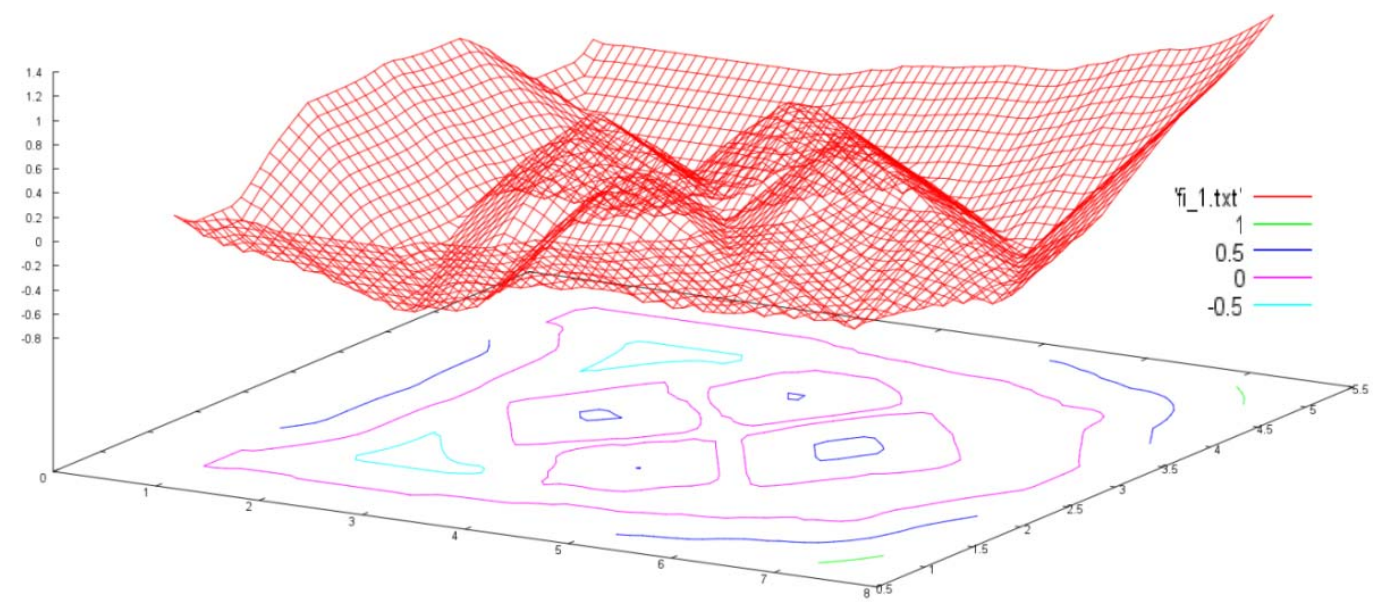

Figura 6.14 - Superfície e curvas de nível do exemplo 2. 


\subsection{EXEMPLO 3}

Trata-se de uma viga engastada submetida a um carregamento de flexão. A Figura 6.15 ilustra a estrutura inicial do exemplo.

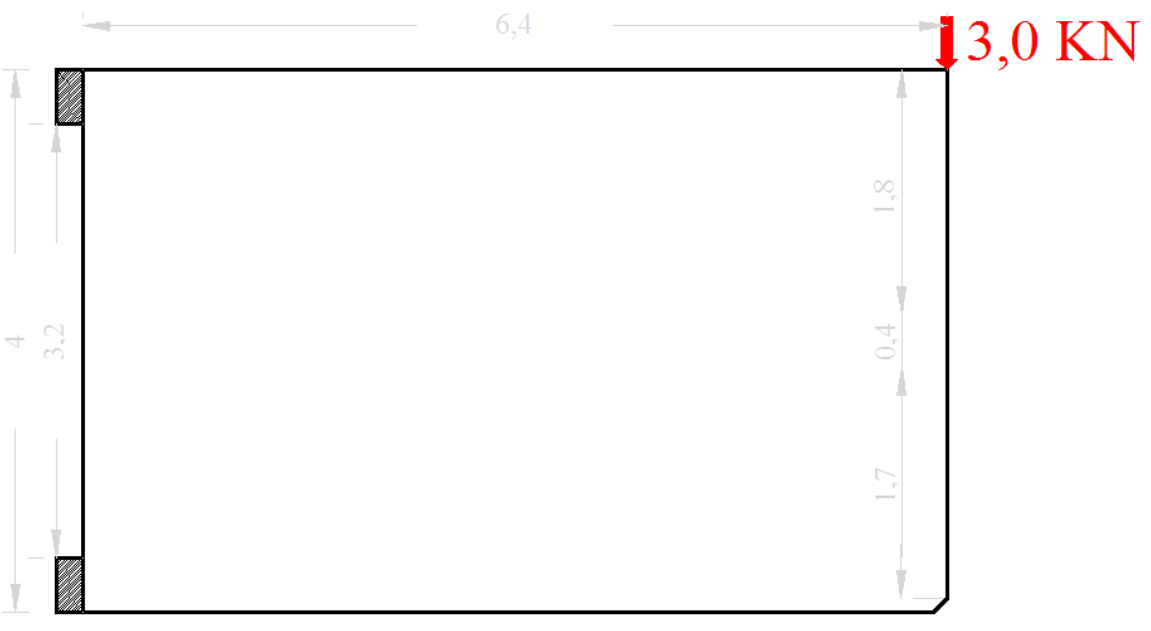

Figura 6.15 - Viga engastada submetida a flexão - carregamento superior.

O fator de redução utilizado foi de $R R=0,25$, adotou-se 5 evoluções para cada etapa do método diferença upwind. O tempo fictício utilizado é de $\Delta t=0,003$. O grid é composto por $67 x 45$ pontos, ou seja, 3015 pontos. Os valores de $\Delta x$ e $\Delta y$ são iguais a $0,1 m$. Optou-se pela introdução de chanfros na quina da extremidade inferior direita da estrutura, o objetivo é reduzir a concentração de tensão existente nesses locais. Necessita-se que a estrutura otimizada contenha $40 \%$ da área inicial.

A Figura 6.16 mostra a evolução da estrutura até sua chegada à estrutura ótima. 

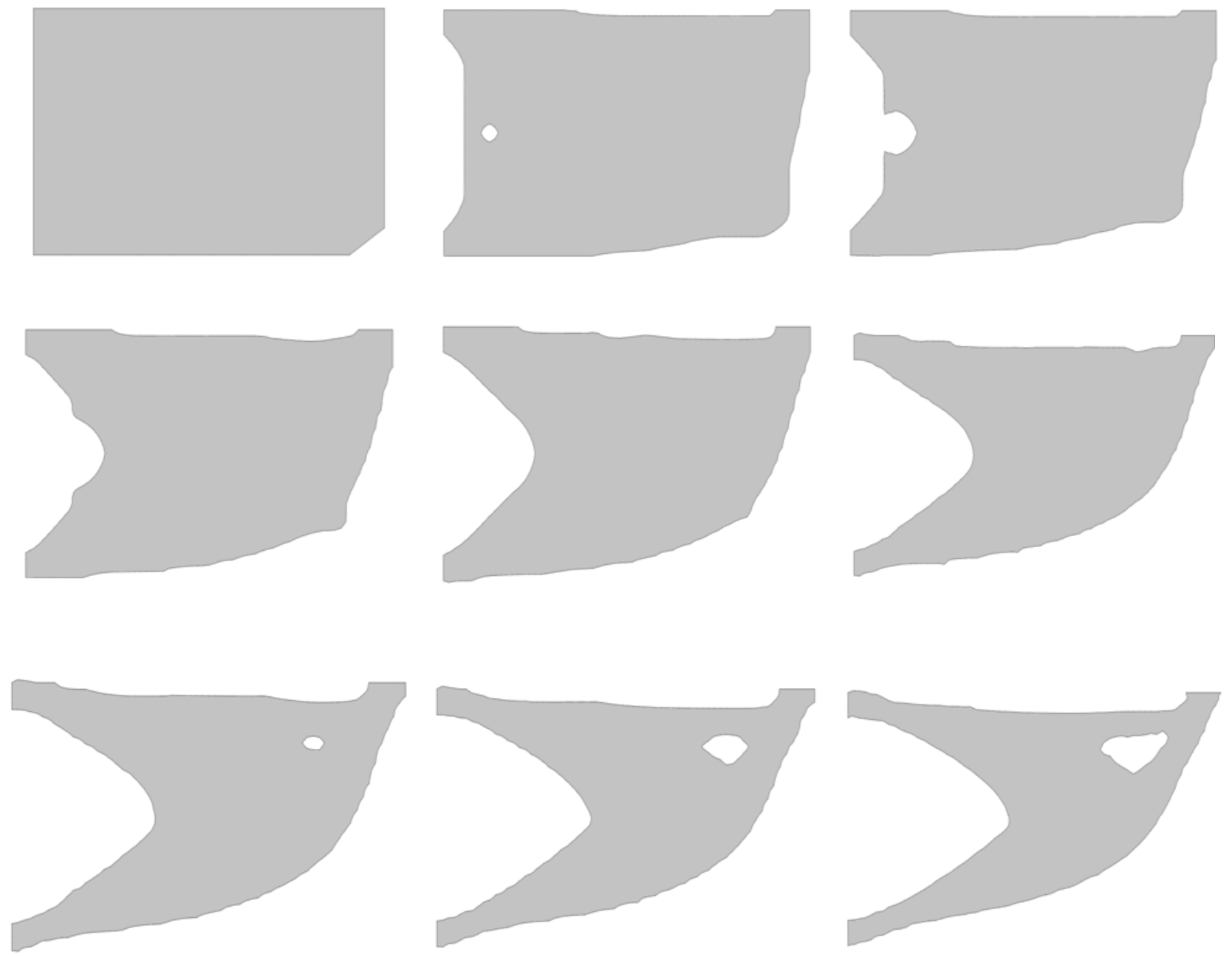

Figura 6.16 - Processo de otimização do exemplo 3.

A Figura 6.17Figura 6.4 compara a estrutura inicial a estrutura otimizada.

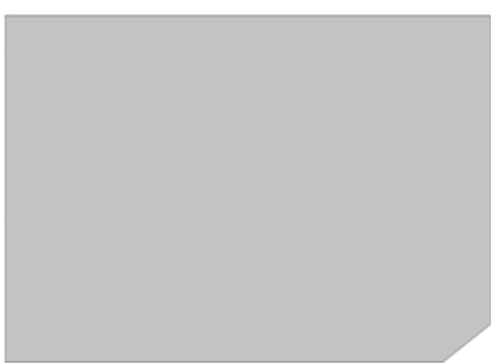

Estrutura inicial

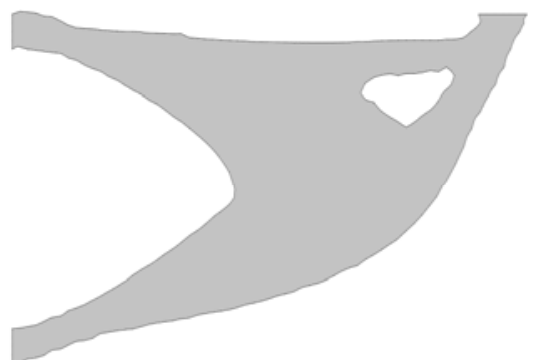

Estrutura final

Figura 6.17 - Comparação estruturas exemplo 3: inicial e final.

A Figura 6.18 ilustra a redução da área durante o processo iterativo. 


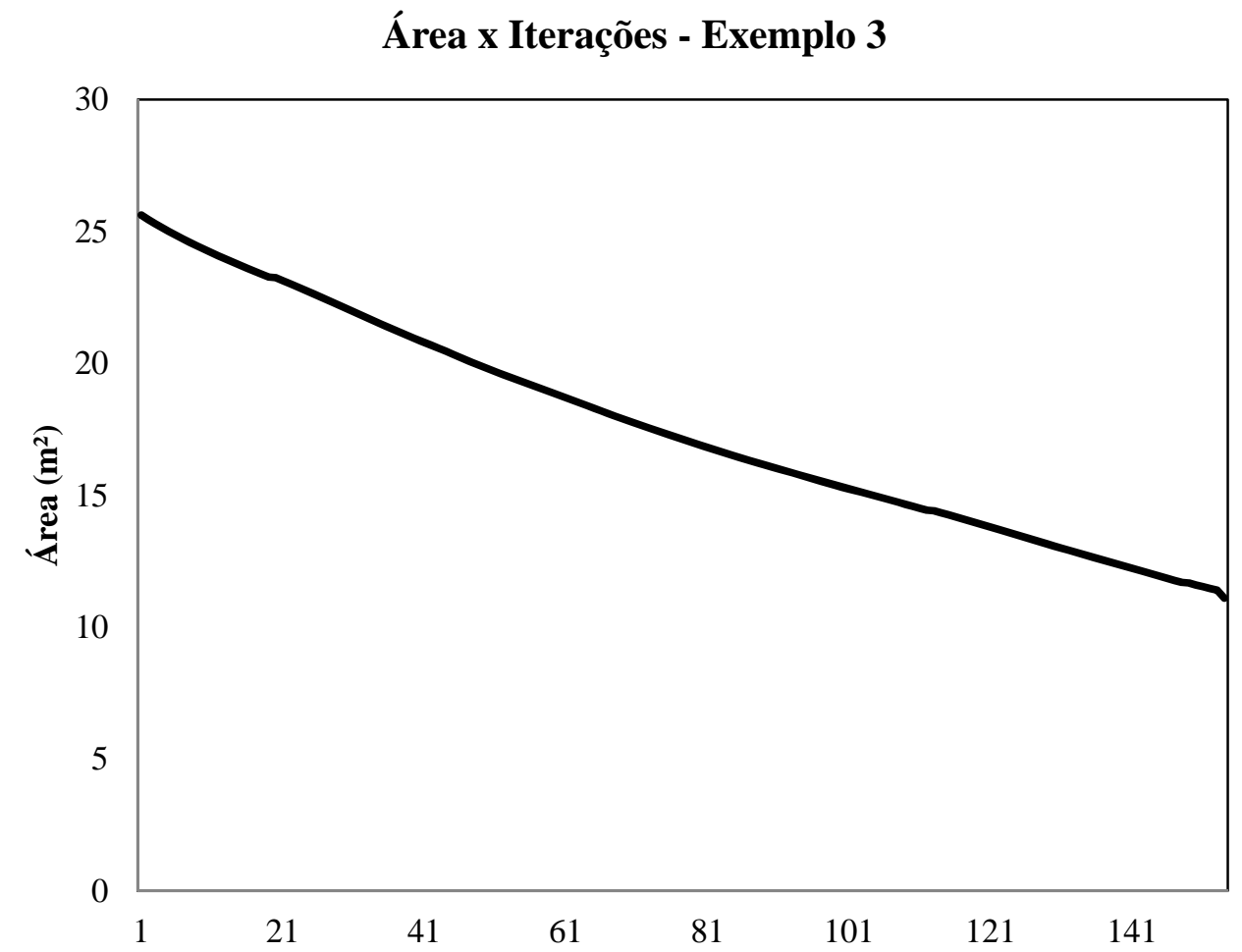

Figura 6.18 - Redução da área da estrutura de acordo com a iteração - Exemplo 3.

A Figura 6.19 ilustra a evolução da estrutura até a chegada a estrutura ótima por meio das superfícies e as curvas de nível. 


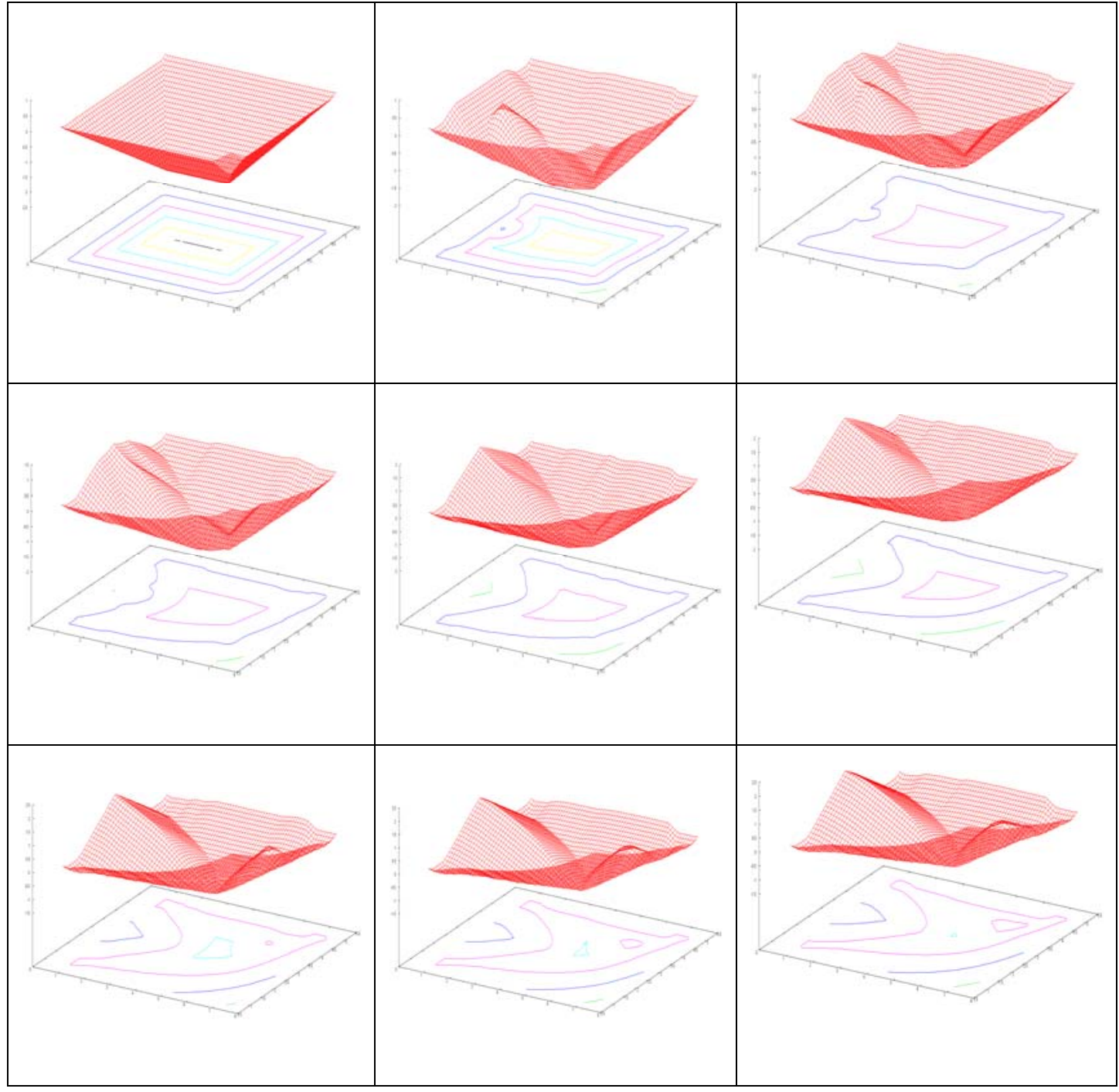

Figura 6.19 - Processo de otimização do exemplo 3 - superfícies.

A Figura 6.20 ilustra a superfície e as curvas de nível da estrutura final, o nível zero representa a estrutura ótima.

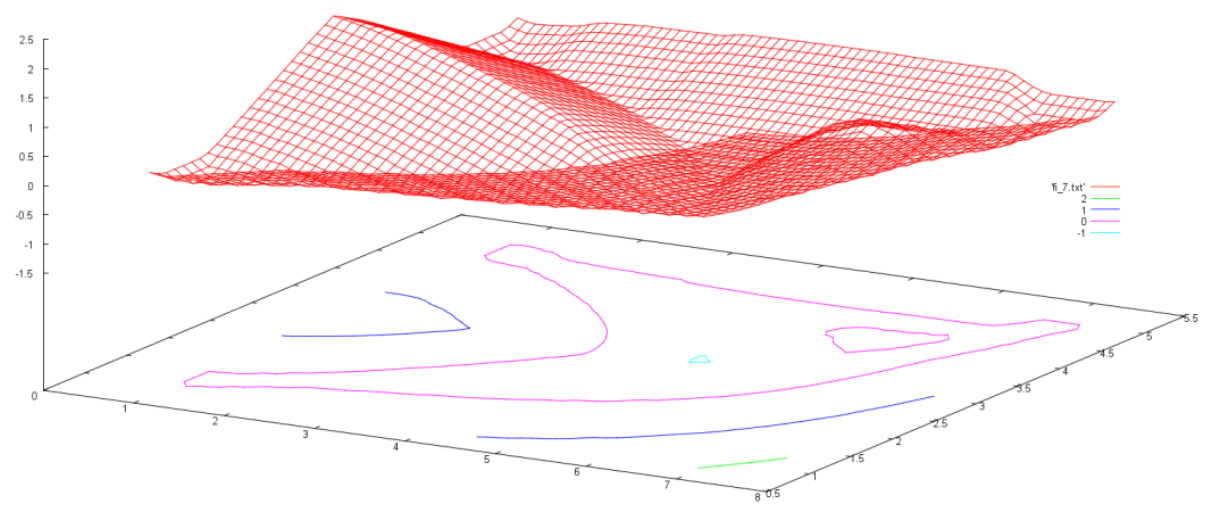

Figura 6.20 - Superfície e curvas de nível do exemplo 3. 


\subsection{DISCUSSÃO DOS RESULTADOS}

A imersão das estruturas na malha Euleriana é realizada manualmente. O cálculo mecânico depende diretamente das condições de contorno impostas na estrutura. Para isso, deve-se garantir que as condições de contorno pertençam aos pontos do grid, ou seja, os elementos onde são aplicados deslocamentos nulos e carregamentos necessitam que as velocidades e os valores da função LS sejam nulos, isso significa que os mesmos pontos do grid que contém as condições de contorno permanecem parados e pertencem ao contorno da estrutura em todas as iterações. Caso as condições de contorno sejam diferentes das especificadas inicialmente, o problema analisado é modificado, o que não é desejável. A atualização das condições de contorno realizada é suficiente para garantir que o problema continue o mesmo em todas as iterações.

Para o calculo mecânico, o MEC necessita das coordenadas cartesianas fornecidas explicitamente, entretanto, para o cálculo da OT é fundamental que o contorno seja representado implicitamente. As distâncias orientadas com sinal são calculadas através da inicialização da função LS e garantem a transformação das coordenadas explícitas para a representação implícita do contorno. A inicialização da função LS garante que o contorno permaneça na posição correta a cada iteração.

A tensão de von Mises é a variável que liga o MEC ao MLS. O MEC tem sua malha composta por nós e elementos imersa na malha Euleriana, o problema mecânico calcula a tensão de von Mises para todos os pontos do grid, com essa informação é possível avaliar se a estrutura precisa de furos e obter a velocidade de propagação utilizada na atualização da função LS.

O objetivo da OT é atingir a mínima quantidade de material que garanta resistência adequada aos esforços solicitantes da mesma forma que a estrutura inicial. A eliminação de material ineficiente é realizada durante todo o processo, a inserção de furos e o método diferença upwind realizam essa função a cada iteração.

A inserção de furos elimina uma quantidade mínima de material, isso pode ser visto na Figura 6.5 e na Figura 6.12; observa-se que nas curvas de redução da área da estrutura existem pequenos patamares onde a área da estrutura permanece praticamente constante durante o processo. Ullah et al. (2014) utilizam um recurso onde a inserção de furos elimina uma grande quantidade de material, isso acontece em função do emprego do método NURBS para a reconstrução do contorno. Para este trabalho ainda não foi possível a eliminação de 
mais material através dos furos, entretanto, para trabalhos futuros já existem algumas estratégias que podem melhorar esse processo.

O método diferença upwind é responsável pela eliminação de grande parte do material ineficiente da estrutura. A movimentação acontece de forma que o material é eliminado em locais com baixa tensão de von Mises e é reconstituído em regiões onde há maior concentração de tensões. Por meio da atualização da função LS analisa-se a coerência da distribuição das tensões de von Mises calculadas. Como as velocidades dependem diretamente das tensões, a eliminação e a reconstituição de material são dadas de acordo com o valor da velocidade $V N$ relacionada pela Figura 5.4. Para velocidade nula os pontos permanecem parados, para velocidades negativas o material é eliminado e para velocidades positivas o material é reconstituído. Pela evolução dos exemplos 1,2 e 3 nota-se que o material é removido e acrescentado adequadamente.

O remalhamento é realizado após a atualização da função LS, calcula-se a nova quantidade de nós, elementos de contorno e conectividade dos elementos. O algoritmo detecta adequadamente as camadas de pontos presentes na estrutura (exterior e furos).

A evolução das estruturas acontece de forma simétrica. Nota-se que há uma relação direta entre a malha Euleriana, a malha de elementos de contorno e o tempo de processamento.

No exemplo 1 chega-se a 40\% da área inicial em 96 iterações, o tempo de processamento é de, aproximadamente, 6 dias. O tempo elevado é dado em função do cálculo das grandezas internas do MEC. Para o cálculo das grandezas internas do MEC, consideramse os pontos do grid com valores da função LS negativos; conceitualmente, estes pontos estão posicionados no interior da estrutura e são considerados pontos fonte para o MEC. Cada um dos pontos internos integra todos os elementos presentes no contorno.

A evolução do método diferença upwind reduz a quantidade de material presente na estrutura, consequentemente, a quantia de pontos internos da estrutura também é reduzida. Teoricamente, a diminuição da quantidade de pontos internos levaria ao decréscimo do tempo de processamento, todavia, não é isso que acontece na prática.

No exemplo 2 chega-se a $50 \%$ da área inicial em 28 iterações, o tempo de processamento é de, aproximadamente, 6 dias. Os furos inseridos manualmente reduzem a quantidade de iterações a serem a realizadas, entretanto, os mesmos aumentam significativamente o tempo de processamento. Isso acontece devido ao número de elementos de contorno adicionados a malha, o MEC necessita de mais de tempo para realizar o cálculo mecânico. Nesse exemplo, a quantidade de pontos internos é reduzida tanto pela evolução do 
método diferença upwind como pelos furos inseridos manualmente, contudo, o tempo de processamento não sofre decréscimo.

Nota-se no exemplo 2, que ao se atingir 50\% da área inicial, a estrutura necessita de mais pontos para a evolução adequada, isso é realizado com o refinamento do grid. Refinouse o grid do exemplo e utilizou-se um número 4 vezes maior por pontos, ou seja, $\Delta x$ e $\Delta y$ iguais a 0,05. Para atender a condição de estabilidade $C F L$ modificou-se o intervalo de tempo fictício para $\Delta t$ igual a 0,001 . O refinamento tornou inviável a análise para áreas inferiores a $50 \%$ da área inicial, pois aumentou, consideravelmente, o tempo de processamento do algoritmo.

No exemplo 3 chega-se a 40\% da área inicial em 154 iterações, o tempo de processamento é de, aproximadamente, 5 dias. Para esse exemplo a evolução não acontece simetricamente devido ao carregamento não possuir simetria.

O processo de remalhamento é baseado na quantidade de pontos do grid, assim, o aumento do número de pontos no grid gera acréscimo na quantidade de nós e de elementos de contorno da estrutura, o que prolonga o tempo de processamento do modelo mecânico e do cálculo das grandezas internas do MEC. Além disso, o remalhamento considerando o grid refinado reduz o tamanho dos elementos da estrutura, o sistema de equações do cálculo mecânico do MEC é comprometido em função do tamanho desses elementos. Para exemplos onde é preciso o refinamento de grid, é preciso a melhoria e aprimoramento do algoritmo. 


\section{CONSIDERAÇÕES FINAIS}

\subsection{CONCLUSÕES}

A otimização topológica é resultado do acoplamento MEC - MLS. Utilizam-se as vantagens de cada um deles para a obtenção de geometrias ótimas de maneira eficiente e precisa.

Divide-se o problema tratado em duas partes: modelo geométrico e modelo mecânico. O modelo geométrico contempla a montagem e a modificação da estrutura em cada iteração. O modelo mecânico inclui a obtenção das tensões e deformações de cada estrutura analisada durante as iterações. Analisando de forma específica, o acoplamento em questão pode ser dividido em três partes: modelo mecânico, otimização topológica e reconstrução da estrutura. O modelo mecânico utilizado são as equações algébricas do MEC. A otimização topológica é constituída pelo MLS. E a reconstrução possibilita que a estrutura esteja adequada para a continuação do processo iterativo.

O acoplamento realizado é de fronteira entre o modelo geométrico e o modelo mecânico. O processo de otimização topológica só existe se os módulos trabalharem em conjunto, a ligação entre os métodos é a tensão de von Mises. A vantagem e a potencialidade desse tipo de acoplamento residem no fato de que as partes constituintes podem ser trabalhadas separadamente. Então, é possível melhorar algoritmo do MEC acrescentando diferentes tipos de carregamentos e vinculações, aumentando as aplicações resolvidas pelo método. Também é possível substituir o MEC por outras metodologias. É possível também melhorar os algoritmos responsáveis pelo controle e mudança da geometria, construindo estruturas melhores e analisando problemas mais próximos da realidade.

O MEC é complexo e necessitou exaustivas horas de estudo e de implementação para ser entendido, contudo, o Departamento de Engenharia de Estruturas (EESC - USP) possui uma forte tradição nas aplicações envolvendo o MEC. Por meio do Grupo de Estudos do Método dos Elementos de Contorno, diversas dúvidas foram sanadas durante os estudos.

Para o MLS e o acoplamento MEC - MLS, o panorama foi diferente, pois o MLS é um método relativamente novo e a quantidade de bibliografias tratando sobre o acoplamento MEC - MLS ainda é reduzida, além disso, a linha de pesquisa em otimização topológica é 
pioneira no Departamento de Engenharia de Estruturas (EESC-USP). Então, nessa área o conhecimento foi adquirido partindo-se da estaca zero.

Anteriormente ao desenvolvimento da formulação, um planejamento detalhado foi montado e as ideias foram discutidas no Grupo de Método dos Elementos de Contorno, isso auxiliou na escolha de melhores alternativas e diminuiu a dificuldade em diversas partes do trabalho. Equacionou-se, implementou-se e testou-se cada uma das partes constituintes individualmente. O algoritmo do MEC utilizado foi desenvolvido pelo Prof. Edson Denner Leonel. A equação LS foi expandida para $2 D$ e implementada com discretização por meio do método diferença upwind, diferentes curvas e velocidades foram testadas e validaram o algoritmo desenvolvido. Posteriormente, acoplou-se o MEC ao MLS, o algoritmo de remalhamento foi desenvolvido e testado simultaneamente ao acoplamento, pois era necessário conhecer a geometria que o algoritmo deveria reproduzir. Após o acoplamento final, vários testes foram realizados até a validação do algoritmo por meio do exemplo de referência de Ullah et al. (2014).

Mesmo com as dificuldades encontradas com os métodos e discussões do equacionamento e estratégias de implementação, o grande desafio desse trabalho foi o desenvolvimento da ferramenta de remalhamento. Para os estudiosos de métodos numéricos, é conhecida a dificuldade e os problemas existentes em análises onde a malha necessita ser reconstruída automaticamente. Além da alteração na quantidade de nós e elementos, as maiores problemáticas encontram-se a aplicação das condições de contorno e a determinação das novas conectividades.

Em cada iteração as condições de contorno necessitam ser aplicadas em nós e elementos diferentes dos anteriores, entretanto, a posição geométrica inicial deve ser mantida independente da alteração da malha.

Na conectividade dos elementos, a dificuldade é estabelecer os nós iniciais e finais, pois é intrínseco do processo de otimização topológica o desaparecimento e o surgimento de material no domínio da estrutura. Quando a função LS é atualizada, são conhecidos apenas os valores da função em cada um dos pontos grid, a presença ou ausência de material é desconhecida, além disso, esse procedimento deve ser repetido eficientemente em todas as iterações. Montar um esquema que trate habilmente todos esses problemas é um ponto crucial para o desenvolvimento do trabalho.

O algoritmo de remalhamento implementado é capaz de localizar novos nós e elementos, encontrar suas conectividades e aplicar as condições de contorno adequadamente. 
Entretanto, ainda existem algumas limitações, pois para vencer todos os obstáculos enumerados, algumas simplificações foram impostas.

A primeira simplificação é o formato do grid, tentou-se encontrar o melhor formato para que o algoritmo fosse capaz de desenhar estruturas curvas, todavia, adotou-se o formato retangular para simplificar o processo de leitura do algoritmo. Então, fica clara a dependência pela malha Euleriana no processo de otimização. Para captar uma estrutura em detalhes é necessário o aumento do número de pontos do grid, o que aumenta o custo computacional (tempo de processamento) e dificulta a montagem do arquivo de entrada (maior possibilidade de erros).

Outra simplificação adotada foi o tipo de elemento de contorno para a análise, todos os elementos são de ordem de aproximação linear. Essa escolha foi feita, pois elementos de ordem superiores dificultariam o processo de remalhamento. Quanto maior a ordem de aproximação escolhida, maior a quantidade nós e mais complexa a análise da conectividade para cada elemento. Com essa simplificação, não é possível utilizar a toda a potencialidade do algoritmo ELAST-2D, pois esse este é capaz de fazer análise utilizando elementos de ordem superior e utilizar ordens de aproximação diferentes para cada elemento.

A estrutura é considerada ótima quando a área final alcança a porcentagem da área final especificada. Muitos estudiosos como Sethian e Wiergmann (2000), denominam a estrutura ótima como ‘projeto melhorado’, pois o critério de volume/área não garante que a porcentagem escolhida seja realmente o valor ideal para a aplicação em questão. Então, conclui-se que cada iteração gera um ponto de 'ótimo local', pois em cada etapa do processo de otimização, a quantidade de material presente na estrutura resiste adequadamente aos carregamentos impostos. As porcentagens de área aqui utilizadas foram escolhidas de acordo com os valores presentes nas bibliografias de referência. Para a determinação da porcentagem ótima de material a ser escolhida deve-se propor uma nova metodologia de pesquisa que leve em conta as restrições para o volume adotado.

Apesar de todas as dificuldades encontradas, diversas limitações no campo da matemática e engenharia foram superadas. Além disso, os aprendizados serviram para amadurecimento profissional e pessoal.

O acoplamento MEC - MLS mostra-se uma ferramenta forte e eficiente para a determinação de geometrias ótimas de estruturas e componentes estruturais. 


\subsection{PROPOSTAS PARA TRABALHOS FUTUROS}

Como se trata de uma nova metodologia para a análise da otimização topológica de estruturas e em função do curto intervalo de tempo disponível, não foi possível explorar muitos tipos de aplicações, sugere-se para investigações futuras a exploração de possíveis aplicações para o programa já montado e também a otimização desse algoritmo a fim de reduzir o tempo de processamento do mesmo.

É importante buscar maior conhecimento no campo do remalhamento para aplicações envolvendo o MEC em duas e três dimensões, códigos melhores nessa área melhorariam os resultados apresentados para a otimização topológica.

Indica-se o acoplamento de outros problemas como: mecânica da fratura, mecânica do dano, confiabilidade. Isso aumentaria os campos de aplicação do acoplamento MEC - MLS.

Sugere-se também a expansão dos estudos do acoplamento MEC - MLS para estruturas em três dimensões. 


\section{REFERÊNCIAS BIBLIOGRÁFICAS}

ABE, K,; FUJIU,T.; KORO,K., A BE-Topology optimization method enhanced by topological derivatives. Advances in Boundary Element Techniques. v.9, p. 235 - 240, 2008.

ABE, K.; KAZAMA, S.; KORO, K., A boundary element approach for topology optimization problem using the level set method. Communications in numerical methods in Engineering. v. 23, p. 405 - 416, 2007.

ALIABADI, M.H; ROOKE, D.P., The dual boundary element method: Effective implementation for crack problems. Numerical Fracture Mechanics, Southampton, Computational Mechanics Publications. v.33, p. 1269 - 1287, 1992.

ANFLOR, C.; MARCZAK, R.J., A boundary element approach for shape and topology design orthotropic heat transfer problems. Asociación Argentina de Mecánica Computacional. v. 27, p. 2473 - 2486, 2008.

ANFLOR, C.T.M., Otimização Evolucionária e Topológica em Problemas Governados pela Equação de Poisson Empregando o Método dos Elementos de Contorno. 2007. Tese (Doutorado em Engenharia), Universidade Federal do Rio Grande do Sul, Porto Alegre, 2007. Appl. Mech. Rev., vol. 48, nº 2, pp. 41-119, 1995.

ARORA, J. S., Introduction to Optimum Design, McGraw-Hill, 1989.

BENDSØE, M. P., Optimal Shape Design as a Material Distribution Problem, Structural Optimization, vol. 1, pp. 193-202, 1989.

BENDSØE, M. P.; KIKUCHI, N., Generating Optimal Topologies in Structural Design Using Homogenization Method, Computer Methods in Applied Mechanics and Engineering, vol. 71, $\mathrm{n}^{\mathrm{o}} 2$, pp. 197-224, 1988.

BENDSØE, M. P.; SIGMUND, O. Topology Optimization: Theory, methods and applications. [S.l.]: Springer-Verlag, 2003.

BENDSØE, M. P.; SIGMUND, O., Material Interpolation Schemes in Topology Optimization, Archive of Applied Mechanics, vol. 69, pp. 635-654, 1999.

BERTSCH, C.; CISILINO, A.P.; CALVO, N., Topology optimization of three-dimensional load-bearing structures using boundary elements. Advances in engineering software. v. 41, p. $694-104,2010$.

BIANCHI, A.G.C., Caracterização, Modelagem e Simulação Matemático-Computacional da Dinâmica do Crescimento e Conexões de Células Neurais. 2003. 173p. Tese (Doutorado em Física Aplicada), Instituto de Física de São Carlos, Universidade de São Paulo, São Carlos, 2003. 
BREBBIA, C. A. The Boundary Element Method for Engineers, London: Pentech Press, 1978.

BREBBIA, C. A.; DOMINGUEZ, J. Boundary Elements: An Introductory Course, Southampton: McGraw Hill, 1989.

BREBBIA, C.A.; DOMINGUEZ, J. (1992). Boundary elements: and introductory course. Computational Mechanics Publications, London.

CERVERA, E.; TREVELYAN, J. Evolutionary structural optimisation based on boundary representation of NURBS. Part I: 2D algorithms. Computers and Structures, v. 83, n. 23, p. 1902-1916, 2005.

CODA, H.B., Contribuição à Análise Dinâmica Transiente de Meios Contínuos pelo Método dos Elementos de Contorno. 2000. São Carlos. Tese (Livre Docência). Escola de Engenharia de São Carlos, Universidade de São Paulo, São Carlos, 2000.

CORDEIRO, M. de F., Uma Técnica de Otimização Estrutural Mediante a Derivada Topológica. 2007. Dissertação (Mestrado em Ciências em Engenharia Mecânica), Universidade Federal do Rio de Janeiro, Rio de Janeiro, 2007.

DIJK, N.P. van; YOON, G.H., KEULEN, F. van; LANGELAAR, M. A Level-set-based Topology Optimization using the Element-connectivity-parameterization Method. In.: International Conference on Engineering Optimization. Anais. Rio de Janeiro, RJ. 2008.

DUNNING, P.; KIM, H.; MULLINEUX G. Introducing loading uncertainty in topology optimization. American Institute of Aeronautics and Astronautics Journal, v 49, n. 4, p. 760-768, 2011.

EMMENDOERFER JUNIOR, H., Problema de Otimização Estrutural com Restrição de Tensão Local usando o Método Level Set. 2011. Dissertação (Mestrado em Engenharia Mecânica), Universidade Federal de Santa Catarina, Florianópolis, 2011.

ESCHENAUER, H.; KOBELEV, V.; SCHUMACHER, A. Bubble method for topology and shape optimization of structures. Structural and Multidisciplinary Optimization v. 8, n. 1, p. 42-51, 1994.

ESEDOGLU, S; SMEREKA, P. A Variational Formulation for a Level Set Representation of Multiphase Flow and Area Preserving Curvature Flow. Journal of Computational Physics, Somerville, v. 6, n. 1, p. 125 - 148, 2008.

ESPATH, L.F.R, Otimização de Forma de Cascas via Deformação Livre de Forma Baseado em NURBS. 2009. 155p. Dissertação (Mestrado em Engenharia), Universidade Federal do Rio Grande do Sul, Porto Alegre, 2009.

FERREIRA, A.B.H. Novo Dicionário Eletrônico Aurélio versão 5.0. 3 ed. Rio de Janeiro, 2004. 2120p.

FONSECA, M., Otimização de Estruturas Treliçadas Planas e Espaciais sob Carregamentos Estáticos e Dinâmicos, Usando Algoritmos Genéticos e Redes Neurais. 2007. 212p. 
Dissertação (Mestrado em Engenharia Civil) - Universidade Federal de Ouro Preto, Ouro Preto, 2007.

GARCIA, M.; STEVEN, G. Fixed grid finite elements in elasticity problems. Engineering Computations. International Journal for Computer-Aided Engineering and Software, v. 16, n. 2, p. 145-164, 1999.

GARZON, M.; ADALSTEINSSON, D.; GRAY, I; SETHIAN J.A. A coupled level setboundary integral method for moving boundary simulations. Interfaces and Free Boundaries, Switzerland, v. 7, p. 277 - 302, 2005.

GOMES, W.J.S., Estudo de Incertezas na Otimização. 2010. 96p. Dissertação (Mestrado em Engenharia de Estruturas) - Escola de Engenharia de São Carlos, Universidade de São Paulo, São Carlos, 2010.

GOVINDJEE, S., The Symmetric Identity. Structural Engineering - Department of Civil Engineering Mechanics and Material - University of California Berkeley. 2010. (Lecture Notes)

HAFTKA, R.; GÜRDAL, Z., Elements of Structural Optimization, Kluwer Academic Publishers, $3^{\text {a }}$ edição, 1992.

HAFTKA, R.; GRANDHI, R. Structural shape optimization-a survey. Computer Methods in Applied Mechanics and Engineering, v. 57, n. 1, p. 91-106, 1986.

HESTENES, M.R., Multiplier and Gradient Methods, Journal of Optimization Theory and Applications, v. 4, p. 303-320, 1969.

JING, G.; MATSUMOTO, T.; TAKAHASHI, T.; ISAKARI, H.; YAMADA, T., Topology optimization for 2D heat conduction problems using boundary element method and level set method. Transactions of JASCOME. v. 13, 6 p., 2013.

KAI, H.; CHAN, T.; OSHER, S. A variational level set approach to multiphase motion. Journal of Computational Physics, Somerville, n. 127, p. 179 - 195,1996.

KIKUCHI, N.; NISHIWAKI, S.; FONSECA, J.O.; SILVA, E.C.N., Design Optimization Method for Compliant Mechanisms and Material Microstructure. Computer Methods in Applied Mechanics and Engineering. v. 151, p.401-417, 1998.

KZAM, A.K.L., Formulação Dual em Mecânica da Fratura Utilizando Elementos de Contorno Curvos de Ordem Qualquer. 2009. 200p Dissertação (Mestrado em Engenharia de Estruturas). Escola de Engenharia de São Carlos, Universidade de São Paulo, São Carlos, 2009.

LEMONGE, A.C.C., Aplicação de Algoritmos Genéticos em Otimização Estrutural. 1999. 218p. Tese (Doutorado em Ciências em Engenharia Civil), Universidade Federal do Rio de Janeiro, Rio de Janeiro, 1999.

LEONEL, E. D., Método dos elementos de contorno aplicado à análise de sólidos multifraturados. 2006. 178p. Dissertação (Mestrado em Engenharia de Estruturas). Escola de Engenharia de São Carlos, Universidade de São Paulo, São Carlos, 2006. 
LEONEL, E.D., Modelos Não Lineares do Método dos Elementos de Contorno para Análise de Problemas de Fratura e Aplicação de Modelos de Confiabilidade e Otimização em Estruturas Submetidas à Fadiga. 2009. 421p. Tese (Doutorado em Engenharia de Estruturas). Escola de Engenharia de São Carlos, Universidade de São Paulo, São Carlos, 2009.

LEUNG, S.; QIAN, J.; OSHER, S. A level set based Eulerian method for paraxial multivalued traveltimes. Journal of Computational Physics, Somerville, v. 2, n. 4, p. 643 672, 2004.

LI, L.; WANG, Y.; WEI, P. XFEM schemes for level set based structural optimization. Frontiers of Mechanical Engineering, China. v. 7(4), p. 335 - 356, 2012.

LIM, T.K.; CHEONG, K.B.; WHITE, J. Bubble Simulation Using Level Set-Boundary Element Method. High Performance Computation for Engineered Systems, Singapura, v. , p. , 2003.

LUENBERGER, D.G., Linear and Nonlinear Programming. 2. ed. Nova Iorque: Springer, 2003.

MAISTROU, A. Level Set Method - Overview. Chair for Computer Aided Medical Procedures \& Augmented Reality, München. 2008.

MAJAVA, K.; TAI, X.C. A Level Set Method for Solving Free Boundary Problems Associated with Obstacles. International Jounal of Numerical Analysis and Modeling, Alberta, v. 1, n. 2, p. 157 - 171, 2004.

MARCZAK, R.J., Optimization of elastic structures using boundary elements and a topological-shape sensitivity formulation. Mechanics of Solids in Brazil. p, 279 - 293, 2007.

MATSUMOTO, T. A level set-based topology optimization method using 3D BEM. Mensagem recebida por paulovitorio@usp.br em 14 de agosto de 2013.

MAUTE, K; RAMM, E. Adaptive topology optimization. Structural and Multidisciplinary Optimization v. 10, n. 2, p. 100-112, 1995.

MERRIMAN, B.; BENCE, J.K., OSHER, S. Motion of Multiple Junctions: A level set approach. Journal of Computational Physics, Somerville, n. 112, p. 334 - 363, 1994.

MIN, C.; GIBOU, F. A second order accurate level set method on non-graded adaptive cartesian grids. Journal of Computational Phisics, Somerville, v. 225, n., p. 300 -321, 2007.

MOSMANN, R.M., Otimização Topológica de Estruturas Contínuas Submetidas a Restrições de Flexibilidade, Volume e Frequência Natural. 2003. Dissertação (Mestrado em Engenharia), Universidade Federal do Rio Grande do Sul, Porto Alegre, 2003.

MUNDSTOCK, D.C., Otimização de Forma Utilizando o Método dos Elementos de Contorno e Cálculo de Sensibilidade por Variáveis Complexas. 2006. Dissertação (Mestrado em Engenharia), Universidade Federal do Rio Grande do Sul, Porto Alegre, 2006. 
NAPOLITANO, L.M.B., Implementação Numérica de Método Level Set para Propagação de Curvas e Superfícies. 2004. 85p. Dissertação (Mestrado em Física Básica) - Instituto de Física de São Carlos, Universidade de São Paulo, São Carlos, 2004.

NECHES, L.C.; CISILINO, A.P., Topology optimization of 2D elastic structures using boundary elements. Engineering analysis with boundary elements. v. 32, p. 533 - 544, 2008.

NOVOTNY, A.A., FEIJÓ, R.A., TAROCO, E. , PADRA, C., Topological Sensitivity Analysis for Three-dimensional Linear Elasticity Problem $\mathbf{, 6}^{\text {th }}$ World Congress on Structural and Multidisciplinary Optimization, Rio de Janeiro, Brazil, 30 de Maio à 03 Junho 2005.

OLIVEIRA, H.L. Uma formulação alternativa de Método dos Elementos de Contorno aplicada à análise da propagação de fissuras em materiais frágeis. 2013. Dissertação (Mestrado em Engenharia de Estruturas), Universidade de São Paulo - Escola de Engenharia de São Carlos, São Carlos, 2013.

OSHER, S.; FEDKIW, R. P. Level Set Methods and Dynamic Implicit Surface. New York: Springer-Verlag, 2003.

OSHER, S.; SETHIAN, J. Fronts propagating with curvature-dependent speed: Algorithms based on hamilton-jacobi formulations. Journal of Computational Physics, v. 79, p. 12-49, 1988.

OTOMORI, M.; YAMADA, T.; IZUI, K.; NISHIWAKI, S., Levet set-based topology optimisation of compliant mechanism using mathematical programming. Mechanical Sciences. v.2, p 91 - 98, 2011.

PAPALAMBROS P.; CHIREHDAST M. An integrated environment for structural configuration design. Journal of Engineering Design, v. 1, n. 1, p.73-96, 1990.

PEIXOTO, A.; VELHO, L. Transformadas de Distância. PUC-Rio.Inf.MCC 35/00. Rio de Janeiro, 2000.

PINTO JR., E.C., Otimização de seções de concreto armado. 2006. Dissertação (Mestrado em Engenharia), Universidade Federal de Santa Catarina, Florianópolis, 2006.

PORTELA, A., Dual boundary element incremental analysis of crack growth. PhD Thesis, Wessex Institute of Tecnology, University of Portsmouth, Southampton. 1992.

PRETO, T.M.; PEDRINI, H.; CENTENO, T.M. Reconstrução 3D de imagens médicas usando level set para controle de metamorfose. In: Ibero-Latin American Congress on Numerical Methods in Engineering, 30, 2009. Anais. Armação dos Búzios, RJ, 2009.

ROZVANY, G. I: N., BENDSØE, M. P.; KIRSCH, U., Layout Optimization of Structures, Appl. Mech. Rev., v.48, p.41 - 49, 1995. 
ROZVANY, G.; ZHOU, M.; BIRKER, T. Generalized shape optimization without homogenization. Structural and Multidisciplinary Optimization, v. 4, n. 3, p. 250-252, 1992.

RUSSO, G.; SMEREKA, P. A level set method for the evolution of faceted crystals. Journal of Computational Physics - Society for Industrial and Applied Mathematics, Somerville, v. 21, n. 6, p. 2073 - 2095, 2000.

SANT’ANNA, H.M., Otimização Topológica de Estruturas Bidimensionais Contínuas submetidas a Restrições de Flexibilidade e Tensão. 2002. Dissertação (Mestrado em Engenharia). Universidade Federal do Rio Grande do Sul, Porto Alegre, 2002.

SECCHI, A.R., Otimização de Processos. Universidade Federal do Rio Grande do Sul. Material Didático da Pós Graduação em Engenharia Química. 2001.

SETHIAN, J. Level Set Methods and Fast Marching Methods: Evolving Interfaces in Geometry, Fluid Mechanics, Computer Vision, and Material Science, Cambridge University Press, 2. ed, 1999.

SETHIAN, J.; WIEGMANN, A., Structural boundary design via level set and immersed interface methods. J. Comput. Phys. v. 163 (2), p. 489-528, 2000.

SETHIAN, J.A.; SMEREKA, P. Level Set Methods for Fluid Interface. Annual Review of Fluid Mechanics, Palo Alto, n. 35, p. 341 - 372, 2003.

SHICHI, S.; YAMADA, T.; SUZUKI, A.; MATSUMOTO, T.; TAKAHASHI, T., A level set-based topology optimization method using boundary element method in three dimension. Japan Society of Mechanical Engineers. v. 78, p. 228 - 239, 2012.

SILVA, C.A. de C., Otimização estrutural e análise de sensibilidade orientadas por objetos. Dissertação (Mestrado em Engenharia Mecânica), Universidade Estadual de Campinas, Campinas, 1997.

SILVA, E. C. N., Notas de Aula: Otimização aplicada ao projeto de sistemas mecânicos. Universidade de São Paulo - Escola Politécnica. 2003.

SILVA, E.E., Otimização de Estruturas de Concreto Armado Utilizando Algoritmos Genéticos. 2001. Dissertação (Mestrado em Engenharia), Escola Politécnica da Universidade de São Paulo, São Paulo, 2001.

SILVA, T.S.A., Programação por Restrições e Escalonamento Baseado em Restrições: Um Estudo de Caso na Programação de Recursos Para Desenvolvimento de Poços de Petróleo. 2012. 151p. Dissertação (Mestrado em Ciências), Instituto de Matemática e Estatística da Universidade de São Paulo, São Paulo, 2012.

SILVA, W.Q., Análise não linear geométrica do acoplamento solo-estrutura através da combinação MEC-MEF. 2010. 148p. Dissertação (Mestrado em Engenharia de Estruturas). Escola de Engenharia de São Carlos, Universidade de São Paulo, São Carlos, 2010. 
SOARES, R. C., Otimização de Seções Transversais de Concreto Armado Sujeitas à Flexão - Aplicação a Pavimentos. 1997. Dissertação (Mestrado em Engenharia Civil), Escola de Engenharia de São Carlos da Universidade de São Paulo, São Carlos, 1997.

SOUSA, F.S.; MANCHIAVACCHI, N. An Arbitrary Lagrangian-Eulerian Level-Set Method for Incompressible Two-Dimensional Two-Fluid Flows. Mecánica Computacional. Buenos Aires, v. 24, p. 65 - 76, 2005.

SOUZA, E.N. de, Otimização do Dimensionamento de Seções Transversais de Concreto Armado com a Utilização de Algoritmo Genéticos. 2001. (Graduação em Engenharia de InfraEstrutura Aeronáutica), Instituto Tecnológico de Aeronáutica, São José dos Campos, 2001.

STUMP, F.V., Otimização Topológica Aplicada ao Projeto de Estruturas Tradicionais e Estruturas com Gradação Funcional Sujeitas a Restrição de Tensão. 2006. 244p. Dissertação (Mestrado em Engenharia Mecânica) - Escola Politécnica, Universidade de São Paulo, São Paulo, 2006.

SUSSMAN, M.; SMEREKA, P.; OSHER, S. A Level Set Approach for Computing Solutions to Imcompressible Two-Phase Flow. Journal of Computational Physics, Somerville, n. 114, p. 146 - 159, 1994.

SUZUKI, K.; KIKUCHI, N., A homogenization method for shape and topology optimization. Comp. Meth. Appl. Mech. Eng., v. 93, p. 291 - 318, 1991.

TIMOSHENKO, S. P., GOODIER, J. N., Theory of Elasticity. New York: McGraw-Hill, 1970. $567 \mathrm{p}$.

ULLAH, B.; TREVELYAN, J.; MATTHEWS, P.C., Structural optimization based on the boundary element and level set methods. Computer and Structures. v. 137, p. 14-30, 2014.

VANDERPLAATS, G. N.; SALAJEGHEH, E., New Approximation Method for Stress Constraints in Structural Synthesis, AIAA Journal, v. 27, n. 3, p. 352-358, 1987.

VANDERPLAATS, G.N., Numerical Optimization Techniques for Engineering Design: With Applications, McGraw-Hill, 1984.

VENTURINI, W.S. (1988). Um estudo sobre o método dos elementos de contorno e suas aplicações em problemas de engenharia. São Carlos. Tese (Livre Docência). Escola de Engenharia de São Carlos, Universidade de São Paulo, São Carlos, 1988.

VIANNA, L.C.C., Otimização de Seções Transversais de Concreto Armado: Aplicação a Pórticos. 2003. Dissertação (Mestrado em Engenharia de Estruturas), Escola de Engenharia de São Carlos da Universidade de São Paulo, São Carlos, 2003.

WANG, C.; WAN, F.S.; CHEONG, K.B.; CHEW, H.K. Multiple Bubbles Dynamics using Level Set Indirect Boundary Element Method. XXI ICTAM, Warsaw, v. , p. , 2004.

WANG, M.; WANG, X.; GUO, D. A level set method for structural topology optimization. Computer Methods in Applied Mechanics and Engineering, v. 192, p. 217-224, 2003. 
XIE, Y.; STEVEN, G., $\quad$ A simple evolutionary procedure for structural optimization. Computers and Structures. v. 49, n. 5, p. 885-876, 1993.

YAMADA, T.; IZUI, K.; NISHIWAKI, S., TAKEZAWA, A., A topology optimization method based on level set set method incorporatinf a fictitious interface energy. Computational Methods Applied Mechanics Engineering. v. 199, n. 45 - 48, p. 2876 2891, 2010.

YAMADA, T.; SHICHI, S.; MATSUMOTO, T.; TAKAHASHI, T.; ISAKARI, H., A level set-based topology optimization method using 3D BEM. Advances in Boundary Element Techniques XIV. p. 432 - 437, 2013.

YAMASAKI, S.; YAMADA, T.; MATSUMOTO, T., An immersed boundary element method for level-set based topology optimization. International Journal for Numerical Methods in Engineering. v. 93, n. 8, p. 960 - 988, 2012. 


\section{ANEXO A - TÓPICOS DA TEORIA DA ELASTICIDADE}

Apresentam-se neste tópico os conceitos e equações principais que regem a teoria da elasticidade linear. Maiores aprofundamentos são encontrados em Timoshenko e Goodier (1970).

\section{A.1 EQUAÇÕES DE EQUILÍBRIO}

Considerando um corpo qualquer com domínio $\Omega$ limitado por um contorno $\Gamma$. Este corpo está sujeito a carregamentos estáticos, como indica a Figura (A.0.1).

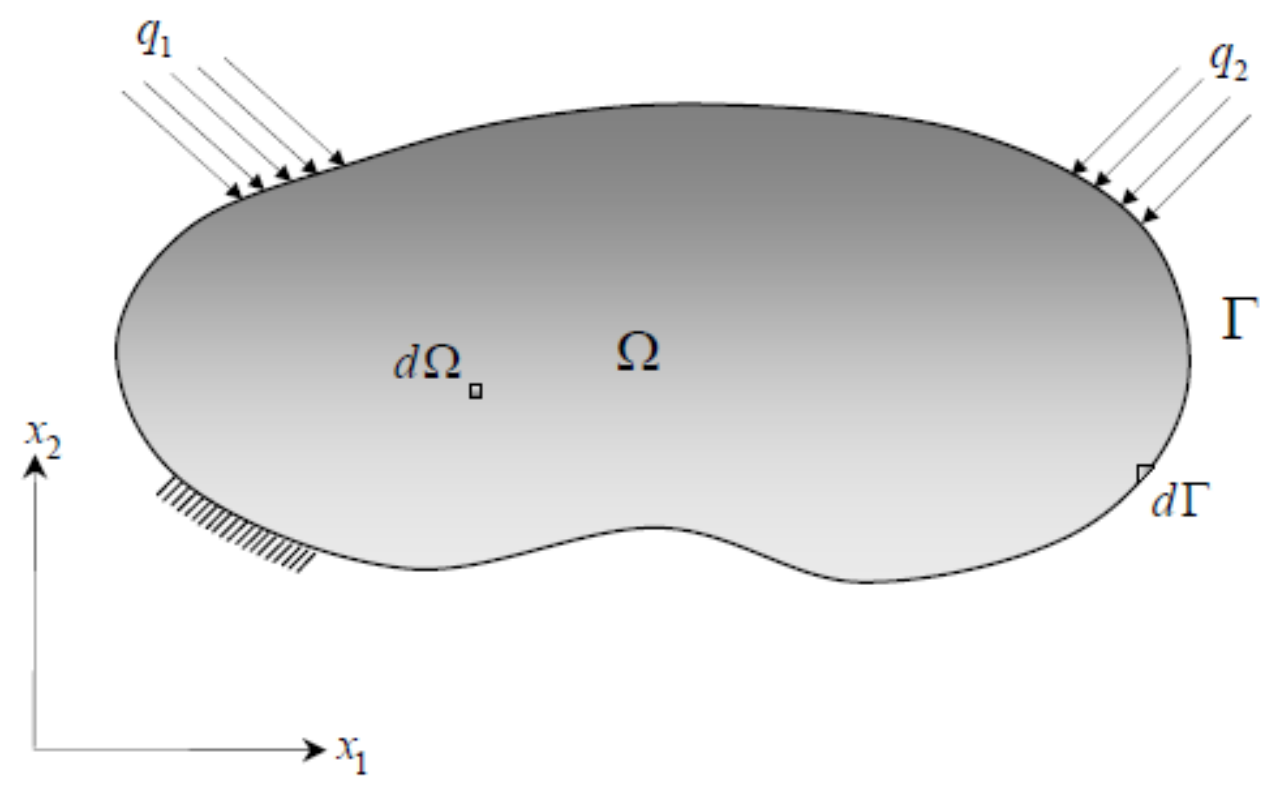

Figura (A.0.1) - Sólido bidimensional. Fonte: Kzam (2009).

Tomando a infinitésima parte, $d \Omega$, desse corpo verificam-se as componentes de tensão atuantes no mesmo. A Figura (A.0.2) mostra o estado de tensões atuantes no infinitésimo. 


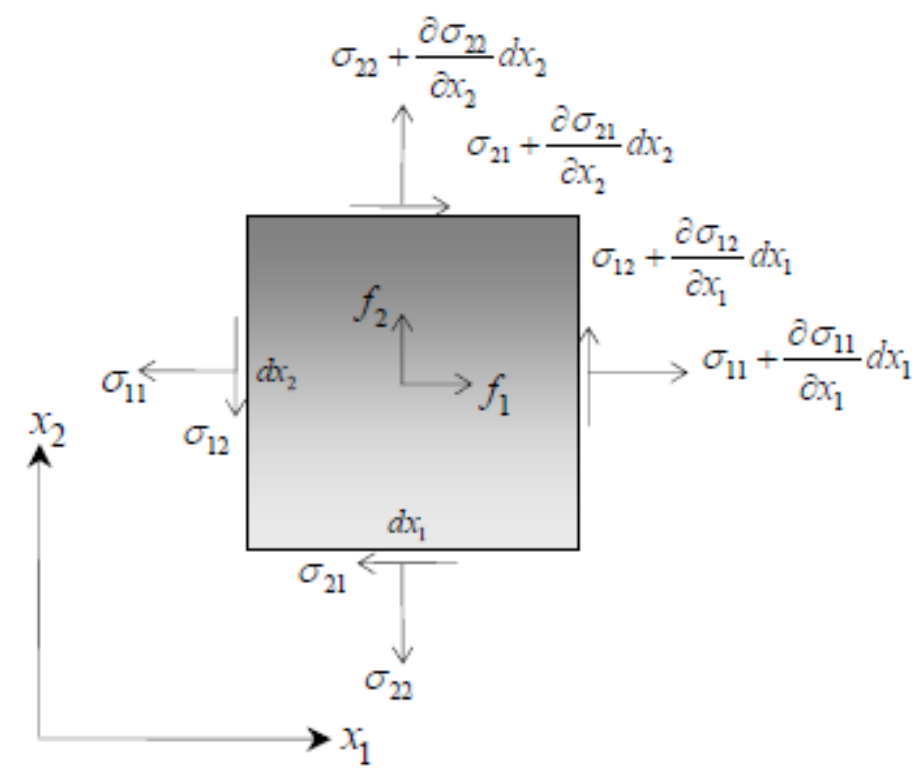

Figura (A.0.2) - Estado de tensão no elemento infinitesimal de domínio. Fonte: Kzam (2009).

Ao todo são conhecidas nove componentes de tensão:

- Três componentes normais: $\sigma_{11}, \sigma_{22}, \sigma_{33}$;

- Seis componentes de cisalhamento: $\sigma_{12}, \sigma_{13}, \sigma_{21}, \sigma_{23}, \sigma_{31}, \sigma_{32}$.

Analisando o infinitesimal verifica-se que algumas dessas tensões não são independentes entre si, na consideração do equilíbrio tem-se que:

$$
\sigma_{i j}=\sigma_{j i}
$$

Onde $\sigma_{i j}$ e $\sigma_{j i}$ são as tensões internas atuantes no infinitésimo.

Fazendo o equilíbrio em termos de forças e admitindo a existência das forças de corpo tem-se:

$$
\sigma_{i j, j}+b_{i}=0
$$

Sendo $b_{i}$ as forças de corpo atuantes na direção $i$ e $\sigma_{i j, j}$ a derivada da tensão $i j$ em relação a direção $j$.

O mesmo equilíbrio pode ser calculado no contorno $\Gamma$ do infinitésimo para a determinação de estado de tensões na superfície do corpo. Entretanto, é necessário realiza-lo 
em função dos cossenos diretores e componentes das forças de superfícies do mesmo. Então, decompõe-se o estado de tensão na direção do contorno de forma que esse seja igual às forças de superfícies presentes no corpo:

$$
P_{i}=\sigma_{i j} \cdot \eta_{j}
$$

Em que $P_{i}$ são as forças de superfície e $\eta_{j}$ os cossenos diretores do versor normal ao contorno.

\section{A.2 RELAÇÕES CONSTITUTIVAS}

Na elasticidade linear a relação entre tensões e deformações é dada através da Lei de Hooke generalizada. Por meio dela, um tensor de quarta ordem é representado, onde cada componente de tensão é linearmente relacionada com as deformações no ponto analisado. Analisando a relação de maneira inversa verifica-se que a relação também é válida, ou seja, as componentes de deformação são linearmente relacionadas às componentes de tensão, porém, o tensor usado para a representação é o inverso das propriedades constitutivas utilizadas anteriormente.

A lei de Hooke generalizada é dada por:

$$
[\sigma]=\left[D_{c}\right] \cdot[\varepsilon]
$$

Sendo, $\left[D_{c}\right]$ o tensor de quarta ordem contendo as propriedades constitutivas do material. $[\sigma]$ e $[\varepsilon]$ os tensores de segunda ordem das tensões internas e deformações do corpo, respectivamente.

Em casos onde o material é anisotrópico o tensor constitutivo $\left[D_{c}\right]$ possui 81 termos independentes os quais são função somente da direção dos eixos de referência. Considerando a simetria presente nos tensores de tensão e deformação os termos independentes passam a ser 36. Admitindo-se o caso de material isotrópico, o tensor $\left[D_{c}\right]$ pode ser representado por meio do módulo de elasticidade longitudinal, $E$, e do coeficiente de Poisson, $v$.

Escreve-se inicialmente, a Lei de Hooke generalizada para materiais isotrópicos: 


$$
\sigma_{i j}=\frac{E}{1+v} \cdot\left[\frac{v}{(1-2 \cdot v)} \cdot \delta_{i j} \cdot \varepsilon_{k k}+\varepsilon_{i j}\right]
$$

Em que $\delta_{i j}$ é o delta de Kroenecker, $\varepsilon_{i j}$ as deformações do corpo, $v$ o coeficiente de Poisson, $E$ o módulo de elasticidade transversal.

Inversamente, escrevem-se as deformações em função das tensões:

$$
\varepsilon_{i j}=\frac{1+v}{E} \cdot \sigma_{i j}-\frac{v}{E} \cdot \sigma_{k k} \cdot \delta_{i j}
$$

\section{A.3 RELAÇÕES DEFORMAÇÃO-DESLOCAMENTO}

Em um corpo sujeito a regime de pequenas deformações, as configurações deformada e indeformada podem ser representadas tomando-se a vizinhança de um dado ponto $P$.

Antes da deformação as coordenadas do ponto são as próprias coordenadas do ponto $P$. Após a atuação do carregamento, uma simples subtração de vetores mostra que o ponto desloca-se para $P^{\prime}$. Obtém-se as deformações através variação dos deslocamentos em uma dada direção de interesse. As deformações estão diretamente ligadas aos gradientes de deslocamentos.

Simplificando-se por meio de deformações infinitesimais, considerando o regime de pequenas deformações, as componentes de $\varepsilon$ em função dos deslocamentos são dadas inicialmente por:

$$
\varepsilon_{i j}=\frac{1}{2} \cdot\left(u_{i, j}+u_{j, i}\right)
$$

Onde $u_{i, j}$ é a derivada do deslocamento da direção $i$ em relação a direção $j$.

Para regimes de grandes deformações, usa-se o conceito de deformações finitas, entretanto, as deformações e os gradientes de deslocamento não são mais linearmente relacionadas: 


$$
\varepsilon_{i j}=\frac{1}{2} \cdot\left(u_{i, j}+u_{j, i}+u_{i, j} \cdot u_{j, i}\right)
$$

\section{A.4 CONDIÇÕES DE COMPATIBILIDADE DE DEFORMAÇÕES}

A relação de deformações-deslocamentos para pequenas deformações representam um sistema composto por três componentes de deslocamentos e seis componentes deformações. Optando-se em determinar os deslocamentos partir das deformações, utilizam-se as equações de compatibilidade em termos de deformação:

$$
\varepsilon_{i j, k l}+\varepsilon_{k l, i j}-\varepsilon_{i k, j l}-\varepsilon_{j l, i k}=0
$$

\section{A.5 EQUACIONAMENTO DOS PROBLEMAS ELÁSTICOS}

Para a determinação de tensões, deformações e deslocamentos em corpos sujeitos a esforços externos e a condições de restrição aos deslocamentos, emprega-se a relação constitutiva, deformação-deslocamento e de equilíbrio.

É necessário também atender às condições de contorno impostas assim como as condições de compatibilidade presentes no problema.

Os problemas elásticos resultam em 15 equações para a obtenção de15 variáveis desconhecidas, sendo: 6 tensões, 6 deformações e 3 deslocamentos.

\section{A.6 TENSÕES PRINCIPAIS}

Em muitos casos a grandeza de interesse está na análise do estado de tensão com referência em outro sistema de coordenadas. Para a transformação do estado de tensão no ponto de um sistema de referência para outro é necessário o conhecimento dos ângulos de inclinação entre os sistemas de referência anterior e atual.

O procedimento é bastante utilizado na determinação do estado de tensão em direções particulares onde existem apenas as tensões normais e as tensões de cisalhamento são nulas. 
As tensões normais encontradas para esse caso são chamadas de tensões principais e os eixos onde elas acontecem, eixos principais.

O vetor de tensão é chamado principal se a seguinte relação é atendida:

$$
\left\{\sigma^{P}\right\}=\lambda \cdot\{\hat{\eta}\}
$$

Sendo $\lambda$ um escalar denominado valor principal e $\{\hat{\eta}\}$ o versor da normal particular que define a direção principal.

Considerando a relação de equilíbrio para forças presentes no contorno, escreve-se:

$$
[\sigma] .\{\hat{\eta}\}=\lambda \cdot\{\hat{\eta}\}
$$

Em termos de componentes:

$$
\begin{aligned}
& \left(\sigma_{i j} \cdot \widehat{\eta_{J}}\right) \cdot e_{i}=\left(\lambda \cdot \widehat{\eta}_{l}\right) \cdot e_{i} \quad \therefore \quad \sigma_{i j} \cdot \widehat{\eta_{J}}=\lambda \cdot \widehat{\eta_{l}} \\
& \sigma_{i j} \cdot \widehat{\eta_{J}}=\lambda \cdot \widehat{\eta}_{l} \cdot \delta_{i j} \quad \therefore \quad\left(\sigma_{i j}-\lambda \cdot \delta_{i j}\right) \cdot \widehat{\eta_{J}}=0 \\
& \left(\sigma_{i j}-\lambda \cdot \delta_{i j}\right) \cdot \widehat{\eta}_{J}=0 \rightarrow\left[\begin{array}{ccc}
\sigma_{x}-\lambda & \sigma_{x y} & \sigma_{x z} \\
\sigma_{y x} & \sigma_{y}-\lambda & \sigma_{y z} \\
\sigma_{z x} & \sigma_{z y} & \sigma_{z}-\lambda
\end{array}\right] \cdot\left\{\begin{array}{l}
\widehat{\eta_{1}} \\
\widehat{\eta_{2}} \\
\widehat{\eta_{3}}
\end{array}\right\}=\left\{\begin{array}{l}
0 \\
0 \\
0
\end{array}\right\}
\end{aligned}
$$

Para que o sistema apresente solução diferente da trivial, $\{\hat{\eta}\}=\{0\}$, o determinante da matriz de coeficiente tem que ser nulo. Com isso gera-se o polinômio cúbico em $\lambda$ :

$$
\lambda^{3}-I_{1} \cdot \lambda^{2}+I_{2} \cdot \lambda-I_{3}=0
$$


As raízes para esse polinômio são as tensões principais procuradas. Os invariantes do tensor de tensões, $I_{1}, I_{2}, I_{3}$, possuem valores independentes do referencial adotado, e são definidos como:

$$
\begin{gathered}
I_{1}=\sigma_{x}+\sigma_{y}+\sigma_{z} \\
I_{2}=\sigma_{x} \cdot \sigma_{x}+\sigma_{y} \cdot \sigma_{z}+\sigma_{x} \cdot \sigma_{z}-\sigma_{x y}^{2}-\sigma_{y z}^{2}-\sigma_{z x}^{2} \\
I_{3}=\sigma_{x} \cdot \sigma_{y} \cdot \sigma_{z}+2 . \sigma_{x y} \cdot \sigma_{x z} \cdot \sigma_{y z}-\sigma_{x} \cdot \sigma_{y z}^{2}-\sigma_{y} \cdot \sigma_{x z}^{2}-\sigma_{z} \cdot \sigma_{x y}{ }^{2}
\end{gathered}
$$

\section{A.7 DEFORMAÇÕES PRINCIPAIS}

Analisa-se analogamente ao comportamento das deformações. Dessa maneira, existem direções onde não são observadas deformações distorcionais, acontecem apenas deformações axiais. As direções são chamadas principais e as deformações axiais conhecidas, deformações principais. Considera-se então:

$$
\begin{gathered}
{\left[\begin{array}{ccc}
\varepsilon_{\mathrm{x}}-\lambda & \varepsilon_{\mathrm{xy}} & \varepsilon_{\mathrm{xz}} \\
\varepsilon_{\mathrm{yx}} & \varepsilon_{\mathrm{y}}-\lambda & \varepsilon_{\mathrm{yz}} \\
\varepsilon_{\mathrm{zx}} & \varepsilon_{\mathrm{zy}} & \varepsilon_{\mathrm{z}}-\lambda
\end{array}\right] \cdot\left\{\begin{array}{l}
\widehat{\eta_{1}} \\
\widehat{\eta_{2}} \\
\widehat{\eta_{3}}
\end{array}\right\}=\left\{\begin{array}{l}
0 \\
0 \\
0
\end{array}\right\}} \\
\lambda_{\varepsilon}{ }^{3}-\mathrm{I}_{1} \cdot \lambda_{\varepsilon}{ }^{2}+\mathrm{I}_{2} \cdot \lambda_{\varepsilon}-\mathrm{I}_{3}=0
\end{gathered}
$$

As raízes para esse polinômio são as deformações principais procuradas. Os invariantes de deformação são dados por:

$$
\begin{gathered}
\mathrm{I}_{1}=\varepsilon_{\mathrm{x}}+\varepsilon_{\mathrm{y}}+\varepsilon_{\mathrm{z}} \\
\mathrm{I}_{2}=\varepsilon_{\mathrm{x}} \cdot \varepsilon_{\mathrm{x}}+\varepsilon_{\mathrm{y}} \cdot \varepsilon_{\mathrm{z}}+\varepsilon_{\mathrm{x}} \cdot \varepsilon_{\mathrm{z}}-\varepsilon_{\mathrm{xy}}^{2}-\varepsilon_{\mathrm{yz}}^{2}-\varepsilon_{\mathrm{zx}}^{2}
\end{gathered}
$$




$$
\mathrm{I}_{3}=\varepsilon_{\mathrm{x}} \cdot \varepsilon_{\mathrm{y}} \cdot \varepsilon_{\mathrm{z}}+2 \cdot \varepsilon_{\mathrm{xy}} \cdot \varepsilon_{\mathrm{xz}} \cdot \varepsilon_{\mathrm{yz}}-\varepsilon_{\mathrm{x}} \cdot \varepsilon_{\mathrm{yz}}^{2}-\varepsilon_{\mathrm{y}} \cdot \varepsilon_{\mathrm{xz}}^{2}-\varepsilon_{\mathrm{z}} \cdot \varepsilon_{\mathrm{xy}}{ }^{2}
$$

